\title{
20020312

\section{Ship Navigation Simulation Study, Kalihi Channel Reopening, Honolulu Harbor, Oahu, Hawaii}

Gary C. Lynch and José A. Sanchez

September 2001

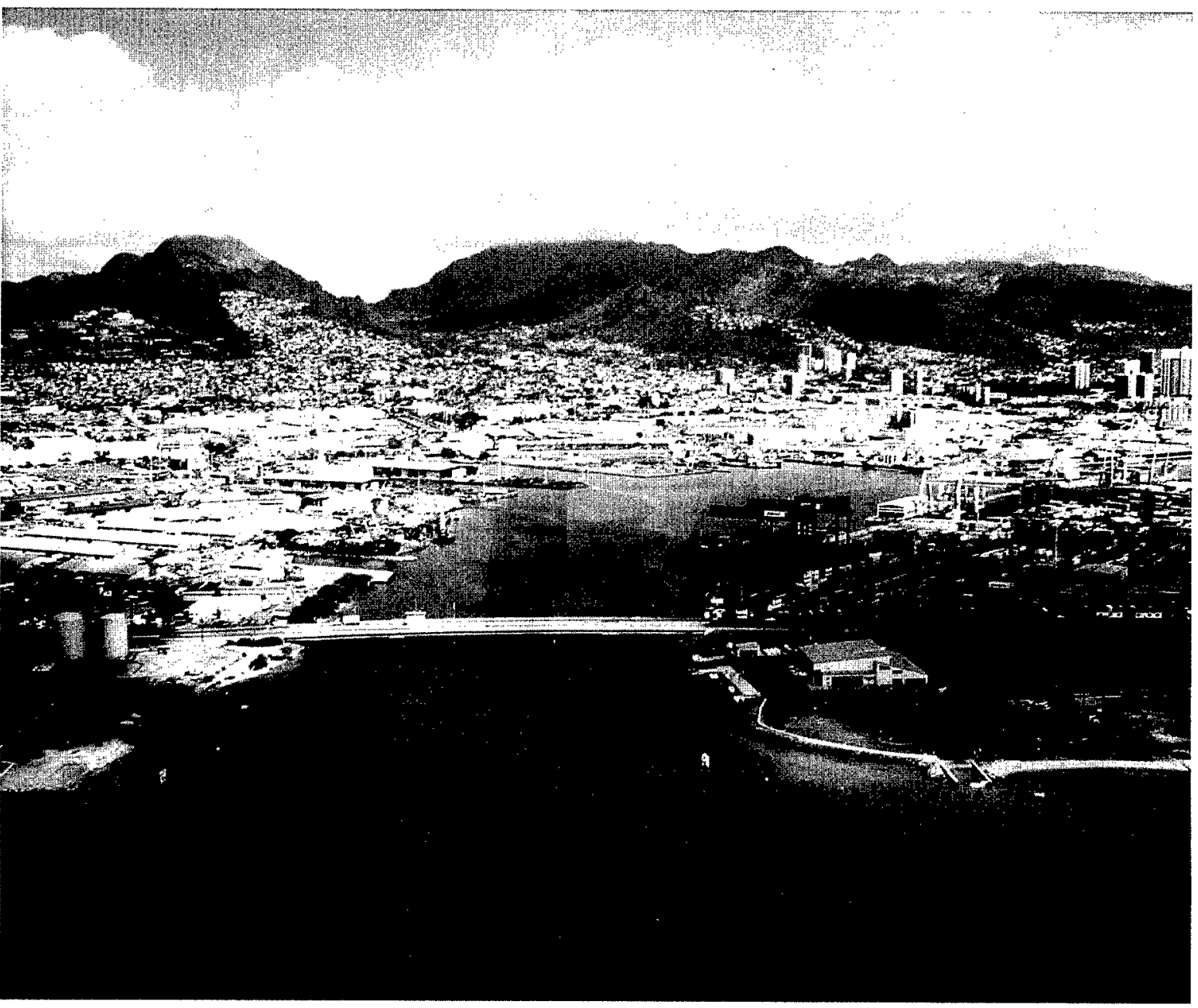


The contents of this report are not to be used for advertising, publication, or promotional purposes. Citation of trade names does not constitute an official endorsement or approval of the use of such commercial products.

The findings of this report are not to be construed as an official Department of the Army position, unless so designated by other authorized documents. 


\section{Ship Navigation Simulation Study, Kalihi Channel Reopening, Honolulu Harbor, Oahu, Hawaii}

by Gary C. Lynch, José A. Sanchez

Coastal and Hydraulics Laboratory U.S. Army Engineer Research and Development Center 3909 Halls Ferry Road

Vicksburg, MS 39180-6199

Final report

Approved for public release; distribution is unlimited 


\section{Contents}

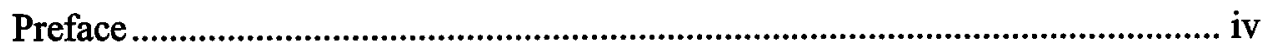

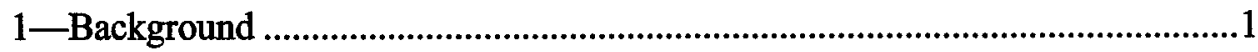

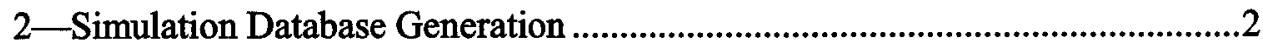

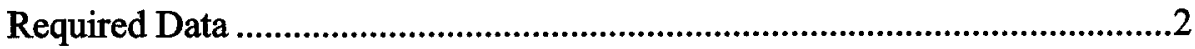

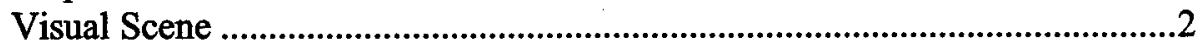

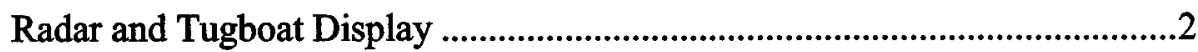

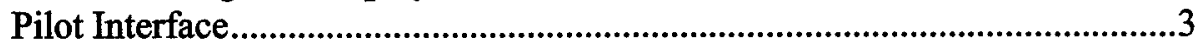

Channel Bathymetry and Current Database.................................................3

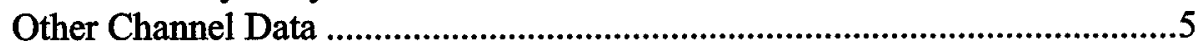

Validation of the Existing Conditions ...........................................................5

Simulation Testing Program ...........................................................................6

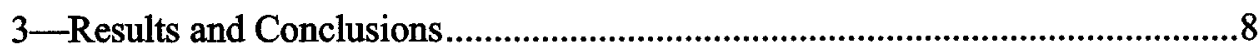

Figures 1-26

Plates 1-56

SF 298 


\section{Preface}

This investigation was performed by personnel of the Coastal and Hydraulics Laboratory (CHL), Vicksburg, MS, of the U.S. Army Engineer Research and Development Center (ERDC) for the U.S. Army Engineer District, Honolulu. The study was conducted with the $\mathrm{CHL}$ research ship simulator during the period February 2000 to August 2000.

The investigation was conducted by Mr. Gary C. Lynch, Navigation Branch, CHL, and Mr. José A. Sanchez, Estuaries, Bays, and Lagoons Group, Tidal Hydraulics Branch, CHL, under the general supervision of Dr. James R. Houston, Director, CHL; Dr. Sandra Knight, Chief, Navigation Branch; and Dr. Robert McAdory, Chief, Tidal Hydraulics Branch. Ms. Sally F. Harrison, Navigation Branch, assisted in the study. This report was prepared by Messrs. Lynch and Sanchez.

At the time of publication of this report, Dr. James R. Houston was Director of ERDC, and COL John W. Morris III, EN, was Commander and Executive Director.

The contents of this report are not to be used for advertising, publication or promotional purposes. Citation of trade names does not constitute an official endorsement or approval of the use of such commercial products. 


\section{Background}

Honolulu Harbor, located on the southern side of Oahu, Hawaii (Figure 1), has one entrance, the main channel entrance. Because of the closure of the lift on the Sand Island Bridge (Figure 2) and the addition of a second, nonlift bridge, Kalihi Channel no longer opens into Honolulu Harbor (Figure 3). A tunnel has been proposed to replace the Sand Island Bridge, and with the destruction of the old bridge, the possibility for ships and tows/barges to transit Kalihi Channel as well as the main Honolulu Channel would be possible once again. Although the harbor operated with these two channels before the closure of the first bridge and the construction of the second bridge, changes in vessel dimensions since the closure and the proposed deepening of Kalihi Channel (to make it the same depth as the rest of the harbor) made a navigation study necessary to evaluate the efficiency and safety of the project. 


\section{Simulation Database Generation}

\section{Required Data}

Data required for a simulation study include channel and harbor layout, bottom topography (bathymetry), channel currents, design ships, and visual database for the existing and plan conditions. The method for developing each of these is described in this chapter.

\section{Visual Scene}

The creation of the visual scene database for Honolulu Harbor was derived mainly from $35 \mathrm{~mm}$ photographs and aerial photographs acquired during the reconnaissance trip conducted by personnel of the Coastal and Hydraulics Laboratory (CHL) in April 2000 and from navigation charts of the area. The reconnaissance trip also provided videotapes taken during a ship transit and harbor tour aboard the Hawaii Pilots Association's pilot boat. That trip was also used to document pilot comments on different areas of the harbor while in transit. A familiarity with the area was obtained and used to prepare the simulation before the pilots arrived at $\mathrm{CHL}$ for the verification stage. Revisions to the visual scene based on the pilots' comments during validation were also made. Bank line configuration, buildings, docks, and other landside features were defined in $\mathrm{x}-, \mathrm{y}-$, and $\mathrm{z}$-coordinates. These features were then preprocessed for input into the Silicon Graphics Onyx, which generated the visual scene for the harbor. The visual scene was displayed on six large-screen projectors with one-way traffic runs, three screens per simulator. The simulator setup at the time of this project is shown in Figure 4. Although two-way traffic was not employed for this simulation, both simulators were used during the full week of testing for concurrent experimentation.

\section{Radar and Tugboat Display}

The radar file was created from the digitized bank line of Honolulu Harbor created for the visual scene database. The radar database contains information available on the radar readout of an actual ship. However, the database image is 
much clearer than a typical ship radar display (Figure 5). The clarity is necessary to counteract the lack of depth perception resulting from using a two-dimensional screen to reproduce the three-dimensional visual scene. For this study, four radar ranges were available on two displays. The $0.4-\mathrm{km}-(0.25-\mathrm{mile}-)$ range screen was visible at all times. The other radar screen was adjustable to ranges of 0.805 $\mathrm{km}(0.50 \mathrm{mile}), 1.207 \mathrm{~km}(0.75 \mathrm{mile})$, and $2.414 \mathrm{~km}$ (1.50 mile).

The 0.4-km (0.25-mile) radar range screen also displayed data about the tugboats being used for maneuvering. A vector on the screen (Figure 6) showed tug placement, heading, and engine setting. The pilots were asked to use tugs as they would in the harbor. Tugboat settings were verified to act as a typical tugboat available in Honolulu Harbor. Most pilots used no more than two tugs during an experiment and were allowed to reposition the tug during the run. The time used for repositioning the tug and setting it up again was based upon the pilot's experience, the type of maneuvering required by the tug, and how long it would take the tug operator to change positions in the actual harbor.

\section{Pilot Interface}

The ship control console, shown in Figure 4, the precision navigation screen, shown in Figure 7, the radar displays, the ship's wheel, and the visual scene displays form the pilot's interface with the simulator. The radar displays were discussed in the previous section. The precision navigation screen informs the pilot of the ship orientation, speed, and engine and rudder status, depth of water, and wind speed and direction.

\section{Channel Bathymetry and Current Database}

A numerical hydrodynamic model of Honolulu Harbor was developed to provide water flow velocities and circulation patterns, as well as the bathymetric data for the simulation. Verification of the hydrodynamic model against prototype velocity data was not considered necessary for this study because water velocities were small and not considered a dominant factor in the design work.

RMA2, a two-dimensional finite element model, was used for the hydrodynamic part of the study. The numerical mesh, composed of 2,005 elements and 5,661 nodes (Figure 8), included Honolulu Harbor, the adjacent Keehi Lagoon, Pearl Harbor, and most of the Oahu Island southern coastline extending about $10 \mathrm{~km}$ (6 miles) offshore. Bathymetric data were digitized from National Oceanic and Atmospheric Administration (NOAA) navigation charts and surveys provided by the U. S. Army Engineer District, Honolulu. Since bathymetric data were not available for Pearl Harbor, depths were estimated at $4.572 \mathrm{~m}$ (15 ft) mllw throughout. ${ }^{1}$ Figure 9 shows a depth contour map of the study area.

\footnotetext{
${ }^{1}$ All depths in this report are given in meters (feet) referred to mean lower low water (mllw).
} 
The predicted spring tide of January 17, 1999, at NOAA's station 1612340 in Honolulu Harbor was used to drive the model at the offshore boundary. Spring tide was selected to obtain the maximum velocities expected within the harbor. The 6 days ( $144 \mathrm{hr}$ ) simulated were composed of 2 days prior to the spring tide plus the spring tide day repeated four times (Figure 10). The repetition of the spring tide was performed to eliminate any possible effect of the model initial conditions upon the final results.

Turbulent exchange coefficients in the $\mathrm{x}$ - and $\mathrm{y}$-directions were specified to 4,787.9 Pa-sec $\left(100 \mathrm{lb}-\mathrm{sec} / \mathrm{ft}^{2}\right)$ for the study area and $95,758 \mathrm{~Pa}-\mathrm{sec}$ $\left(2,000 \mathrm{lb}-\mathrm{sec} / \mathrm{ft}^{2}\right)$ for the offshore section of the mesh to achieve numerical stability due to the proximity of the tidal boundary. The roughness coefficient values assigned to the model were similar to those used on other studies of this kind. Roughness was set to 0.05 in shallow areas where coral reefs or vegetation were located; 0.025 was assigned elsewhere. Table 1 shows the assignment of turbulent exchange and roughness coefficients by material type. The material type distribution over the mesh is shown in Figure 11.

\begin{tabular}{|l|l|l|}
\hline \multicolumn{2}{|l|}{$\begin{array}{l}\text { Table 1 } \\
\text { Material Type Properties }\end{array}$} \\
\hline \hline Materlal Number & $\begin{array}{l}\text { Turbulent Exchange Coefficlent } \\
\text { Pa -sec (lb-sec/ft2) }\end{array}$ & Mannlng's n \\
\hline 1 & $95,758(2,000)$ & 0.030 \\
\hline 2 & $4,787.9(100)$ & 0.025 \\
\hline 3 & $4,787.9(100)$ & 0.025 \\
\hline 4 & $4,787.9(100)$ & 0.050 \\
\hline
\end{tabular}

East-northeast wind was applied throughout the model with a speed magnitude of $16.09 \mathrm{~km} / \mathrm{hr}$ (10 miles $/ \mathrm{hr}$ ), following yearly average observations obtained from the National Climatic Data Center, NOAA.

Results from the simulation of existing conditions show a qualitative agreement with prototype conditions. Velocities were very small throughout the model including Honolulu Harbor, where maximum velocities were about 0.0457 $\mathrm{m} / \mathrm{sec}(0.15 \mathrm{ft} / \mathrm{sec})$. An offshore drift current toward the west was also reproduced. The existence of the drift was corroborated by comments from the pilots during the reconnaissance trip of the harbor on March 1, 2000, and from studies performed by the University of Hawaii. Two flow fields were extracted from the 144-hr-long simulation to be used by the ship simulator: hours 122.5 and 130.0, corresponding to flood and ebb (Figures 12 and 13), respectively.

In addition to existing conditions, the plan condition was simulated. Under this plan, the Sand Island Bridge was removed to allow for two-way access to the harbor, and a portion of the harbor was deepened. Depths throughout the main harbor remained the same excluding Kalihi Channel located in Keehi Lagoon, where depths were increased from $10.973 \mathrm{~m}(36 \mathrm{ft})$ to $13.716 \mathrm{~m}(45 \mathrm{ft})$. No considerable hydrodynamic differences were found between existing conditions and the proposed scenario. 


\section{Other Channel Data}

Along with the currents, the channel and harbor navigable area need two other defining conditions: wind and bank forces. The wind forces act upon the superstructure of the vessel during the transit (Figure 14). Bank force, also referred to as bank suction (Figure 14), is a lateral force and moment acting on the vessel due to the geometry of the bank. Generally, the lateral force moves the vessel toward the bank as the moment turns the bow from the bank. These two forces are important for Honolulu Harbor because of the coral reef in the area adjacent to the channel and the prevailing trade winds on the island (Figure 15).

\section{Validation of the Existing Conditions}

Pilots licensed for the harbor study area operated the simulator during validation of the existing conditions. Completion of validation occurs when the pilot is satisfied that the conditions in the simulator reproduce actual harbor and ship handling conditions. Included in the validation process are the visual scene, the currents, the bank forces, the wind forces, and the ship handling characteristics.

During visual scene validation, a consensus was reached on the population of the harbor terminals. Each of the runs performed had two barges docked at the Sealand Terminal, a containership at the Matson Terminal (with crane booms extended over the ship), a car carrier docked directly across from the containership at Matson, and several other vessels docked about the harbor (Figures 3 and 16). For the design test, two more containerships were docked by the location of the existing bridge (the site of a proposed terminal). Each of the items was either common in the existing environment or expected to be in the future environment.

Currents were quickly validated for the model. Once inside the harbor, the currents pose almost no problem for the pilot. A close inspection of the numerical model results shows that the tide never really reaches a full ebb direction in the harbor. Therefore the simulation tests were run with flood tide currents, a condition that seemed to have a potential for more difficulties during the transit. The pilots validated the location of a crosscurrent in the ocean in front of the entrance to the harbor, as produced by the current simulation model.

Wind and bank forces, although not difficult to model, did take some time to validate. As was shown in Figure 15, the reef and the wind forces are not consistent throughout the harbor; therefore, it was important to tailor the simulation forces to those found in the actual environment. These forces, as well as the currents, can be changed at each cross section that is defined in the simulation. Figure 17 shows the cross sections for Honolulu Harbor. In the case of cross sections 23-28, the mountains shield the harbor from the trade winds in that area; but before and after that area in the transit, the vessel is being constantly acted upon by the trade wind. In the case of the tests for this project, the trade winds were set to $33.336 \mathrm{~km} / \mathrm{hr}$ (18 knots). 
The following two ships were used for both existing and plan testing during the simulation:

a. Tanker: $277.37 \mathrm{~m}(910 \mathrm{ft})$ length overall (LOA) by $32.31 \mathrm{~m}(106 \mathrm{ft})$ beam (B) by $11.887 \mathrm{~m}(39 \mathrm{ft})$ draft $(\mathrm{T})$ (bow image shown in Figure 18).

b. Containership: $294.13 \mathrm{~m}(965 \mathrm{ft})$ LOA by $32.31 \mathrm{~m}(106 \mathrm{ft}) \mathrm{B}$ by 10.97 $\mathrm{m}(36 \mathrm{ft}) \mathrm{T}$ (bow image shown in Figure 19).

Each of these ships had been previously validated on several other projects performed by the CHL ship/tow simulator, although some minor changes were made for this study. The most notable changes were the handling characteristics of the ships at slow speeds (less than $1.9 \mathrm{~km} / \mathrm{hr}$ ). The majority of the maneuvering performed during this study used assist tugs and slow speeds.

The ships used had the following characteristics:

a. The containership had a smaller draft than the tanker; this is generally true for ships in all ports.

$b$. The tanker was less maneuverable than the containership and posed more of a concern than the containership.

c. The containership was more affected by the wind during the simulation (due to the sail area of the containers and superstructure).

\section{Simulation Testing Program}

Table 2 lists the tests conducted during the simulation.

\begin{tabular}{|l|l|l|l|}
\hline \multicolumn{2}{|l|}{$\begin{array}{l}\text { Table 2 } \\
\text { Simulation Tests }\end{array}$} \\
\hline Condltion & Channel & Directlon & Vessel \\
\hline \multirow{3}{*}{ Existing } & \multirow{4}{*}{ Honolulu } & Inbound & Containership \\
\cline { 3 - 4 } & & Outbound & Containership \\
\cline { 3 - 4 } & & Inbound & Tanker \\
\cline { 3 - 4 } & & Outbound & Tanker \\
\hline \multirow{3}{*}{ Plan } & Kalihi & Inbound & Containership \\
\cline { 3 - 4 } & & Outbound & Containership \\
\cline { 3 - 4 } & & Inbound & Tanker \\
\cline { 3 - 4 } & & Outbound & Tanker \\
\hline
\end{tabular}

Although the majority of runs were made to the Sealand Terminal, several were also made to the Matson Terminal, as described in Chapter 3.

The testing session for each of the pilots began with several familiarization runs in the existing Honolulu Channel - typically, one or two with a containership and one or two with the tanker, depending on how comfortable the pilot was with the maneuverability of the ship. After these initial runs, the tests 
listed in Table 2 were performed in random order. Each run used the wind and flood tide currents as discussed in the "Validation of the Existing Conditions" section.

Ship handling was accomplished by the pilot and/or helmsman performing the commands given by the pilot. The pilot also generally performed the tugboat commands during the tests. The demands placed upon the pilot are considerable during simulation testing: adapting to existing and plan channel configurations, swapping design ships, and enduring long hours of intense concentration (typically 7-8 hours a day). When the pilots perform the tugboat commands themselves, the possibility of confusing commands and invalidating the test results by someone unfamiliar with their methods is removed.

Initially, inbound runs were begun at the entrance to the main channel to maximize the number of runs that could be performed during the testing period. However, after several tests were completed, a consensus was reached that the pilots did not seem to have enough setup time to prepare the vessel to enter the harbor. The starting position was then moved east of the sea buoy. For inbound tests, the run was concluded once the pilot was in a position that required no further extensive maneuvering on his part (i.e., tugs and/or slight maneuvering could bring the vessel the last distance to the terminal). Outbound runs were begun a short distance from the terminal, and concluded when the pilot was away from the harbor and exiting the channel.

As each test was run, the ship speed, position, engine rotations per minute, rudder angle, tug usage, and port and starboard channel clearances were recorded every $5 \mathrm{sec}$. The recorded data were stored in a file for each run and later processed on a personal computer for the trackplots discussed in Chapter 3. 


\section{Results and Conclusions}

The central focus of the results of this navigation study is the track plots shown in Plates 1-56. As stated, each test had certain features that were recorded every $5 \mathrm{sec}$ for the duration of the test. The track plot is a compilation of several of these features. Most notable are the position and heading of the ship, in some cases the rudder angle, and, indirectly, the speed of the ship (the farther apart the icons are, the faster the vessel is traveling). For the track plots in this study, the ship icon shown was plotted approximately every $25 \mathrm{sec}$. Ship position and direction are shown simply by the location and direction of the ship icon. A rudder icon connected to the back of the ship could have been used to show rudder angle; however, many times during harbor maneuvers extreme rudder angles can and will be used that are not a cause for concern. Additionally, the rudder icon would quickly become lost in the closely spaced ship icons because of the relative slow speeds being used by the vessels during the harbor transit.

Plates 1-24 are track plots of tests using the existing main harbor entrance channel. The first plate in each group shows a composite of all the runs made for that particular set of conditions; each plate after that shows the individual runs. These are divided into the following groups:

- Plates 1-7: containership, inbound to Sealand Terminal

- Plates 8-13: containership, outbound from Sealand Terminal

- Plates 14-16: containership, inbound to Matson Terminal

- Plate 17: containership, outbound from Matson Terminal

- Plates 18-21: tanker, inbound to Sealand Terminal

- Plates 22-24: tanker, outbound from Sealand Terminal

The existing condition runs were executed smoothly without problems. The pilots maneuver these size vessels in the harbor daily, so the runs verify that the simulation produced the type of transits in the harbor to which the pilots were accustomed.

Plates 25-56 show the track plots of the plan conditions and focus solely upon Kalihi Channel. As with the existing conditions, the first of each group of plates shows the composite of all runs made for the particular test, each 
composite followed by the individual runs. These are divided into the following groups:

- Plates 25-29: containership, outbound from Sealand Terminal

- Plates 30-33: tanker, inbound to Sealand Terminal

- Plates 34-38: tanker, outbound from Sealand Terminal

- Plates 39-44: containership, inbound to Matson Terminal

- Plates 45-47: containership, outbound from Matson Terminal

- Plates 48-52: containership, entrance to Kalihi Channel

- Plates 53-56: tanker, entrance to Kalihi Channel

In general, the tests on Kalihi Channel were successful. No major problems arose during the containership or tanker runs. A few minor concerns were noted:

a. On several transits the vessel (containership or tanker) seemed to run too far down into the Emergency Turning Basin before beginning its turn.

b. Several transits showed signs of "ping-ponging" or swerving from side to side down the channel.

c. Several transits showed problems with the entrance into Kalihi Channel (i.e., cutting through part of the recognized channel line).

The vessel's being too far down into the Emergency Turning Basin before making the turn was probably due in part to the containerships on the northern or right side of the harbor across from Sealand. These ships give a "crowded" feeling to the passage. Safety is always uppermost in the pilot's mind, causing him to give way to these docked vessels and stay to the left. This maneuver would tend to move him farther into the basin before he could make his turn and would also cause the probability of ping-ponging.

The vessel's cutting across part of the recognized channel line during the entrance to Kalihi Channel could be addressed in two different ways. The first would be to locate a sea buoy in line with the channel, just as the sea buoy located on the main channel was placed. This would give the pilot a visual cue to line up the approach to the channel, as shown in Figure 20. The second method would be to dredge a flare in the first part of the channel, possibly something similar to that shown in Figure 21, of about one quarter of the channel length. This would give the pilots a larger opening to enter and give them time to straighten the vessel out and get it into position once inside the channel. The possibility of adding a red buoy marking the beginning of the flare would need to be determined by the Coast Guard. 
The feasibility of the modification to the channel by a flare would also have to be looked at with respect to projected traffic. According to discussions with the pilots in the area and the District personnel, a possible major user of the Kalihi Channel would be the towed barges. Although not included in this navigation study, the towing companies that have used this channel in the past when it was open should be consulted about any problems that may have existed with the entrance and asked if the flare approach would enhance the safety of their operations.

The barges used in Honolulu Harbor for interisland commerce (Figure 22) were beyond the capabilities of the simulator if more that one barge were being towed at one time. Although the simulator could approximate a single towed barge with considerable effort, $\mathrm{CHL}$ and the Honolulu District, with input from those involved, decided that the single towed barge would be no more deterministic in the channel design than the two vessels already available. Since its inclusion in the program would have added substantial time delays, and since the towed barges had used the existing Kalihi Channel when the bridge was still operational, it was removed from the testing program. These vessels will be a large part of the traffic of the reopened Kalihi Channel and should be considered in all decisions.

Perhaps the most significant result of the opening of Kalihi Channel was the possibility of the entrance of one ship while another exits the harbor. With only the main channel open, this was not an option. Figure 23 shows the design tanker waiting for the design containership to clear the harbor before it makes its entrance. Figure 24 exhibits the ability of the tanker to dock at the terminal once the containership has cleared the main channel. The total time for the tanker to dock was $1 \mathrm{hr} 39 \mathrm{~min}$ including the delay time. Figure 25 shows the same setup with Kalihi Channel open. As soon as the incoming tanker knows that the containership is exiting the harbor, the tanker can begin its approach. Total time for docking of the tanker was $45 \mathrm{~min} 30 \mathrm{sec}$.

Although the exit time for other ships from different terminals and orientations would vary, the time savings between an incoming vessel arriving and docking with only the main channel open and two vessels using the harbor simultaneously with both channels open could be approximately $1 \mathrm{hr}$. The possibility also exists for more time delays in the existing harbor if, for example, a containership (or other vessel) was departing and a barge and tow also needed to depart while another vessel was waiting to dock (Figure 26). The incoming vessel might have to wait until both vessels cleared the harbor, whereas opening Kalihi Channel would allow both outgoing vessels an exit from the harbor without delaying the incoming vessel in the main channel.

In conclusion, with the deepening and some minor modifications, the reopened Kalihi Channel could safely accommodate existing and proposed traffic. Towing companies should be consulted regarding their operations and the possible impact modifications might have on them. However, having access to Honolulu Harbor from Kalihi Channel and the main entrance channel should improve the flow of traffic for the harbor and reduce transit time. 


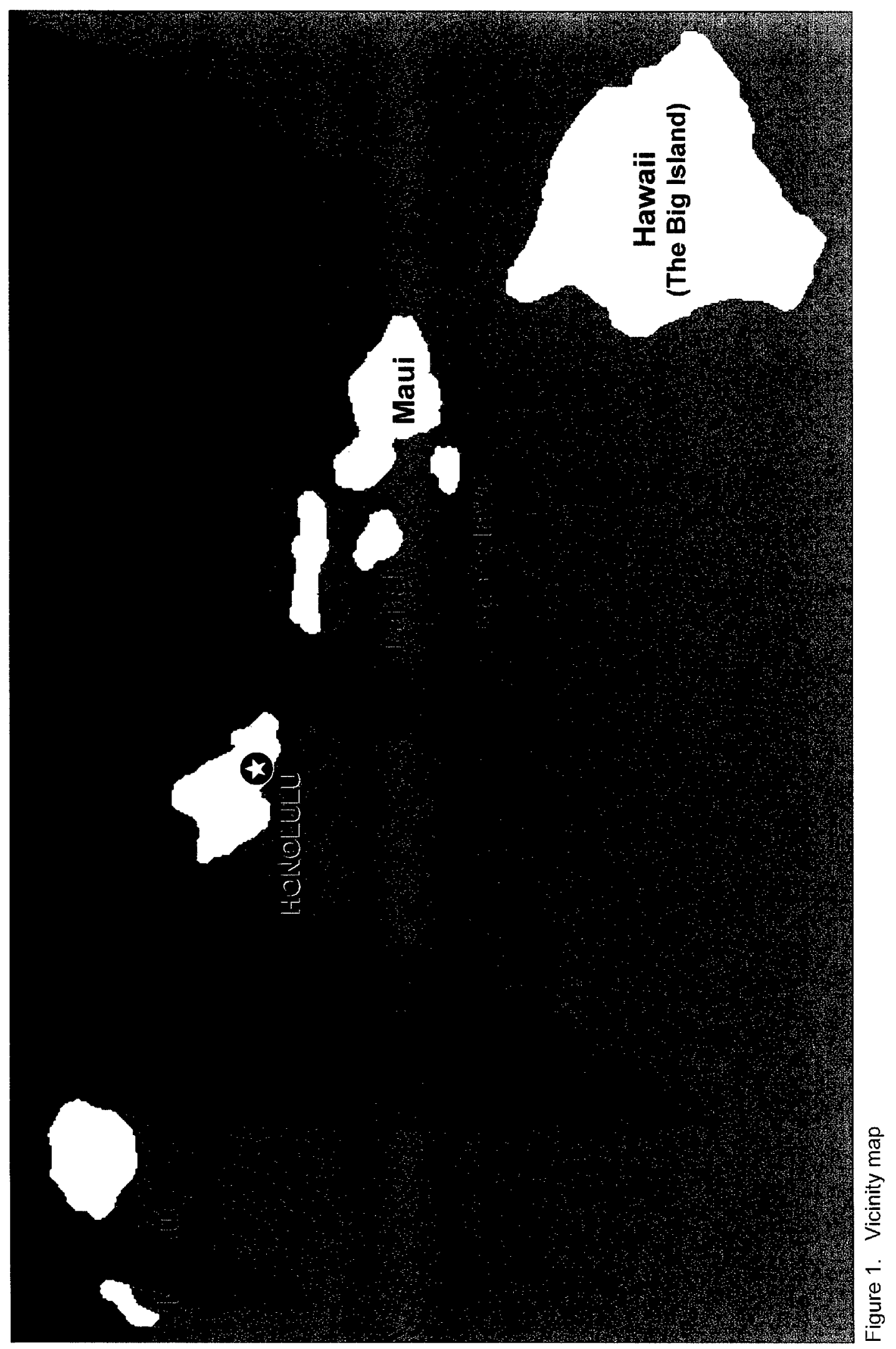




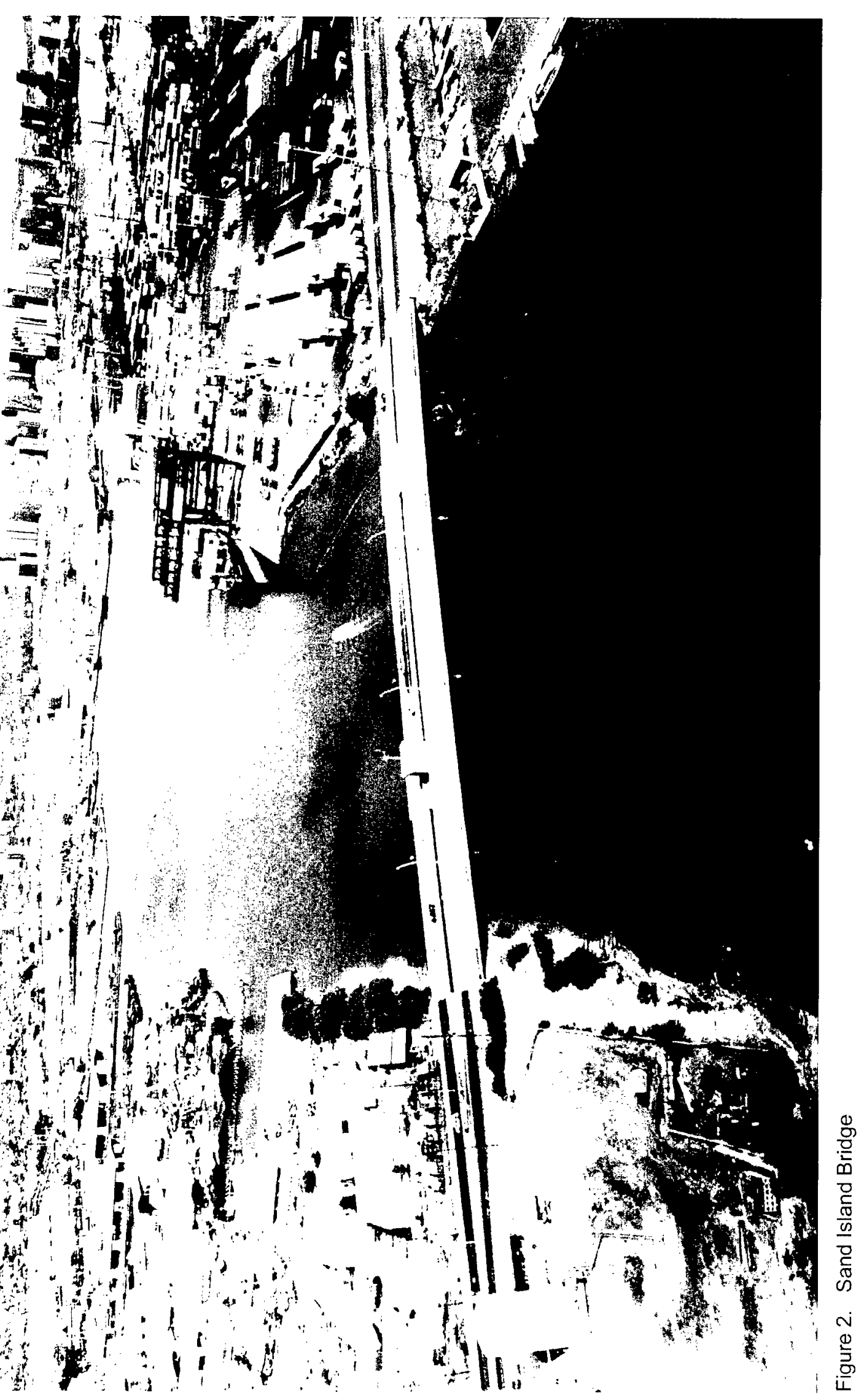



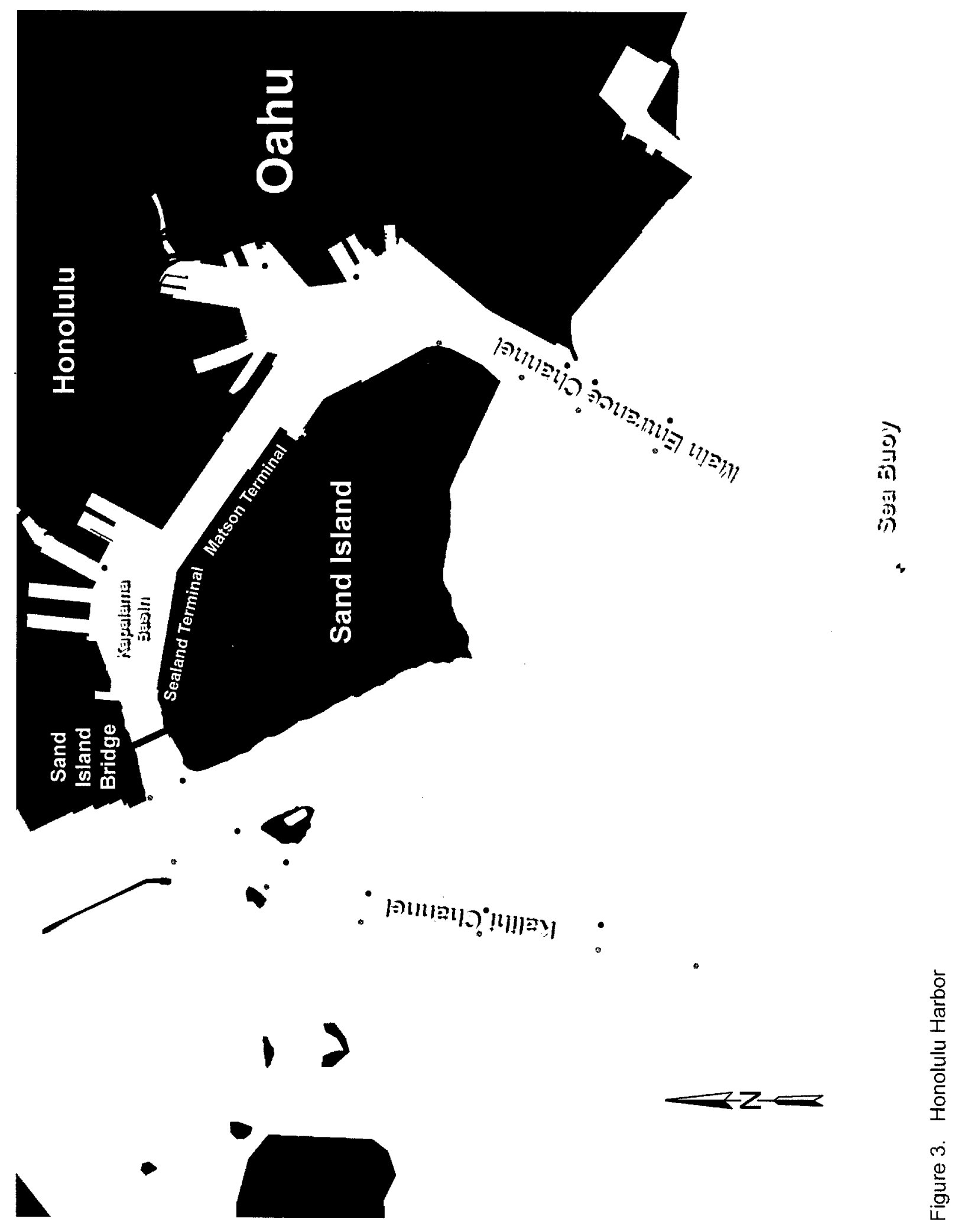


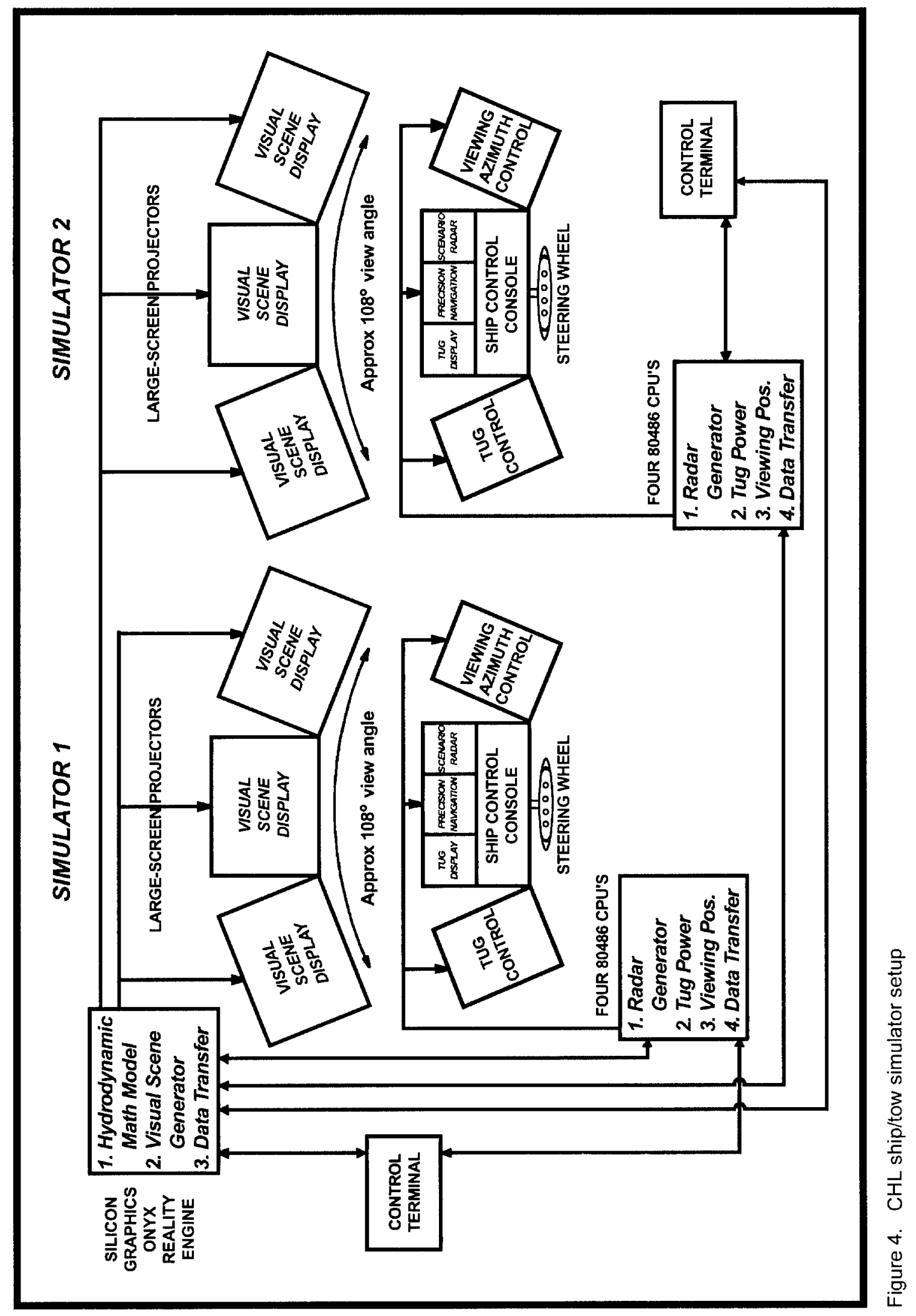




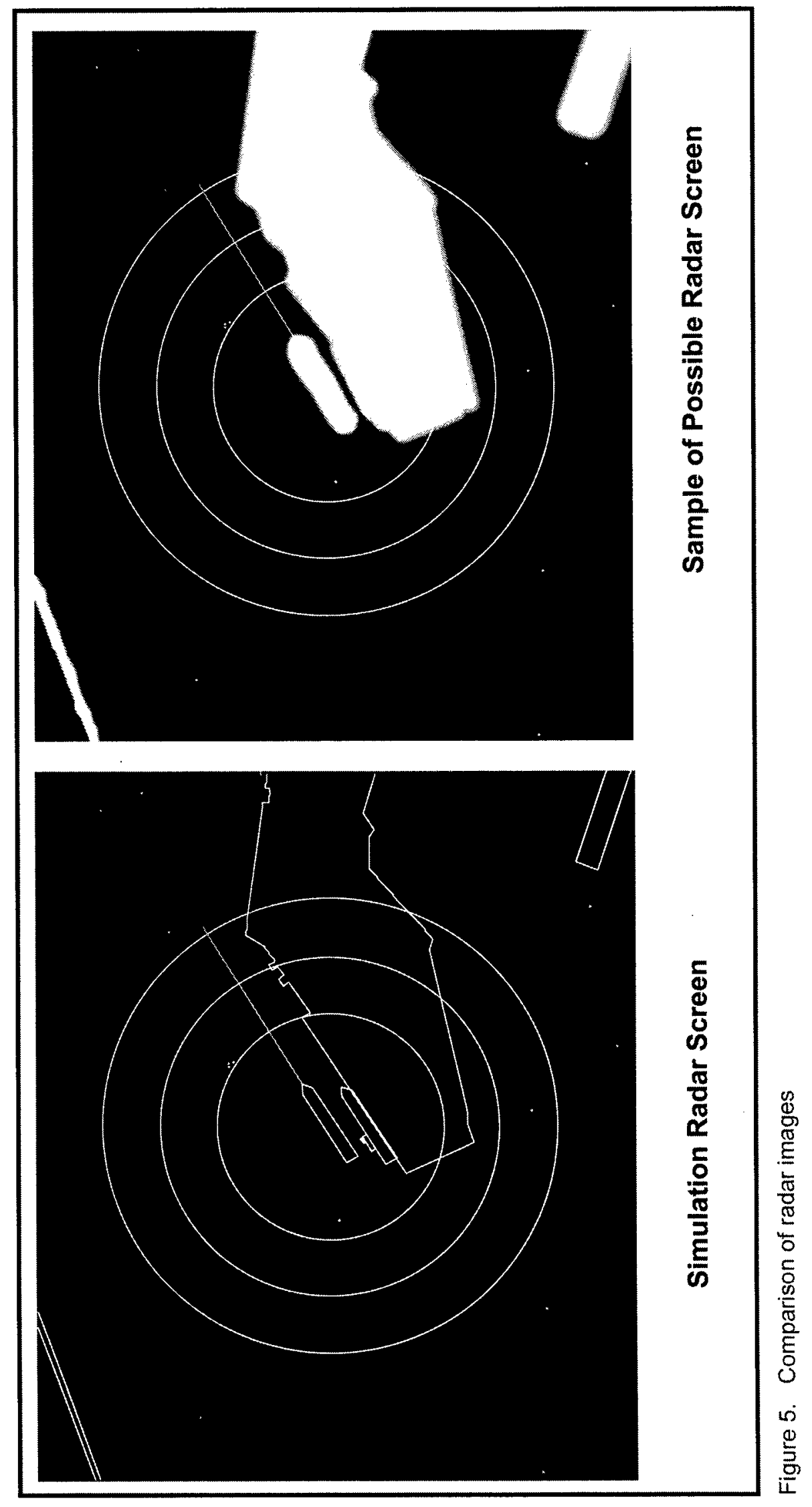




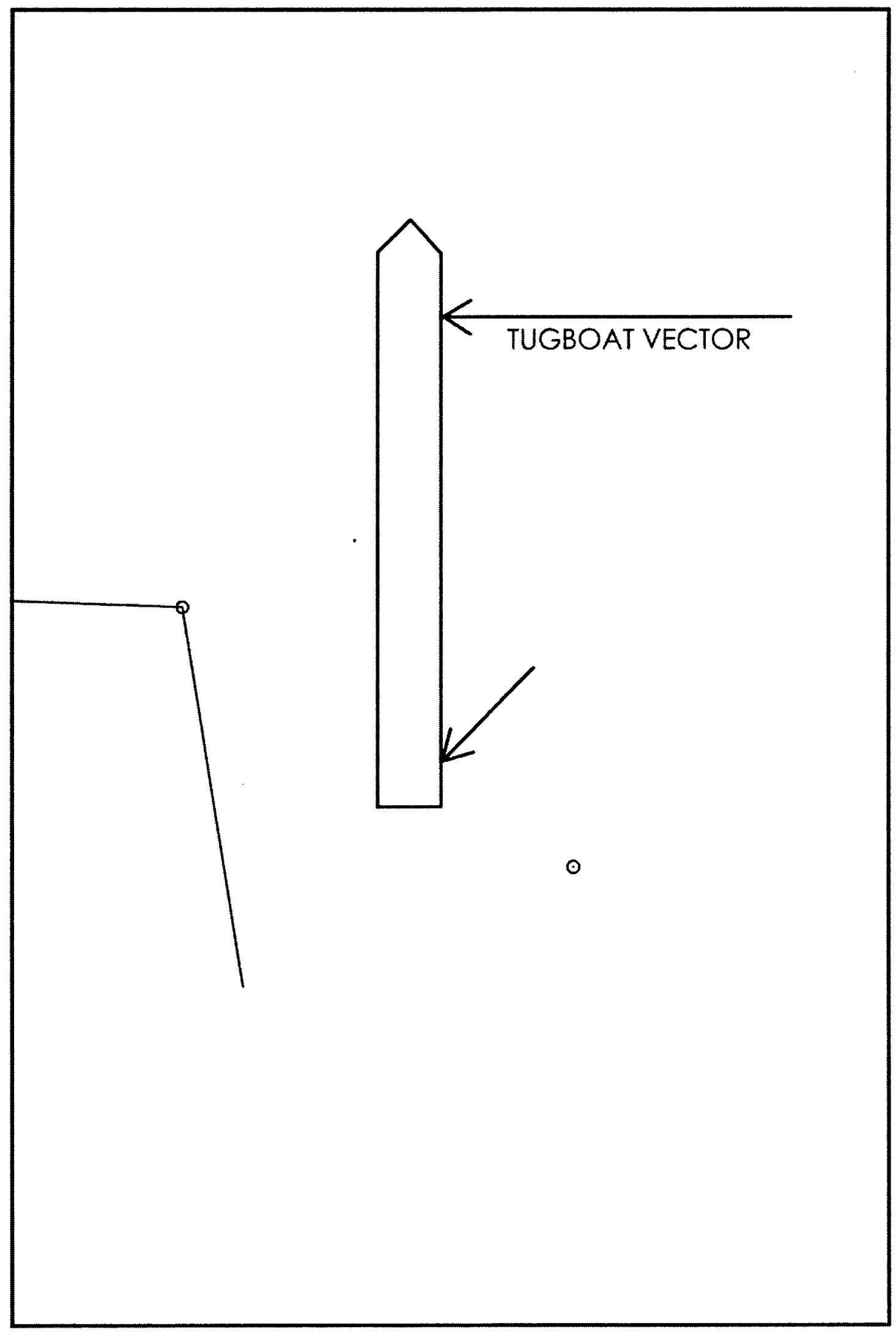

Figure 6. Radar screen at $0.4-\mathrm{km}(0.25$-mile $)$ range with tug visual 


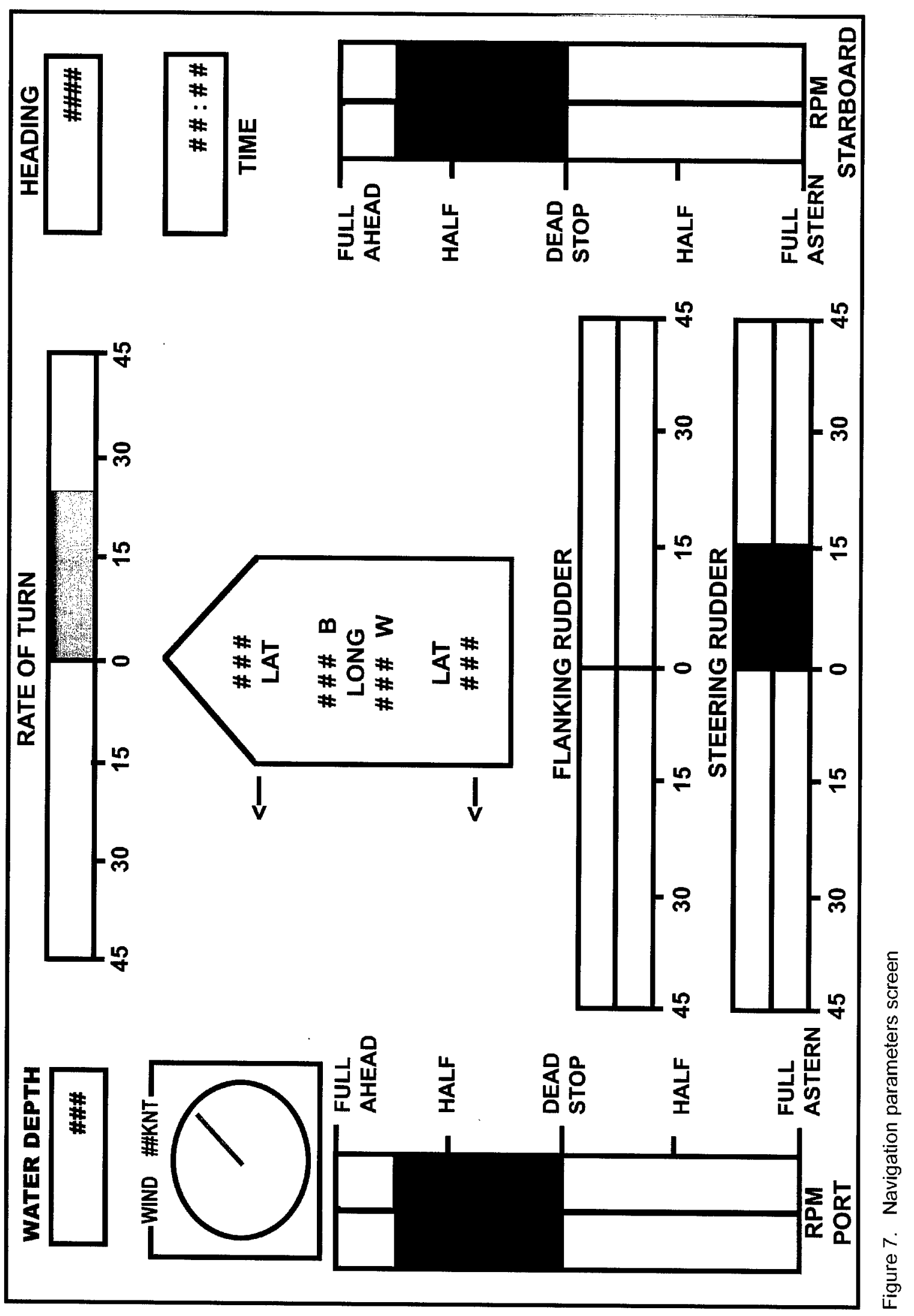




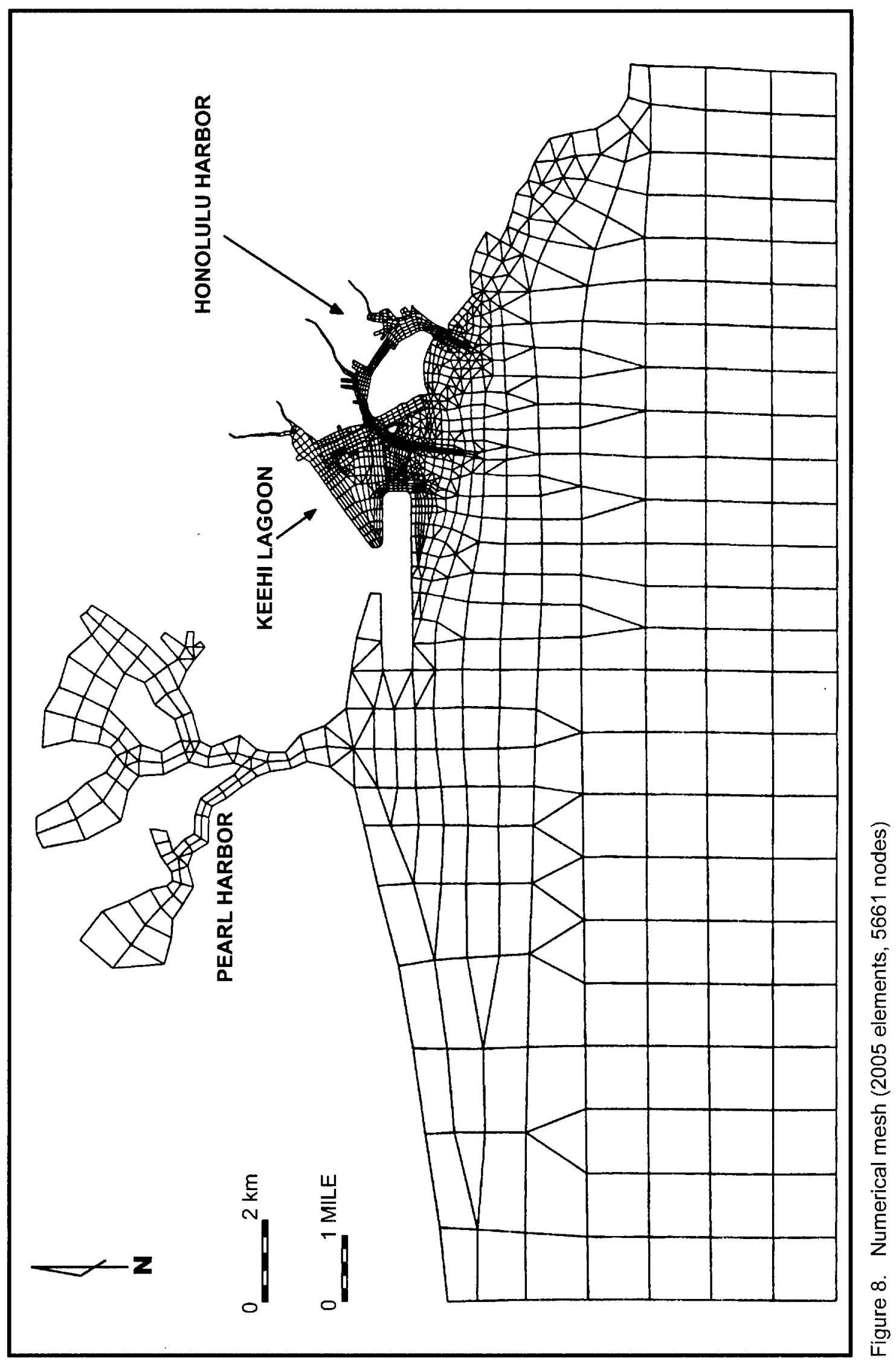




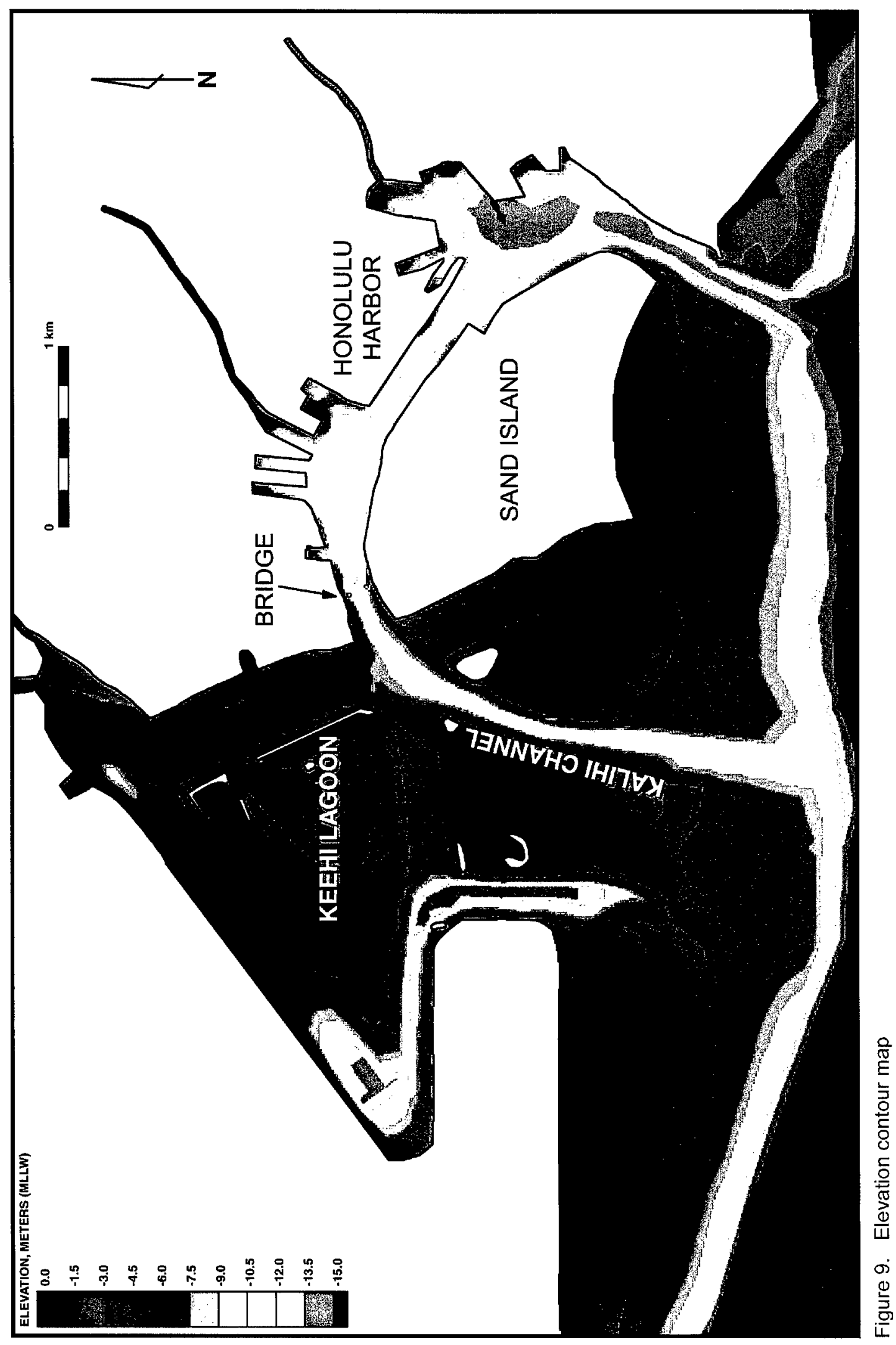




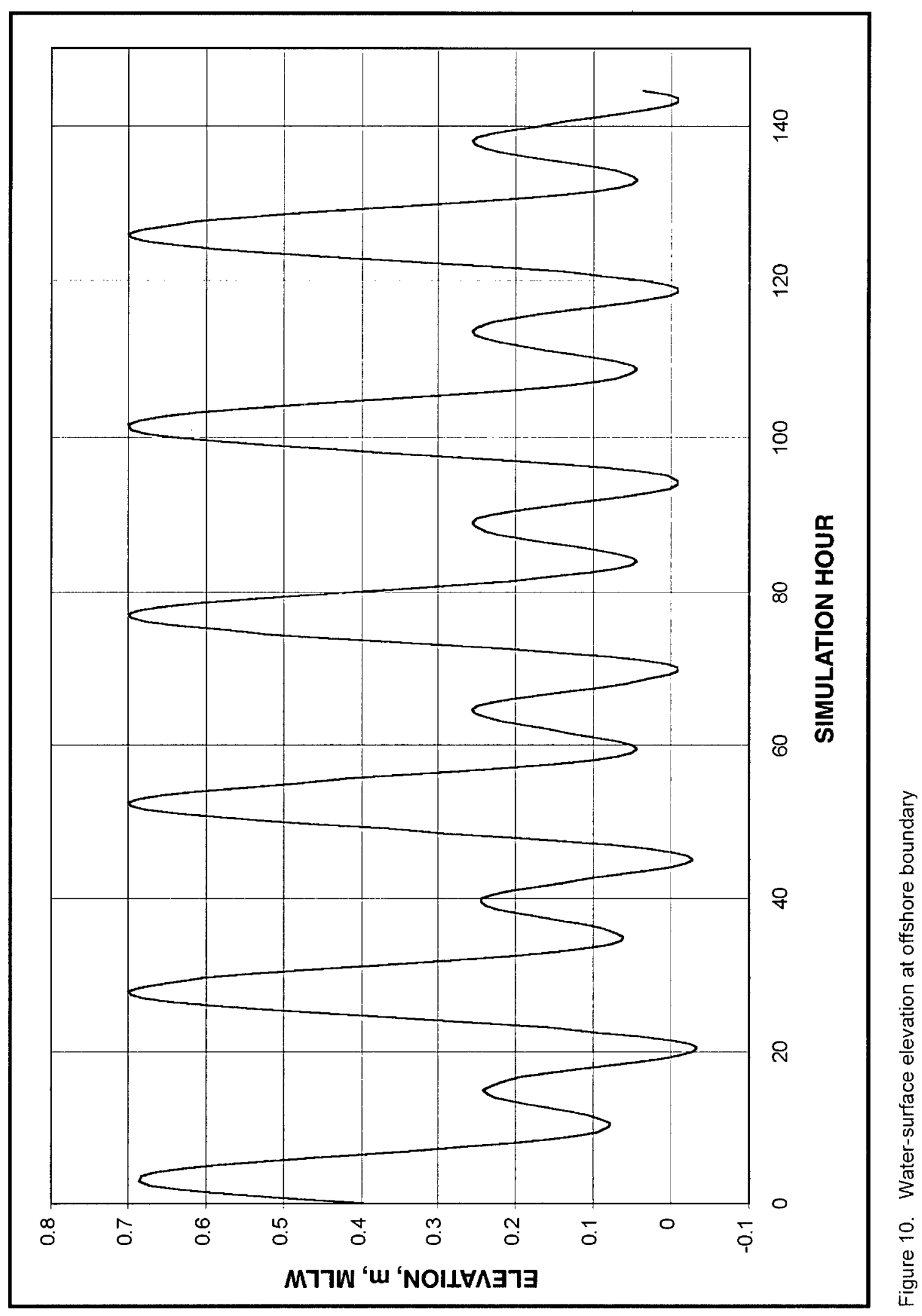




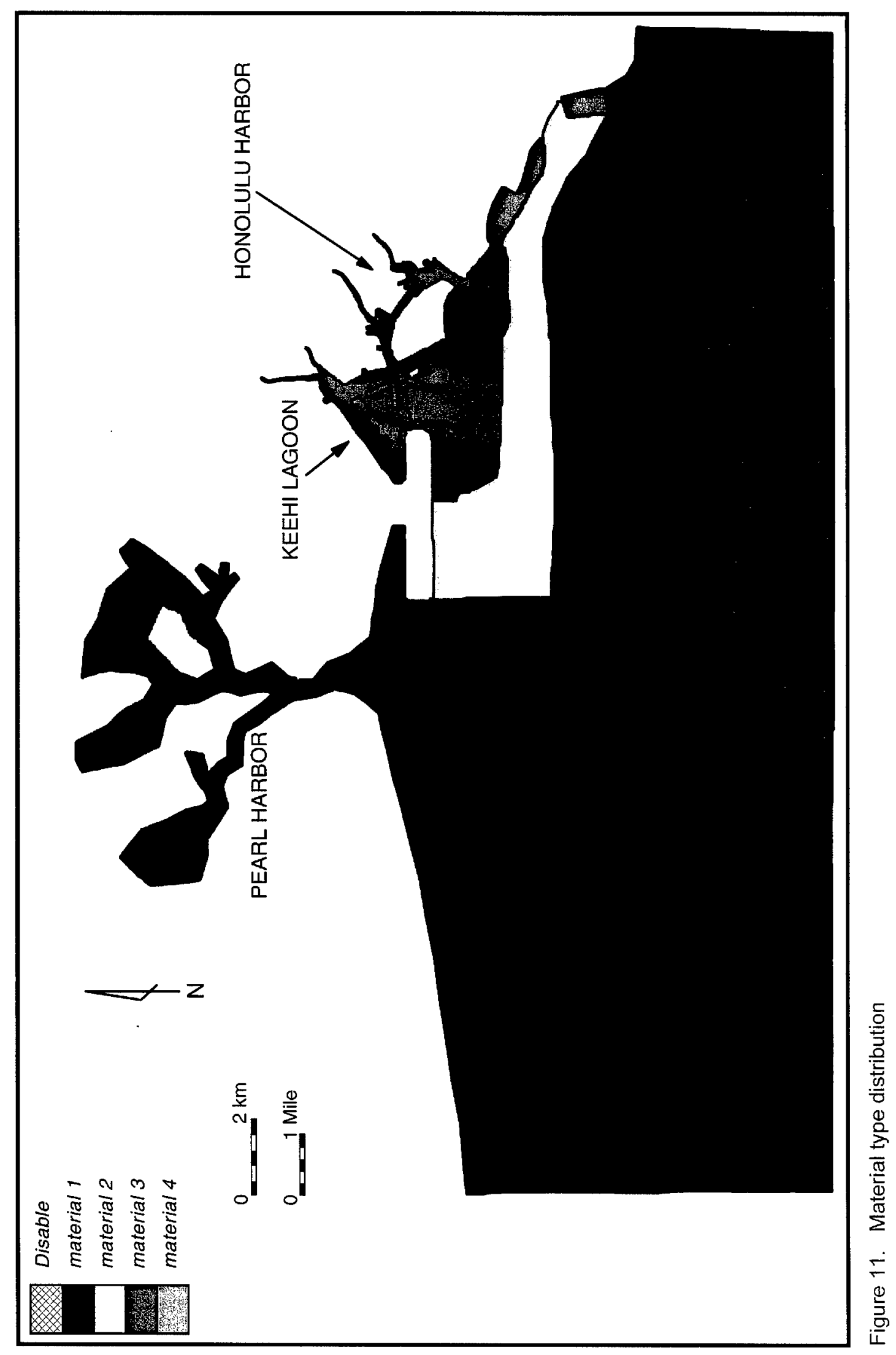




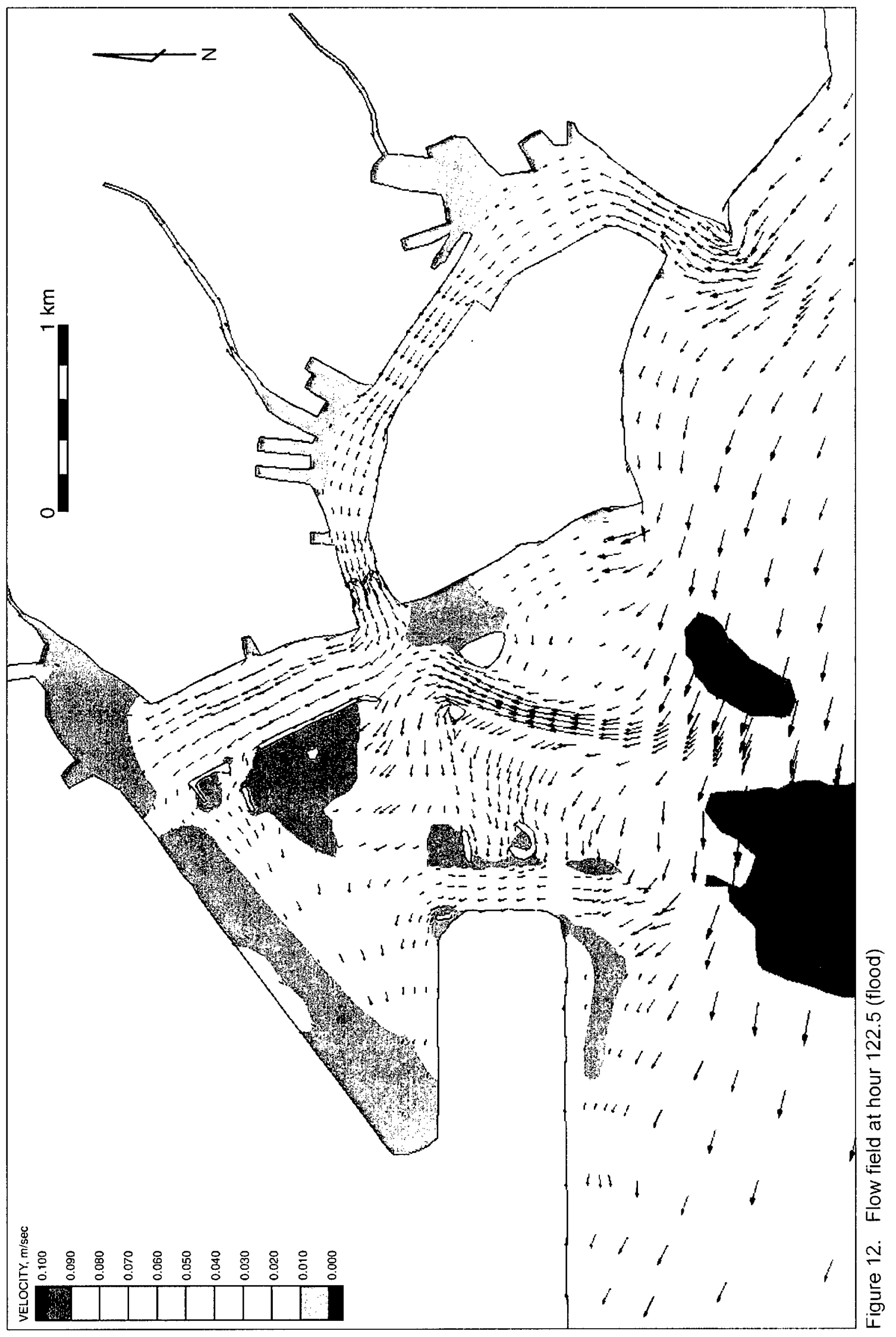




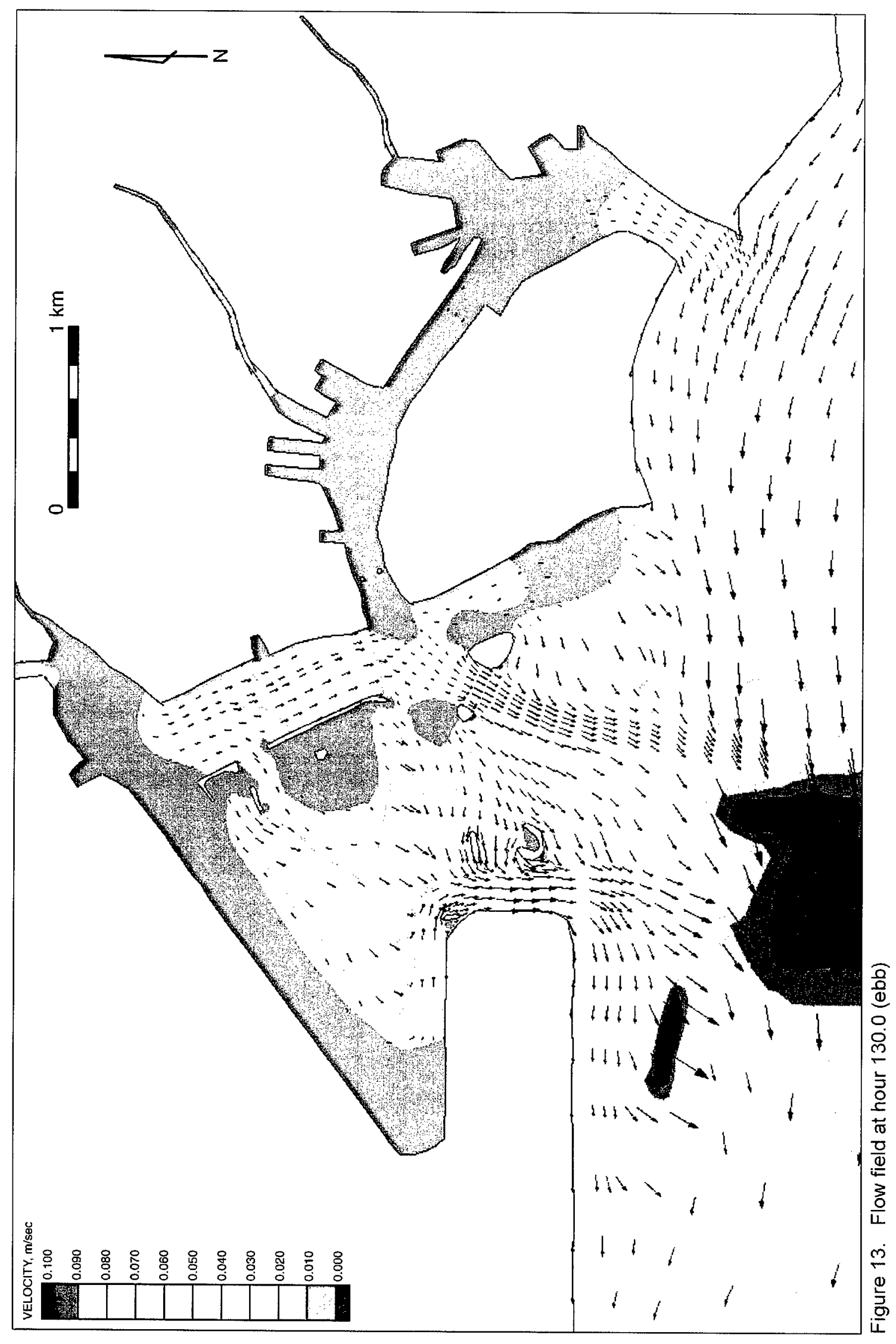




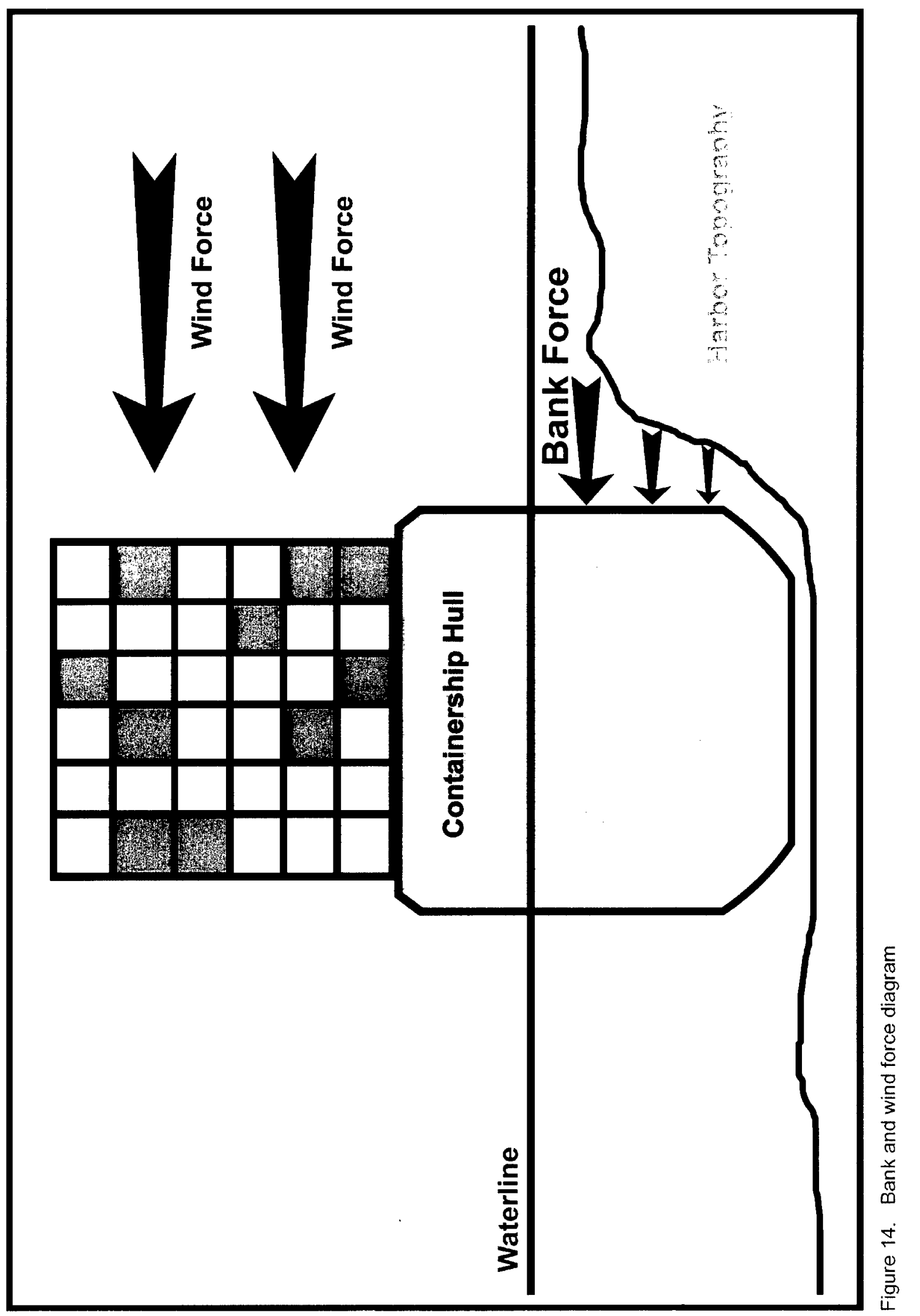




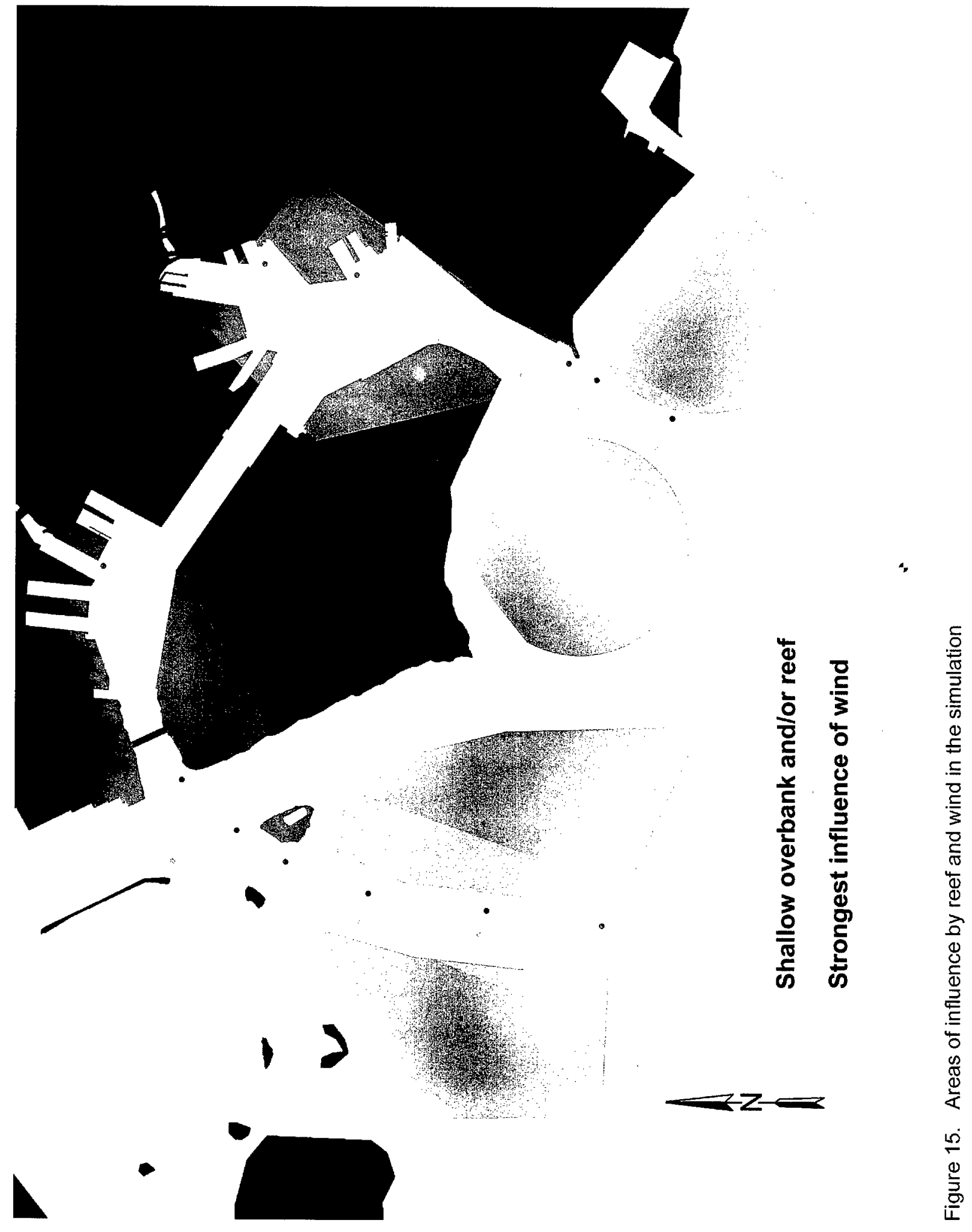




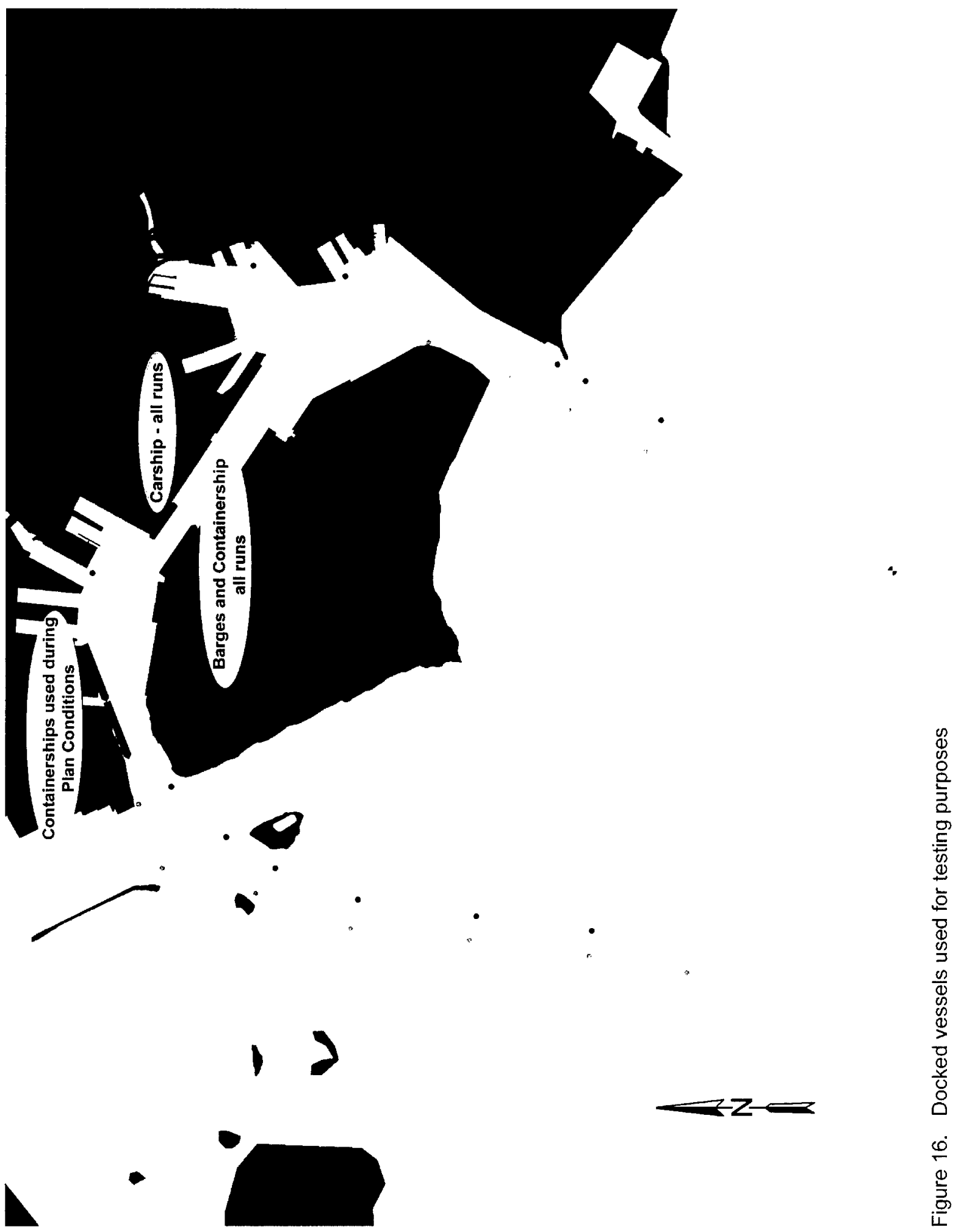




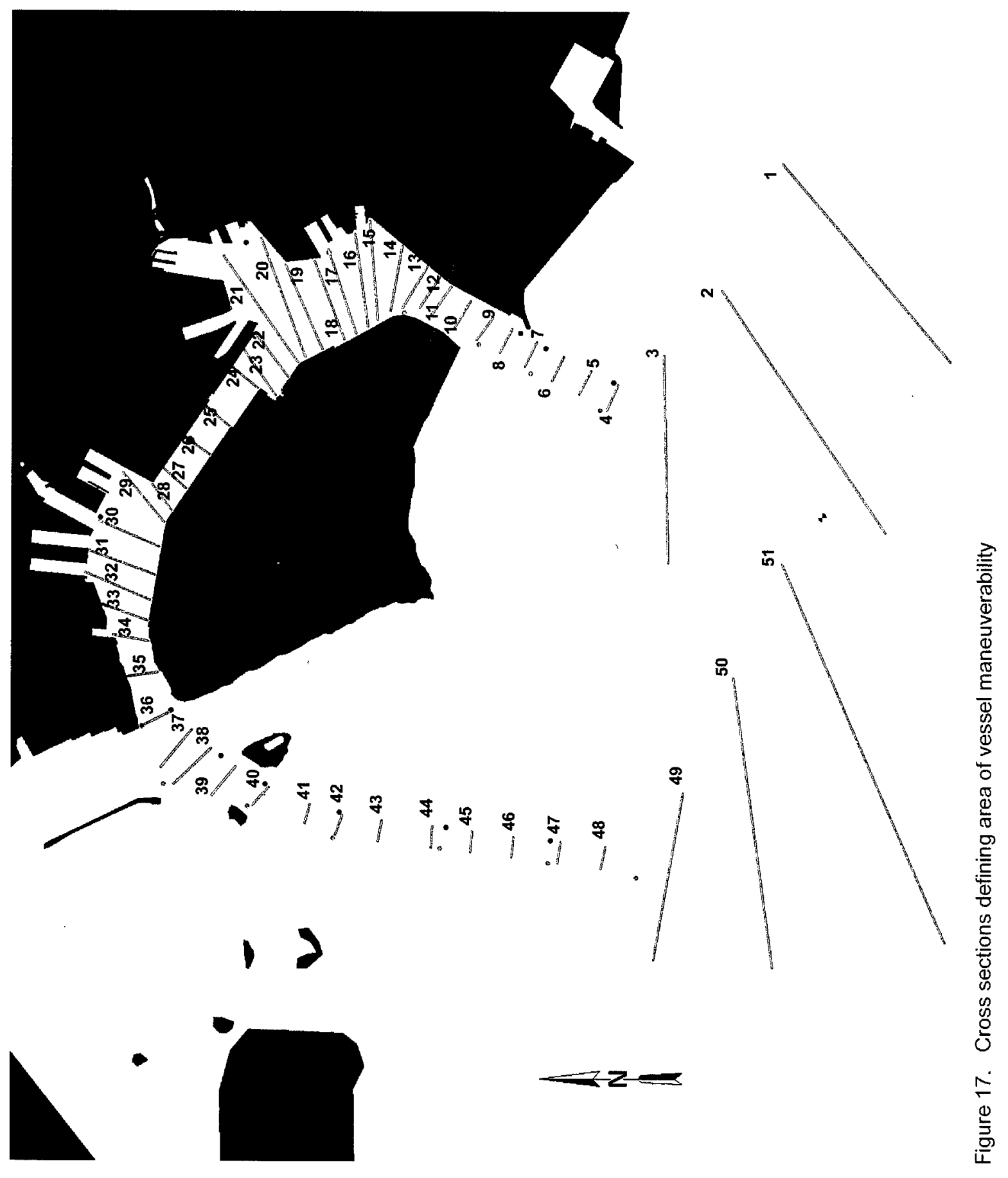




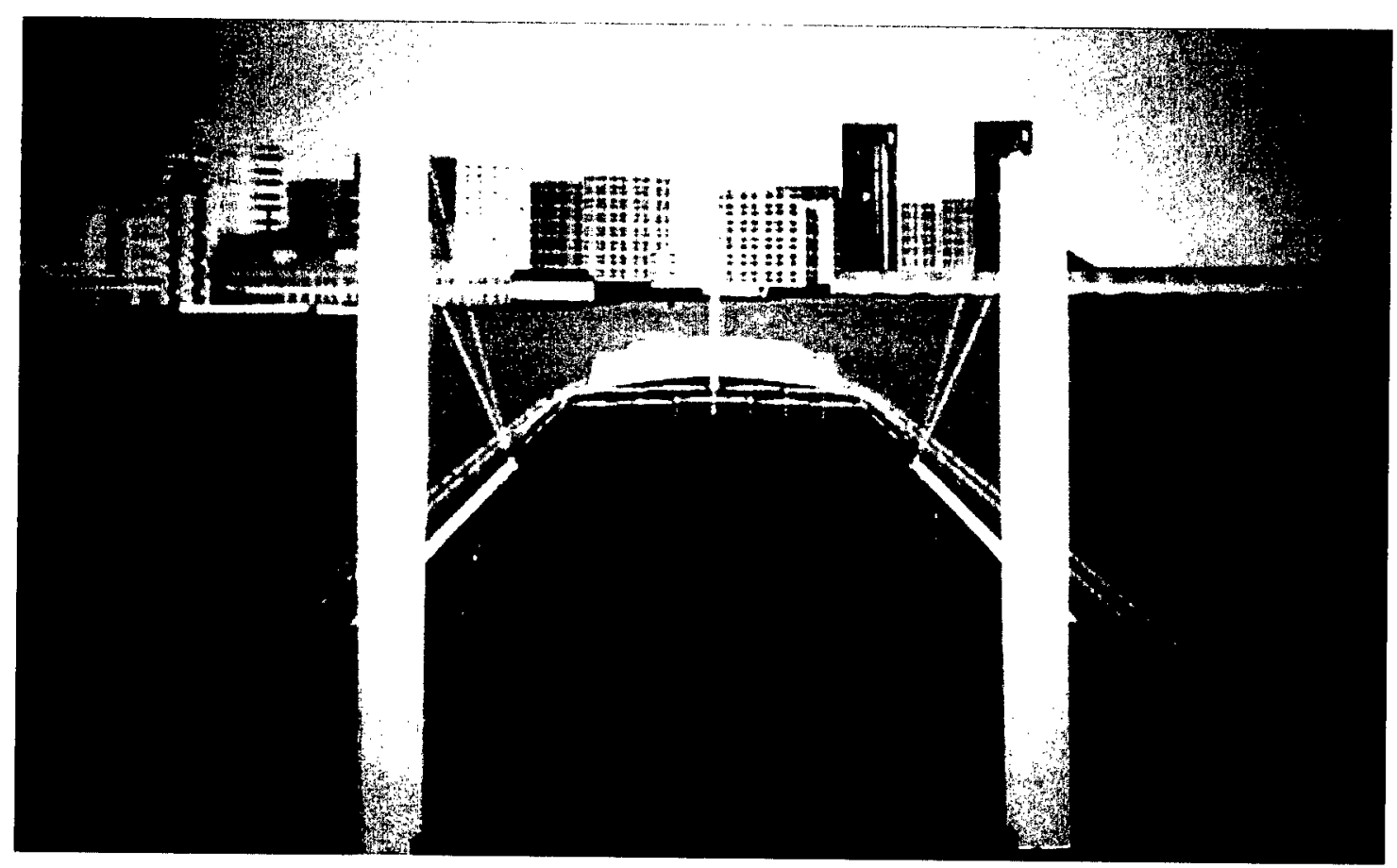

Figure 18. Simulator tanker bow image

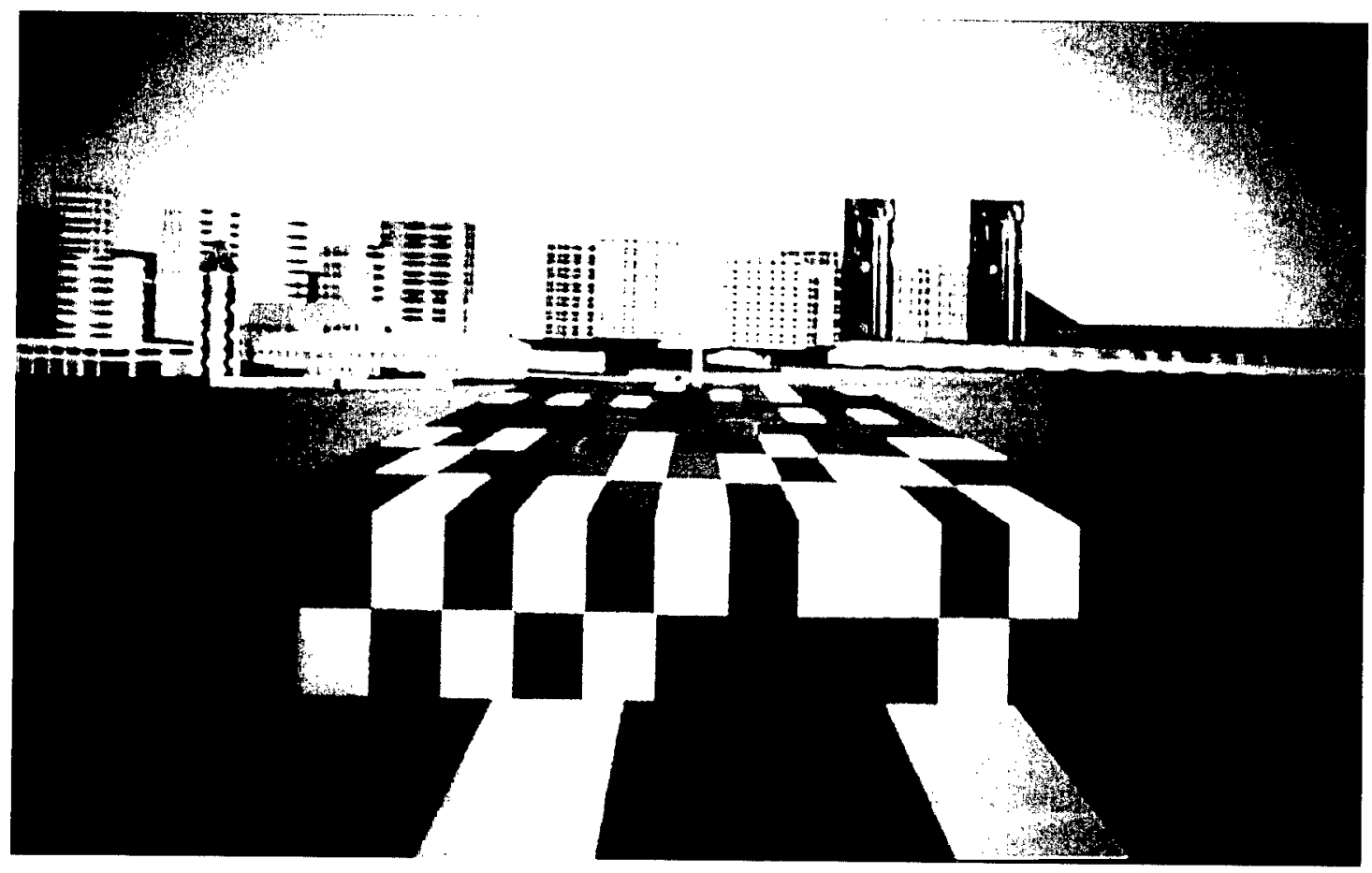

Figure 19. Simulator containership bow image 


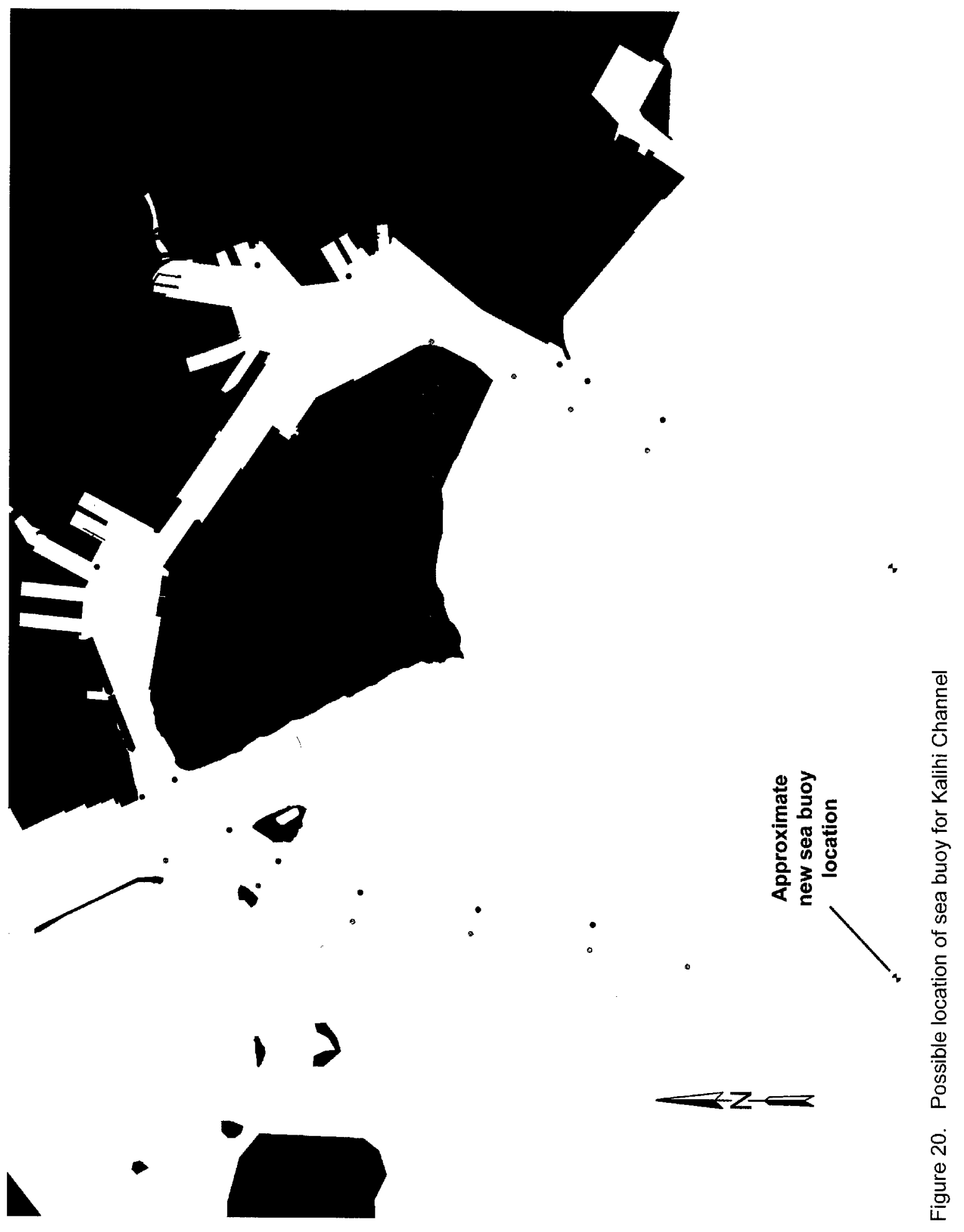




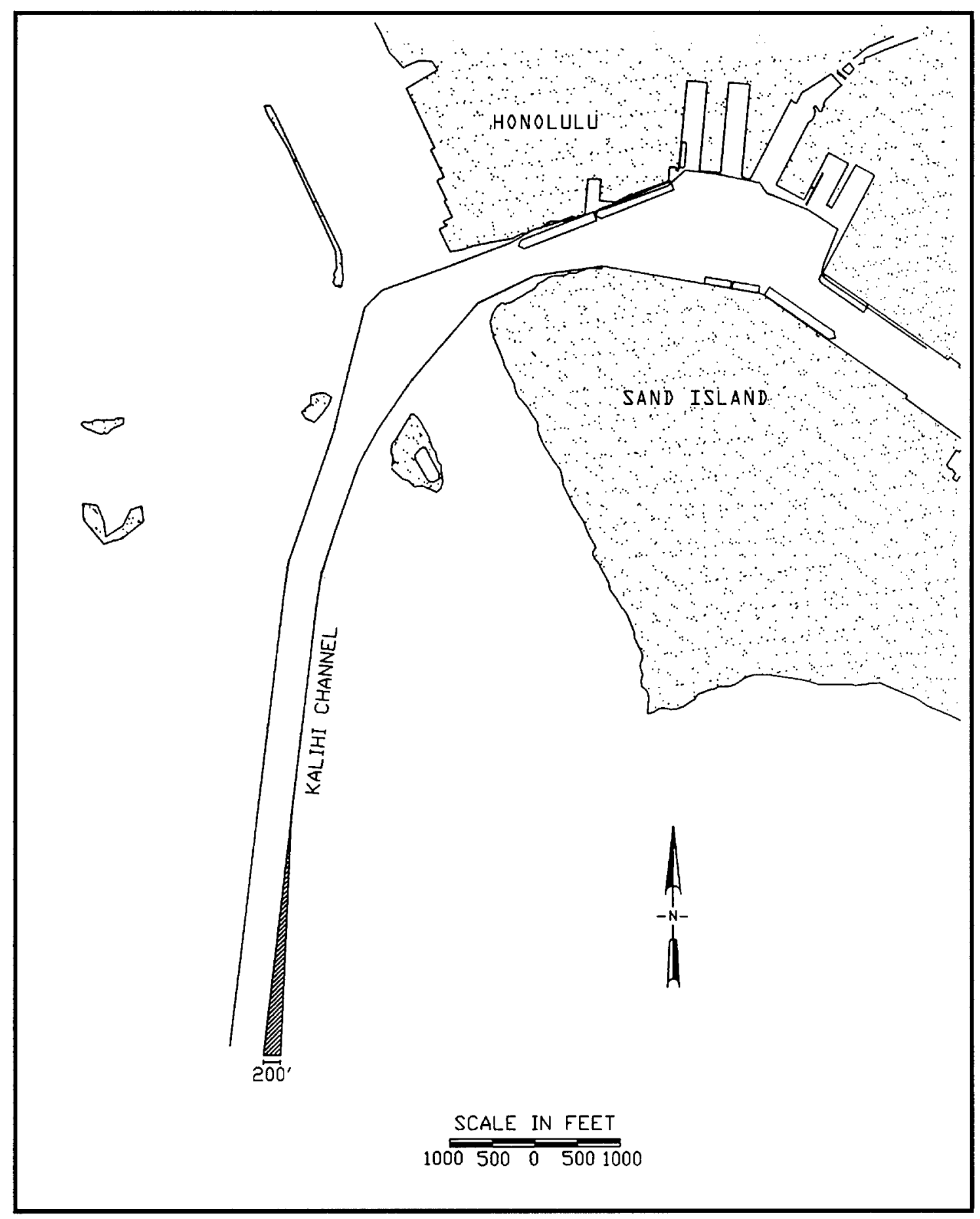

Figure 21. Possible flare option 


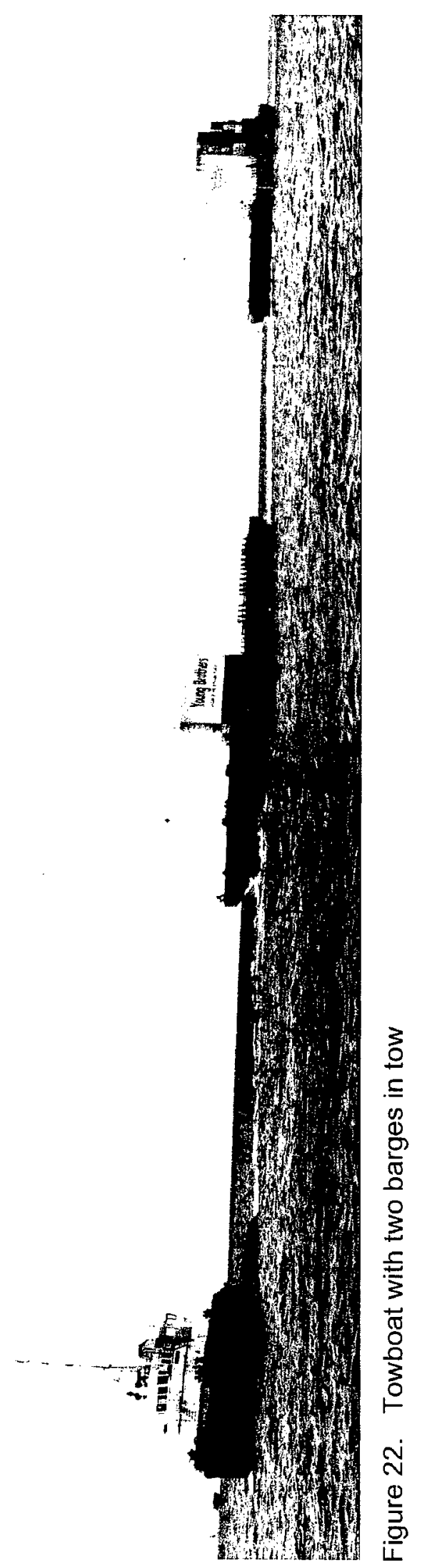




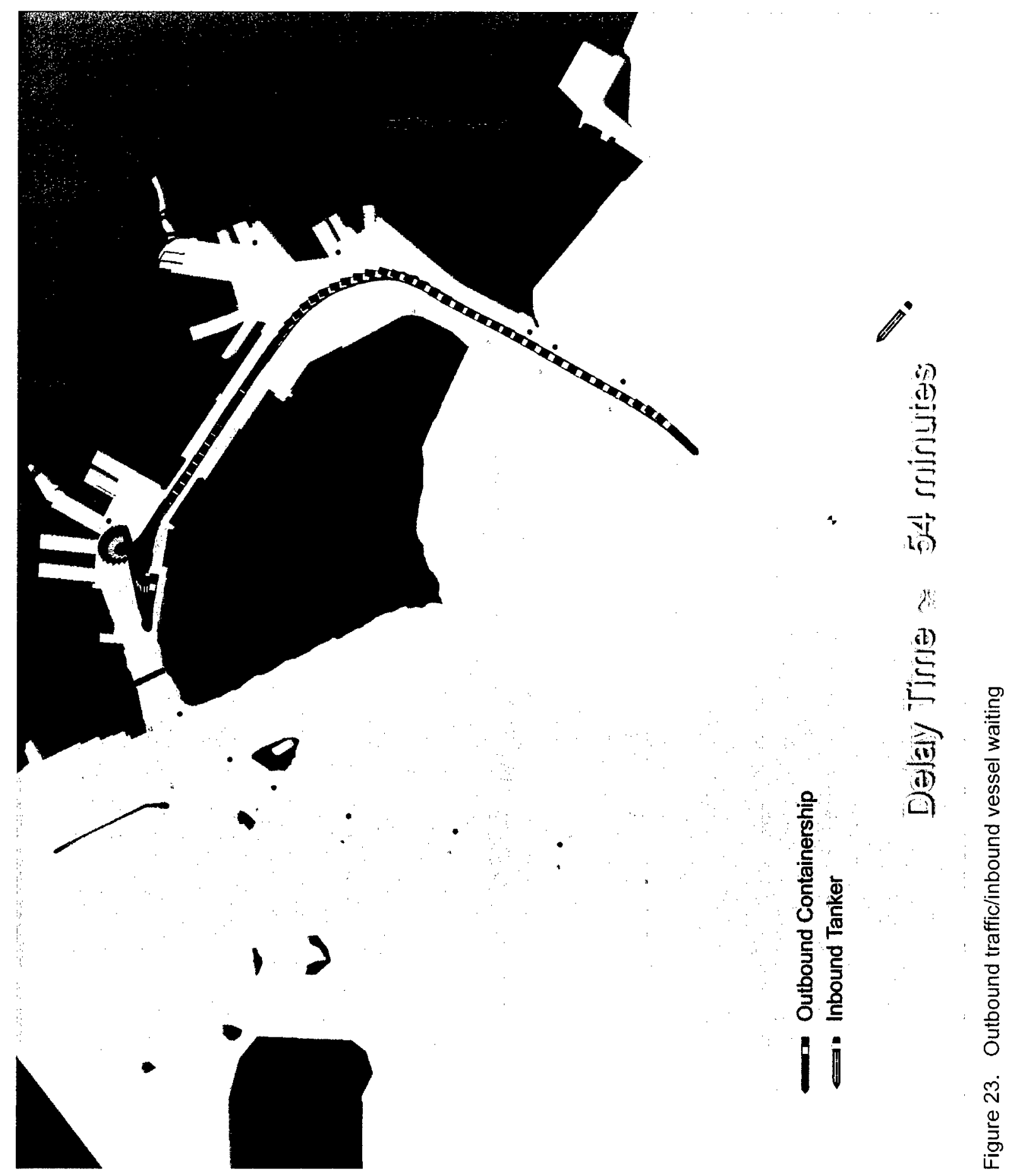




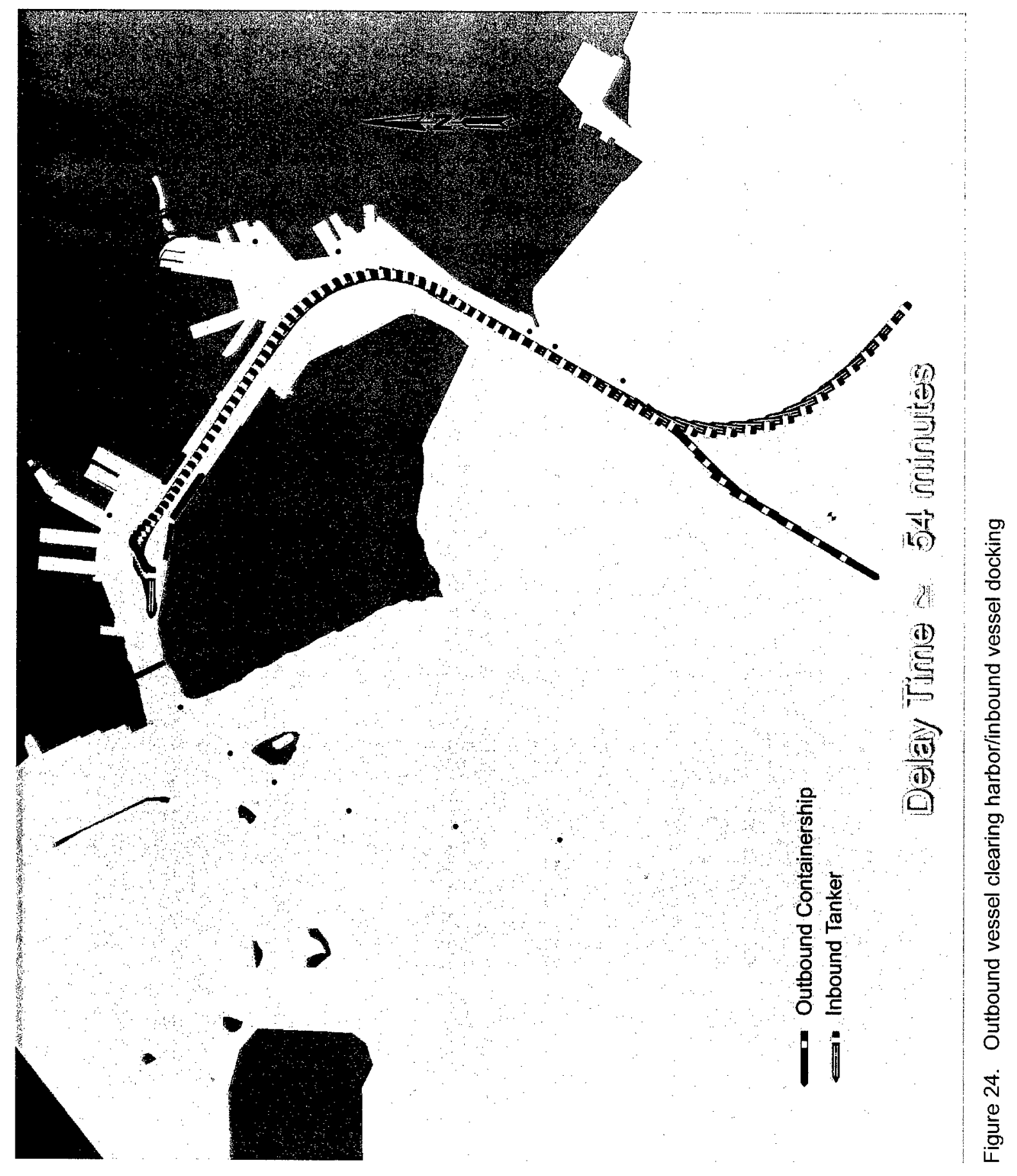




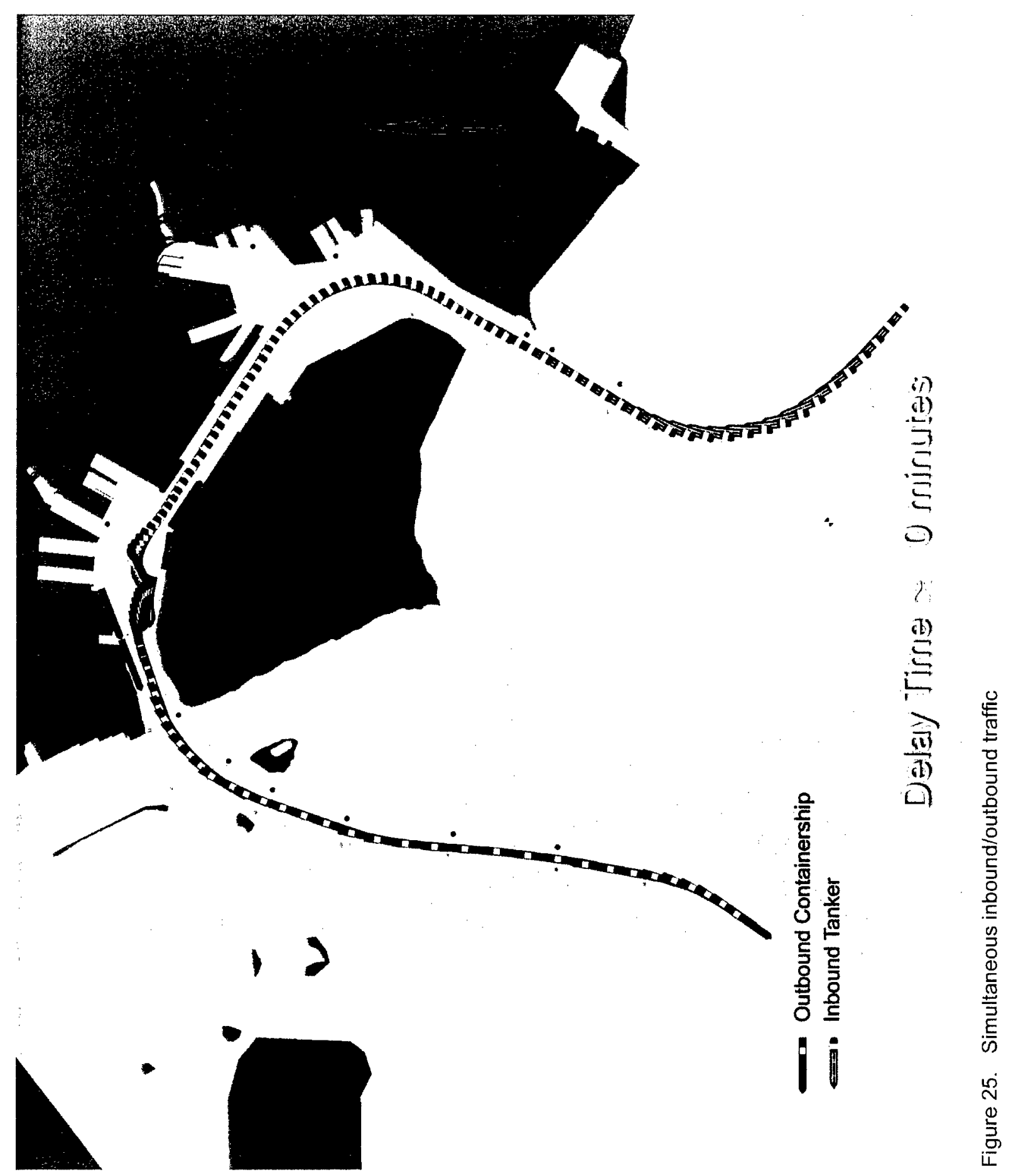




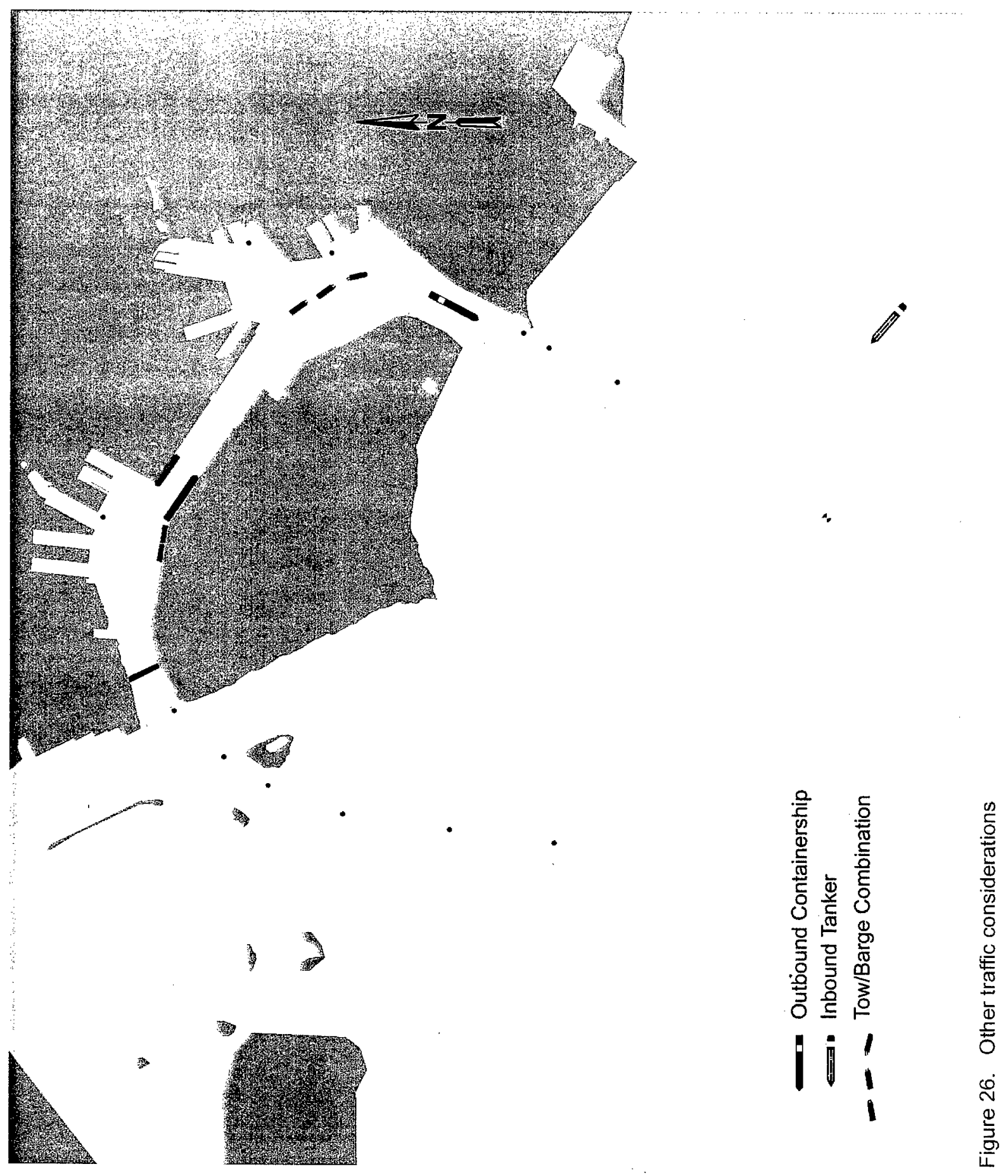




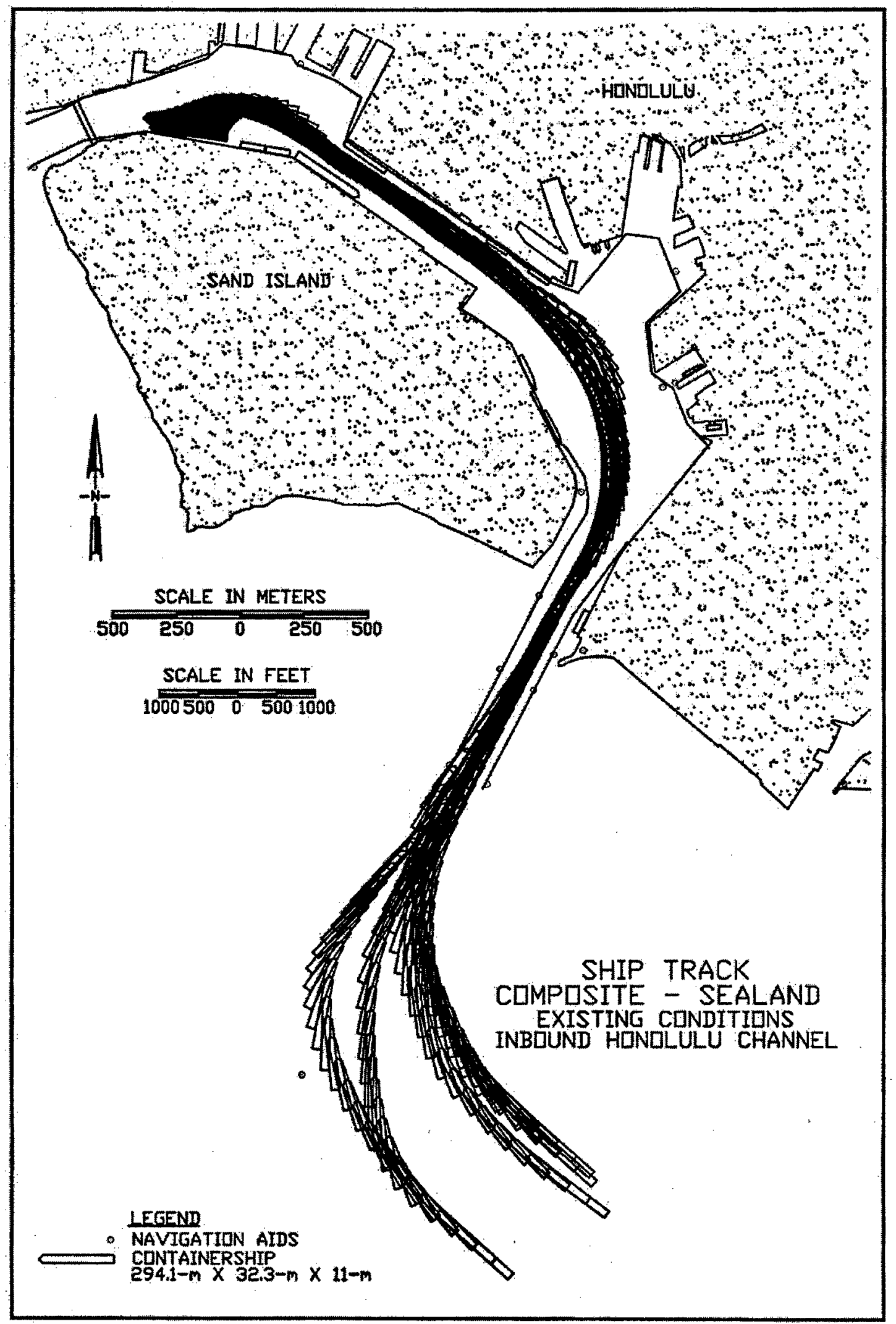

Plate 1 


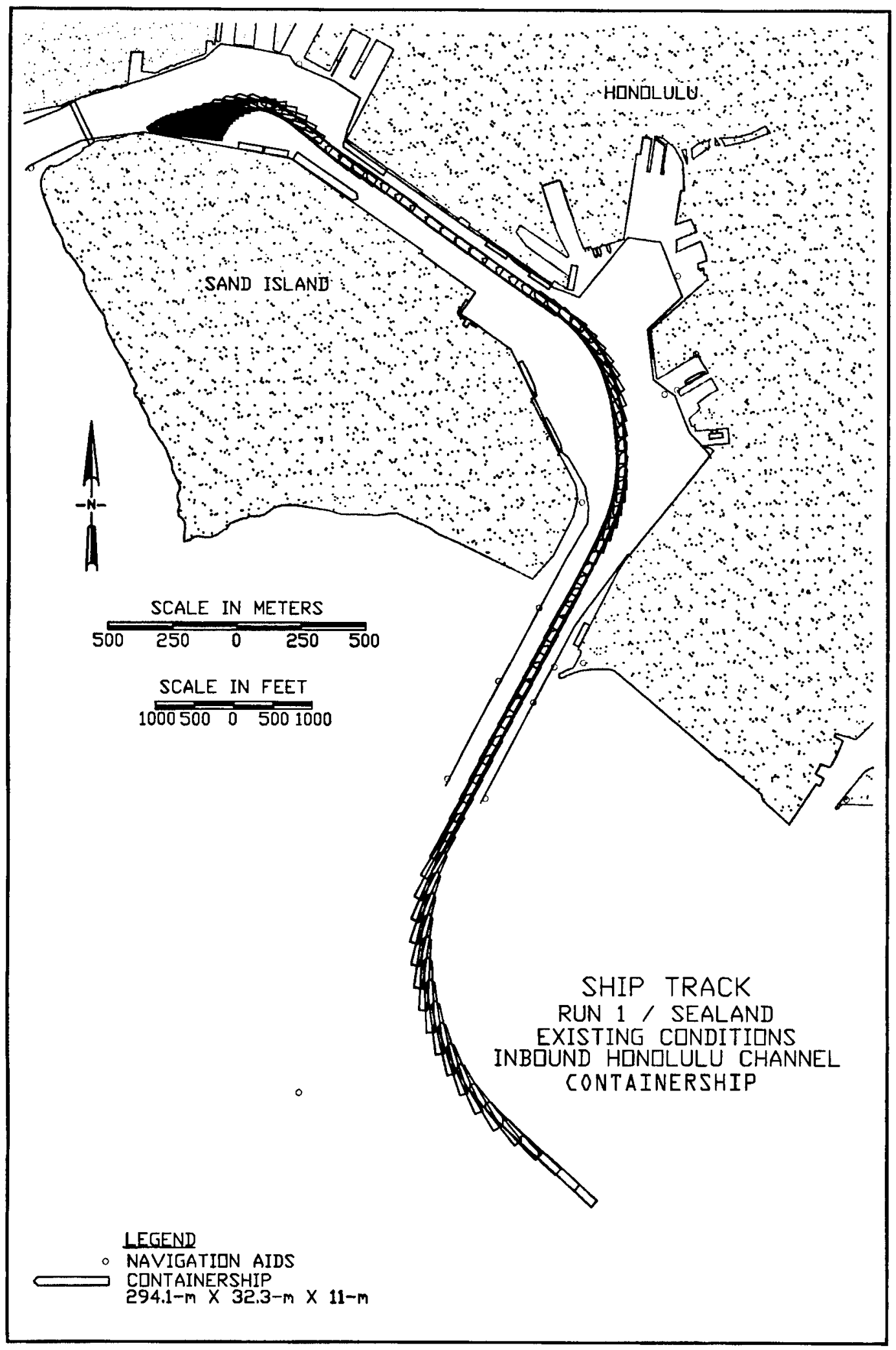

Plate 2 


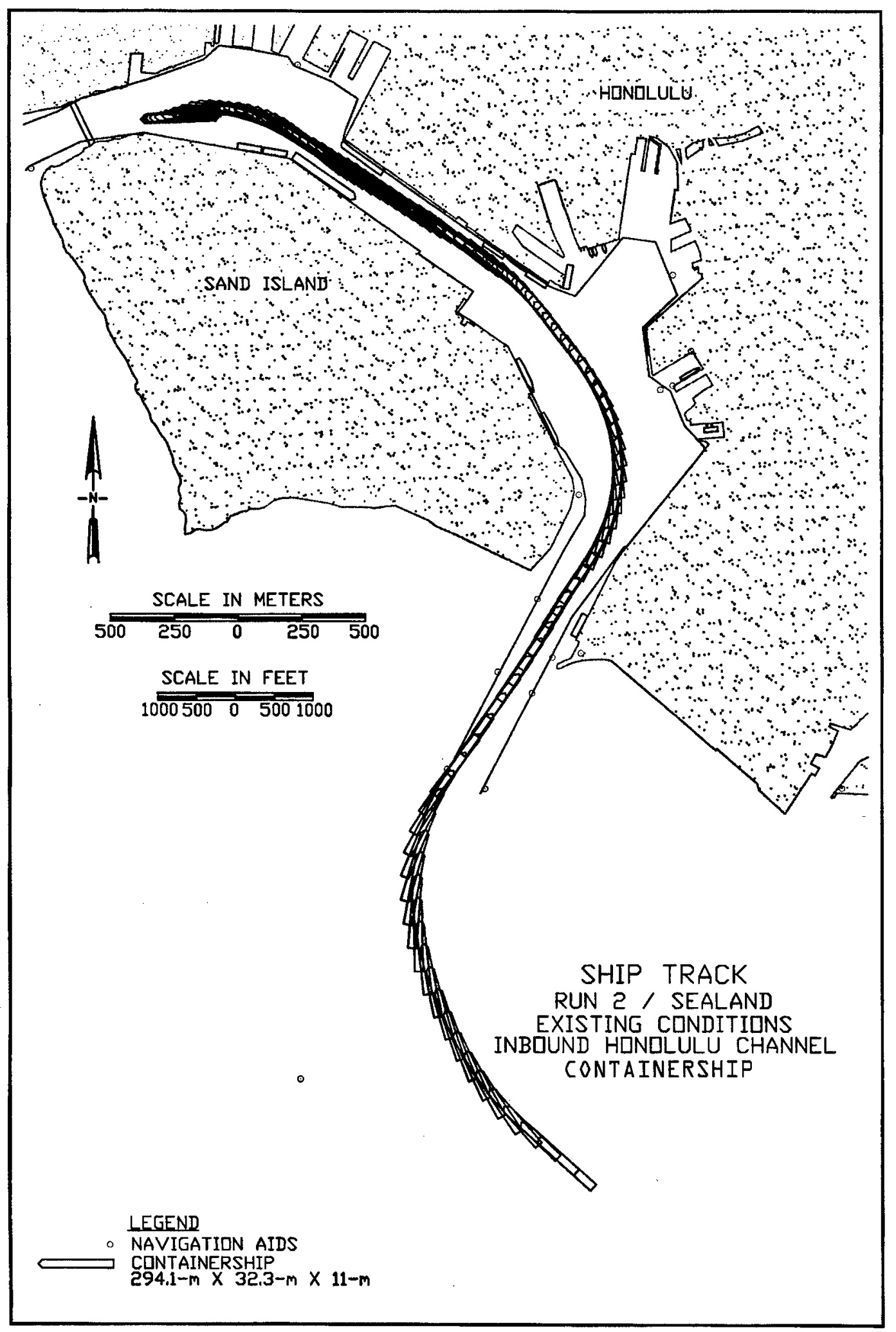

Plate 3 


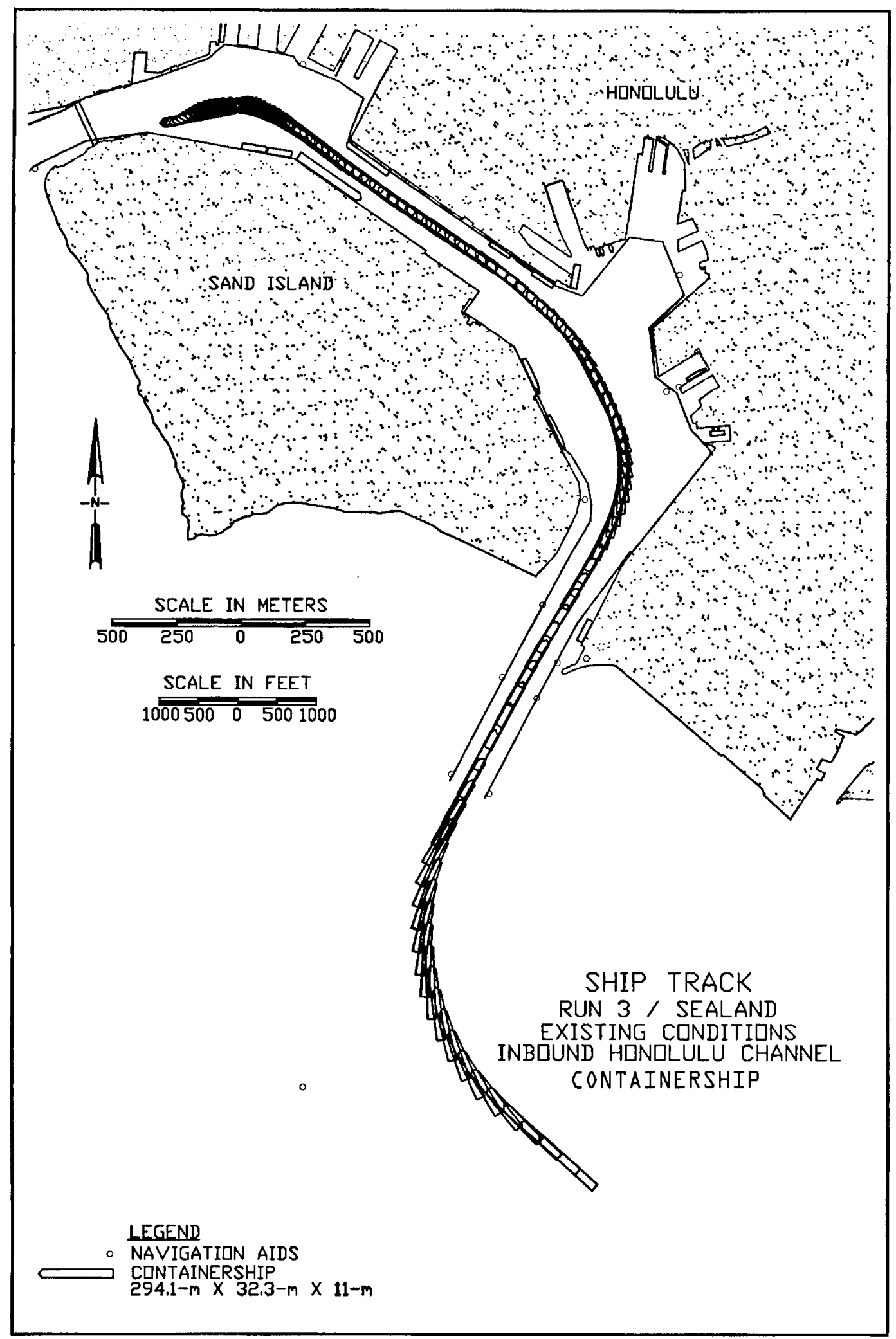

Plate 4 


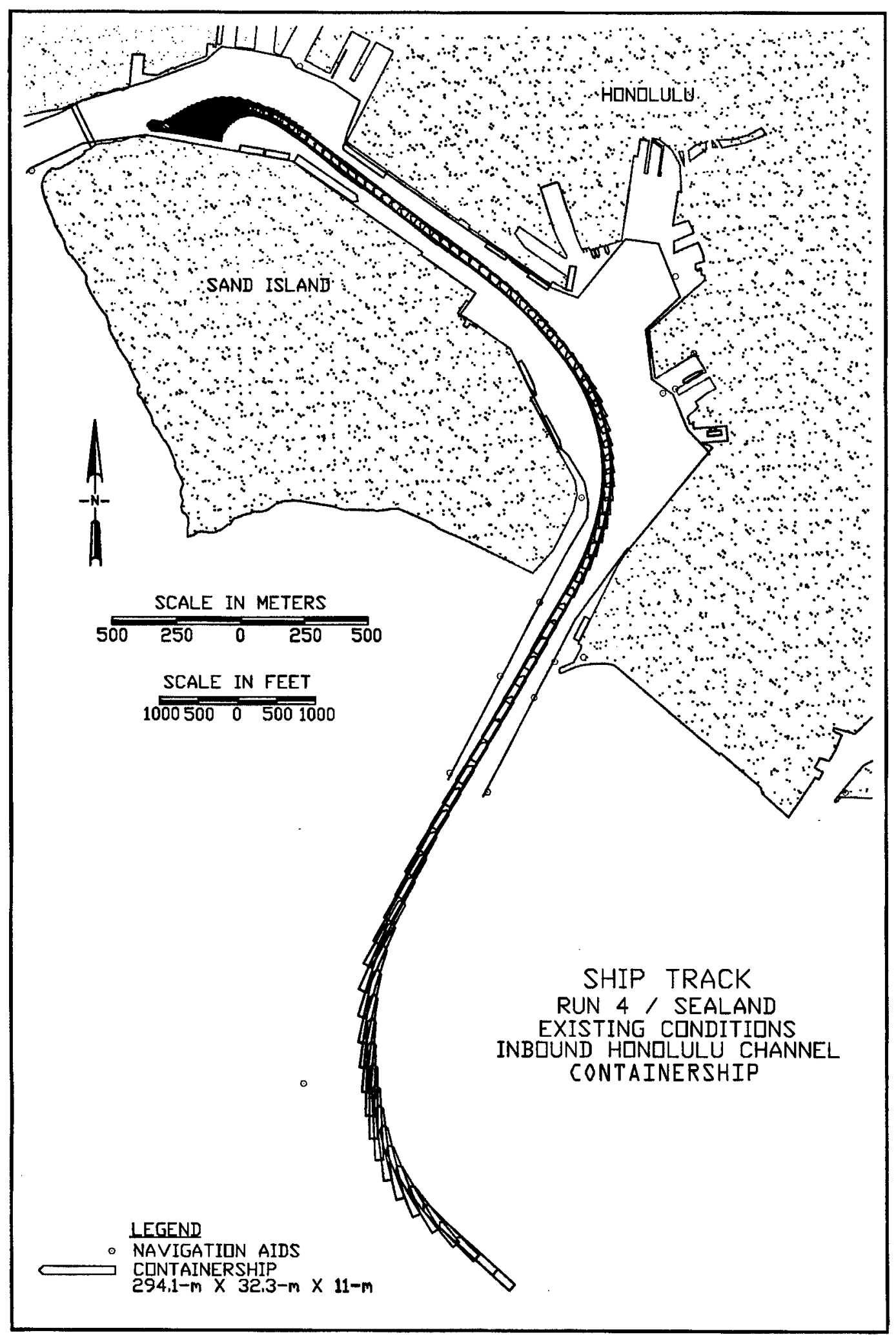

Plate 5 


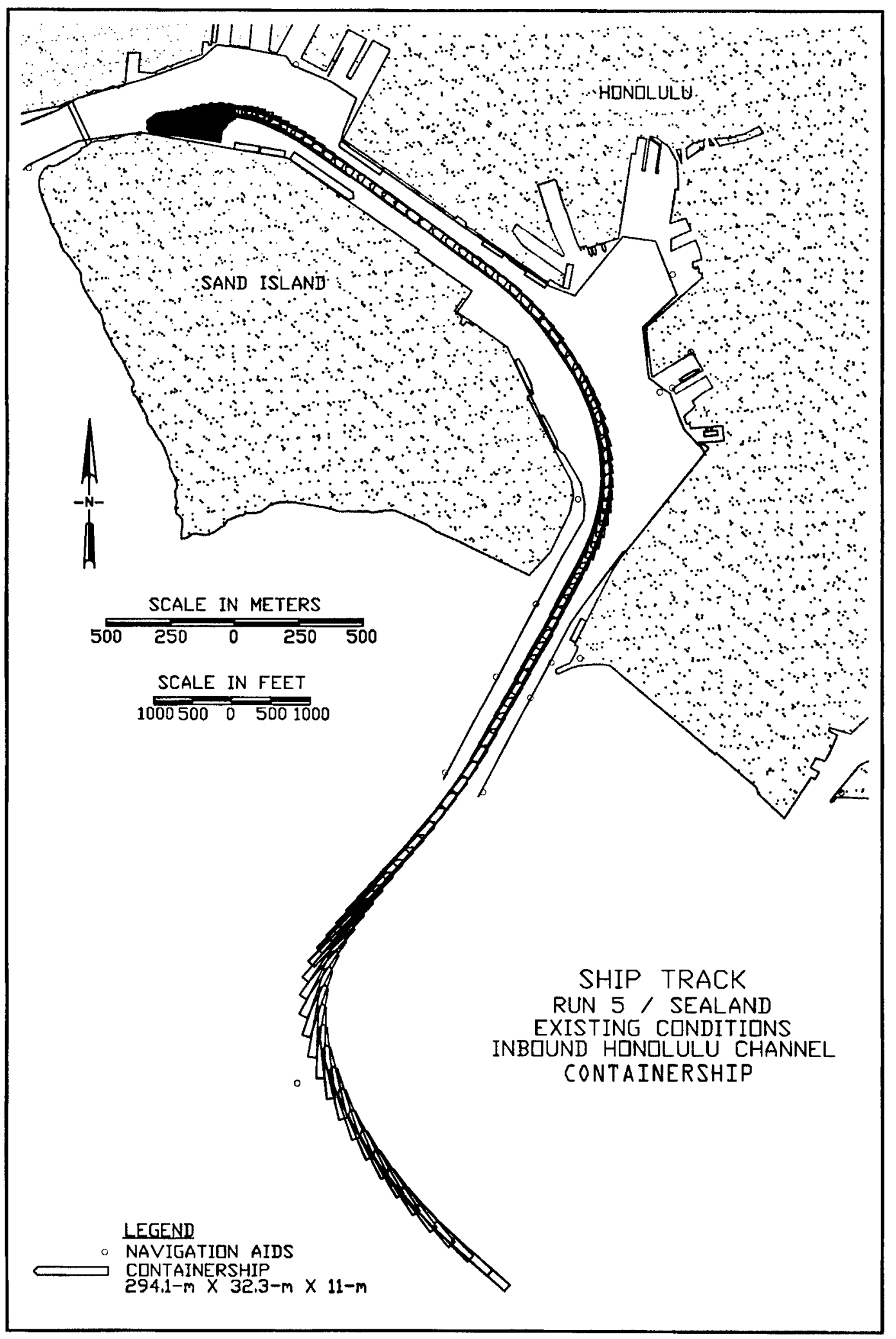

Plate 6 


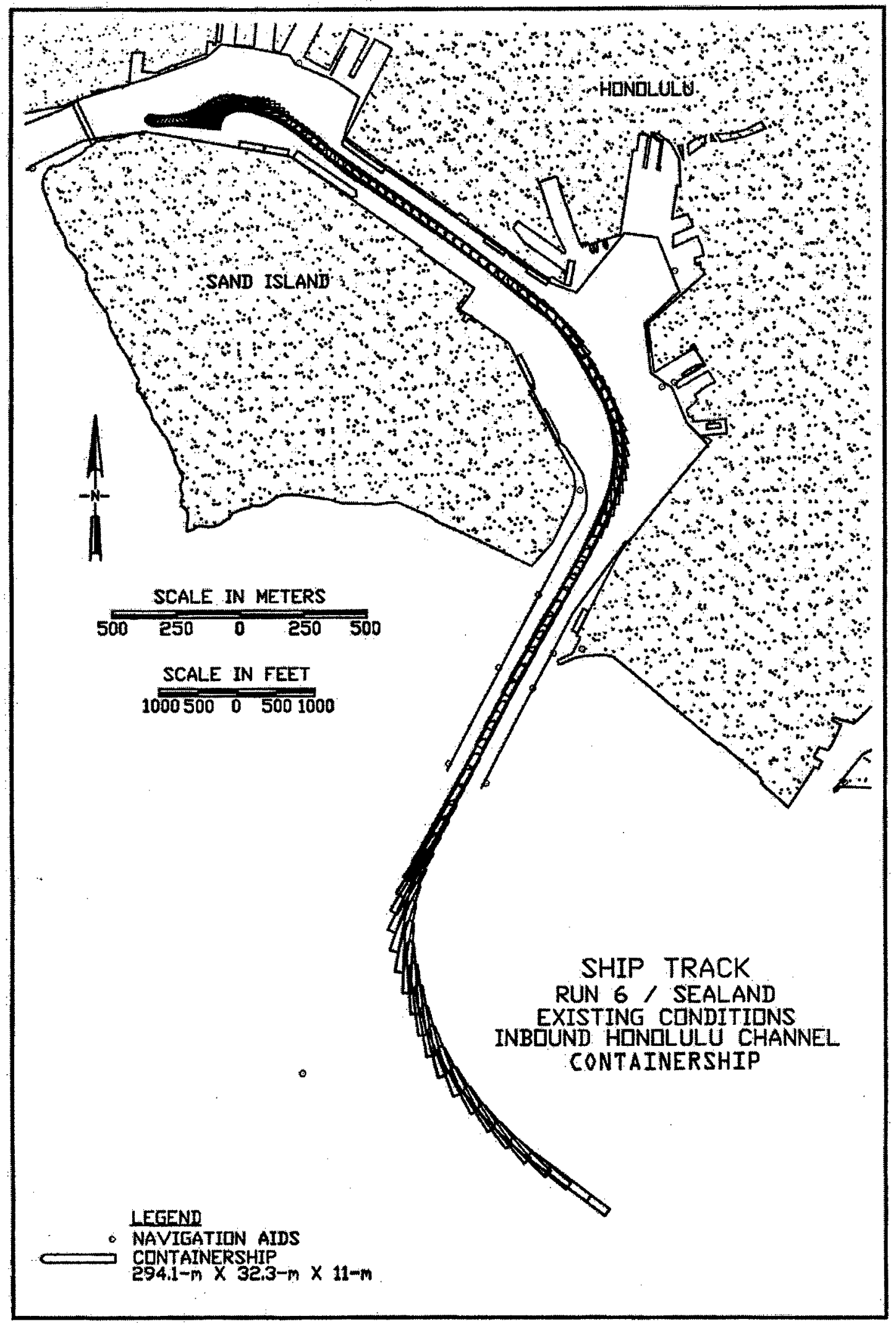

Plate 7 


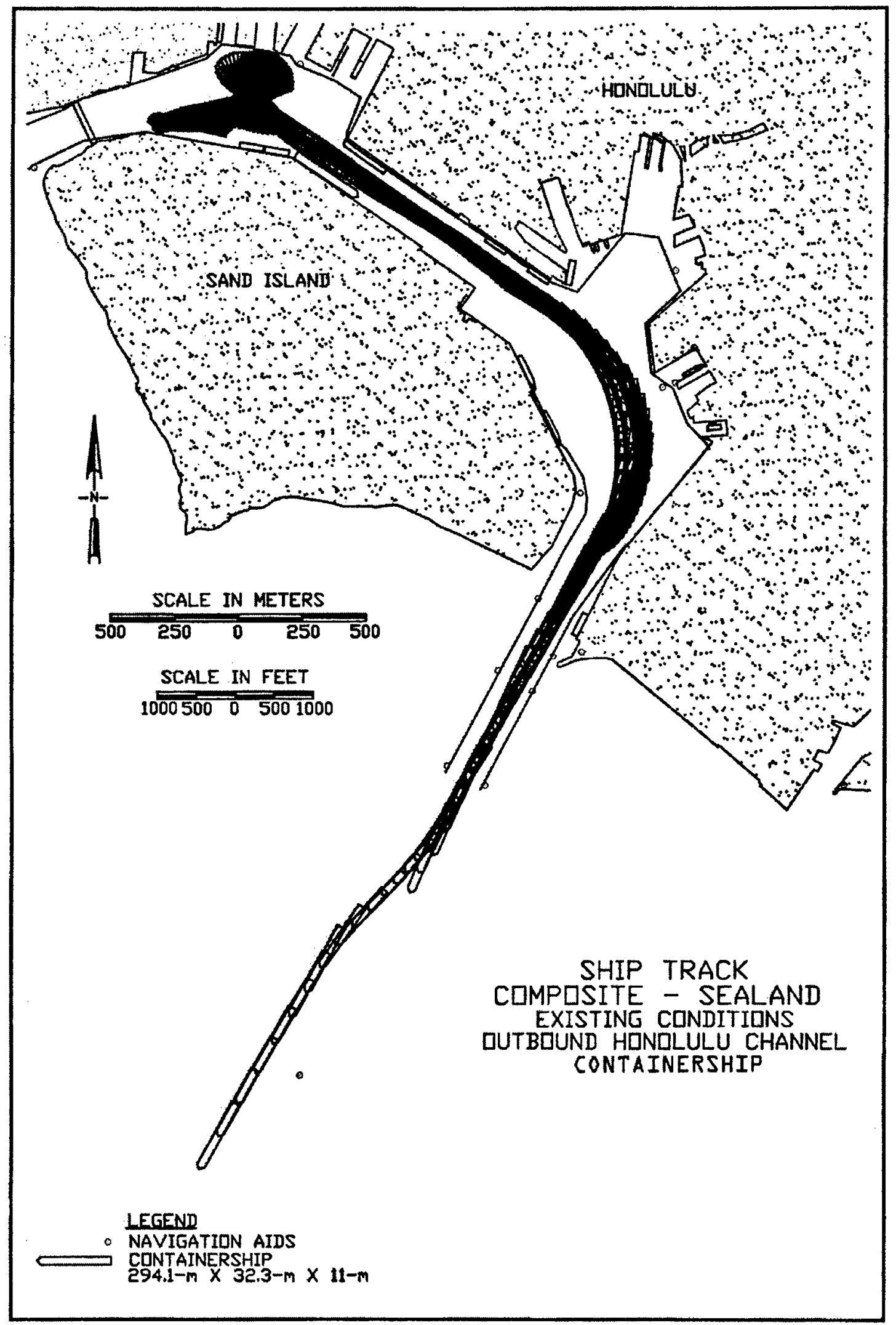

Plate 8 


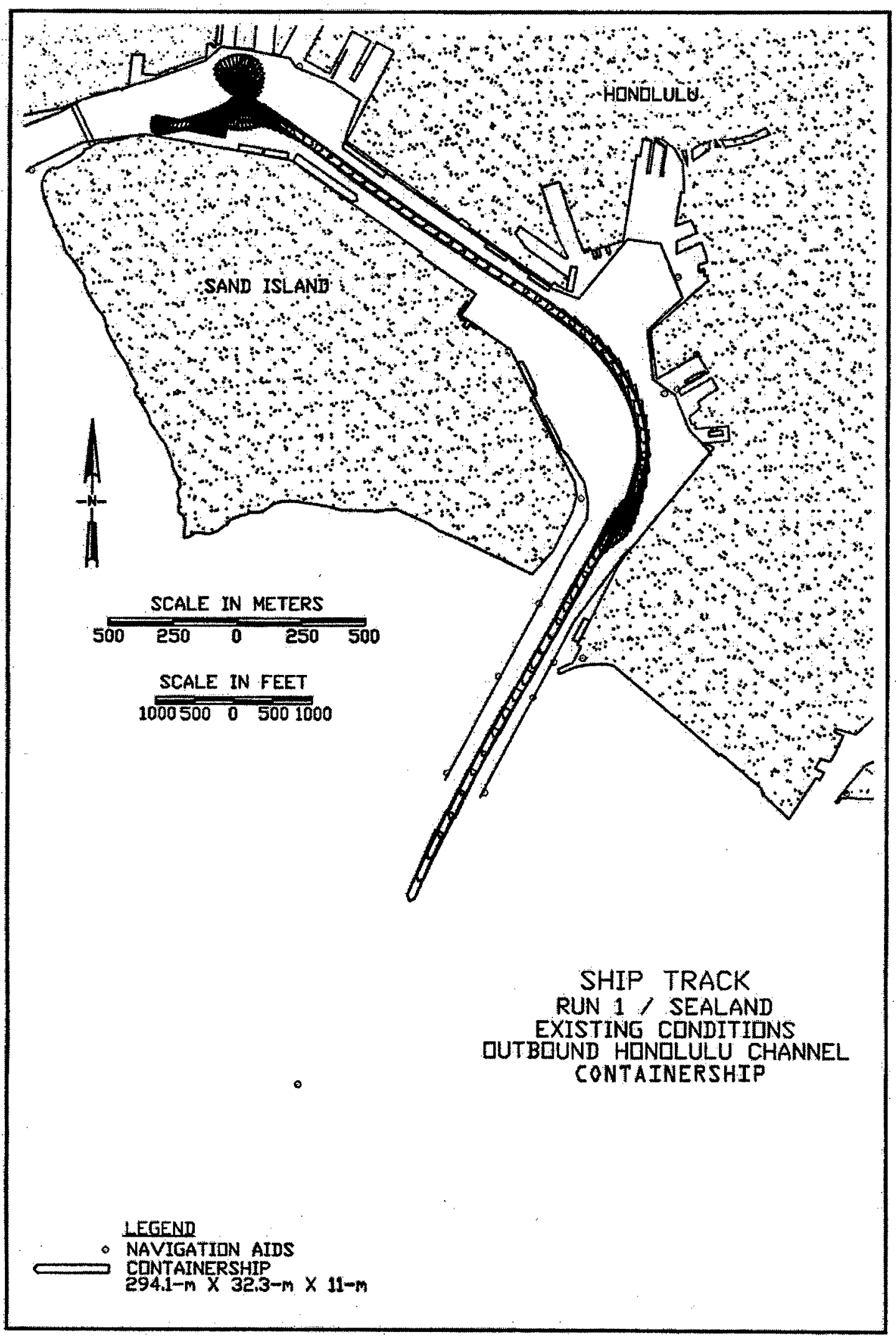

Plate 9 


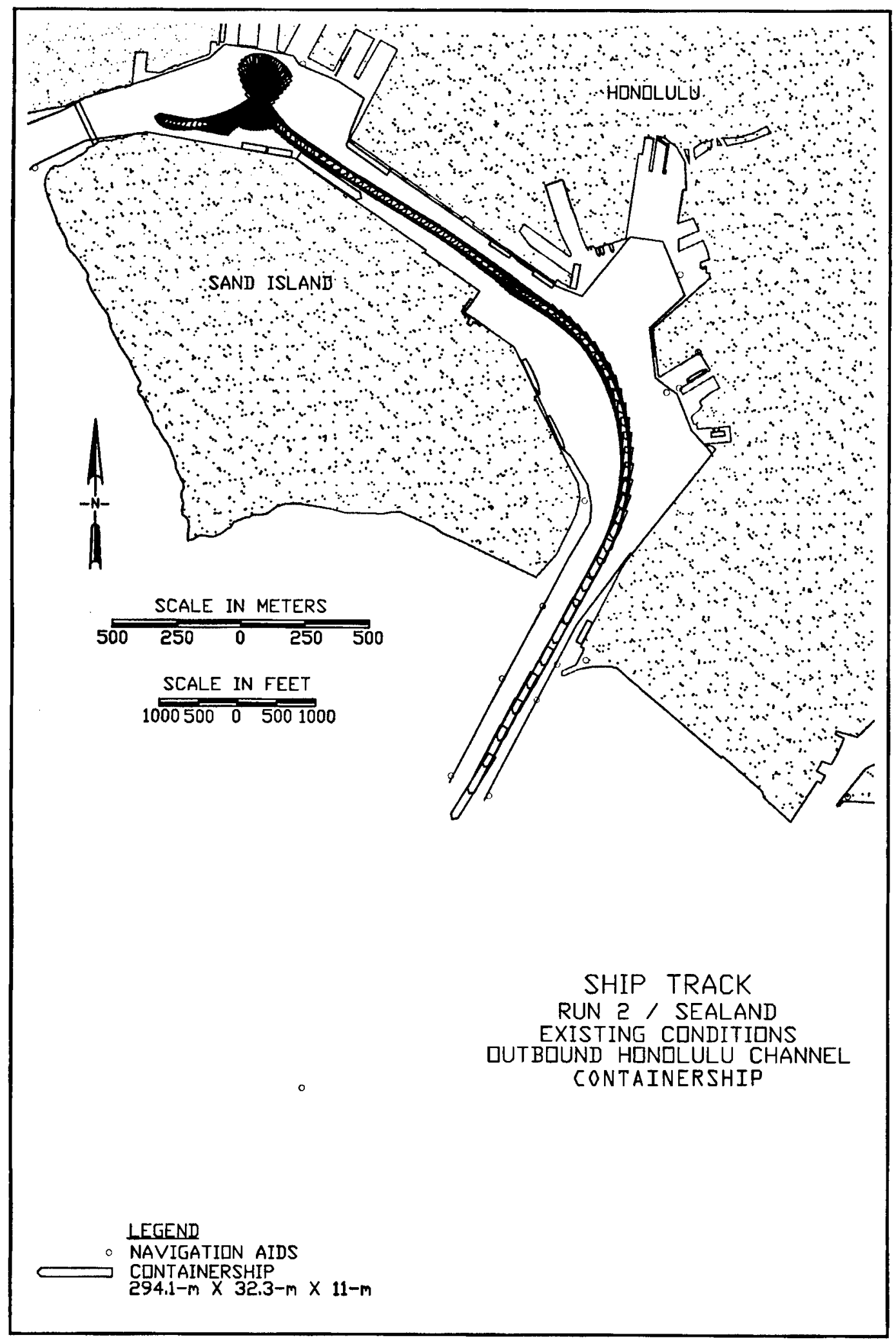

Plate 10 


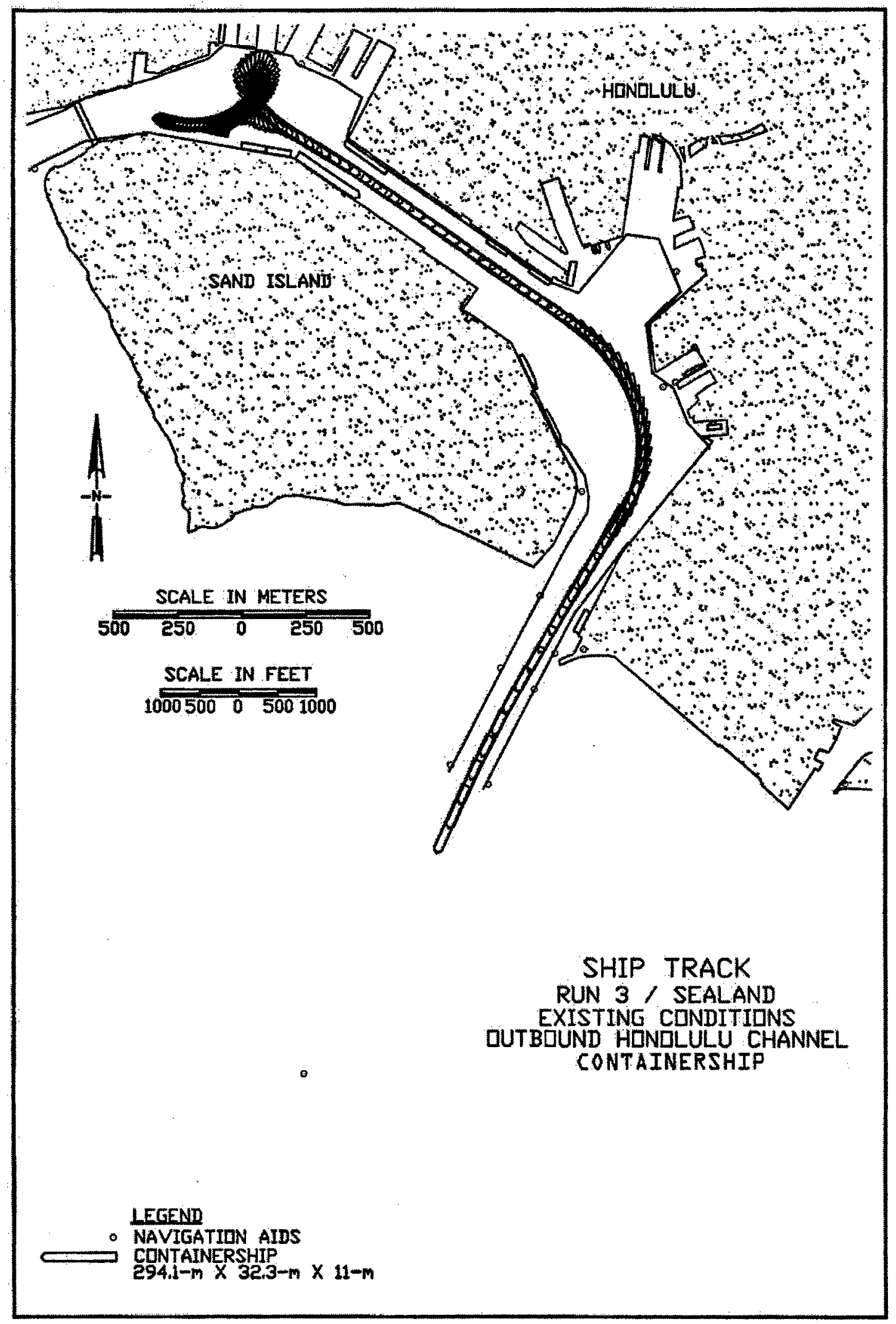

Plate 11 


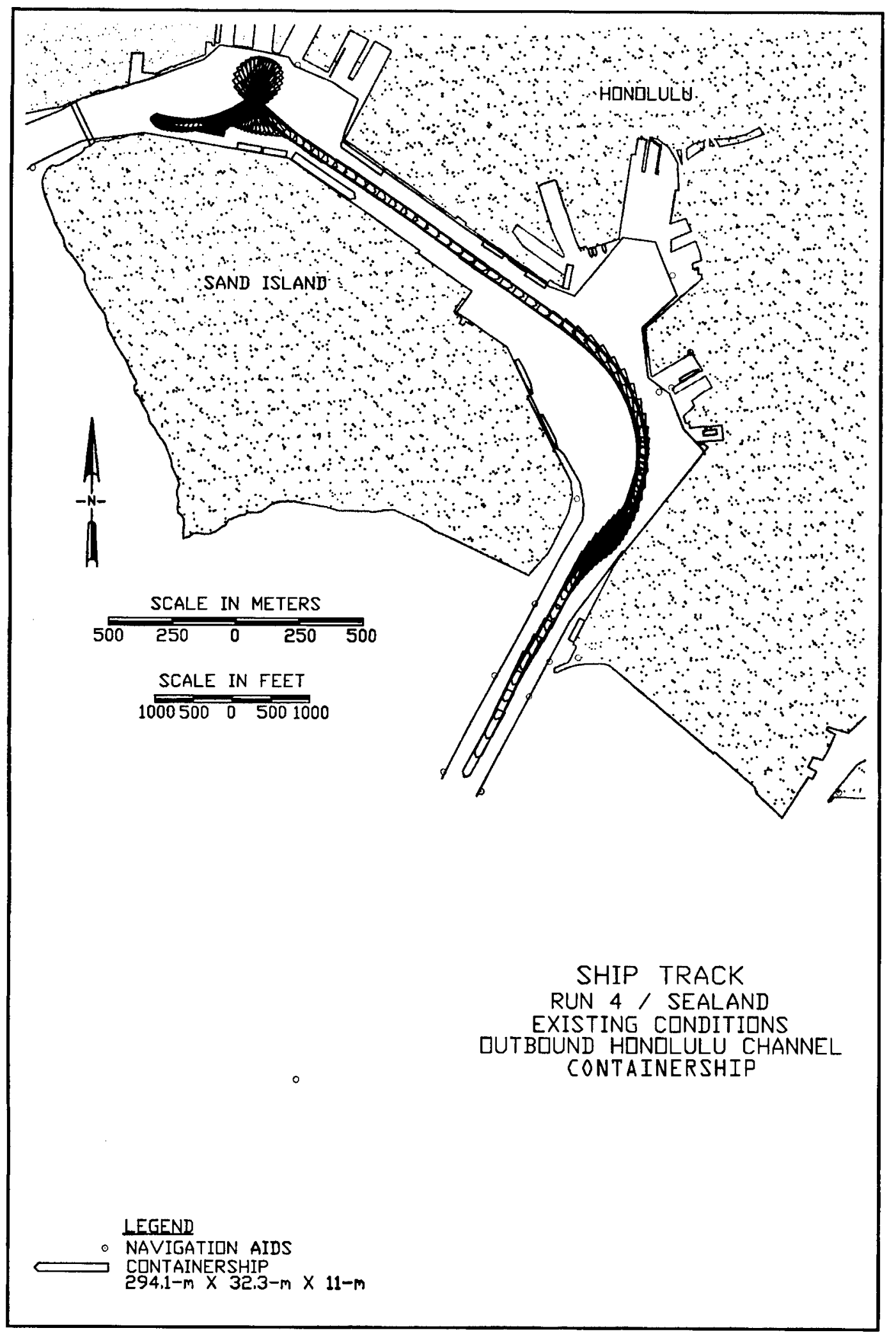

Plate 12 


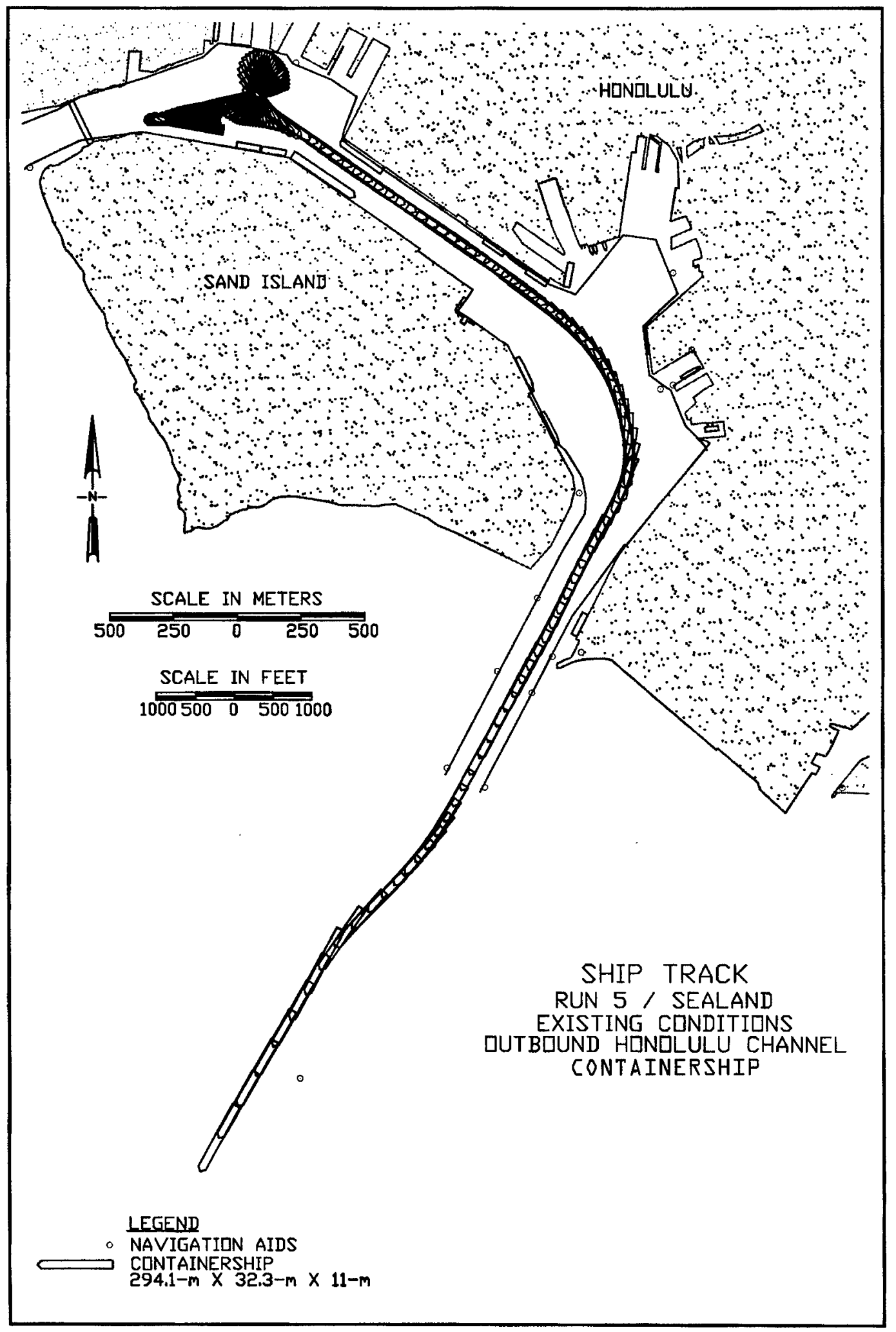

Plate 13 


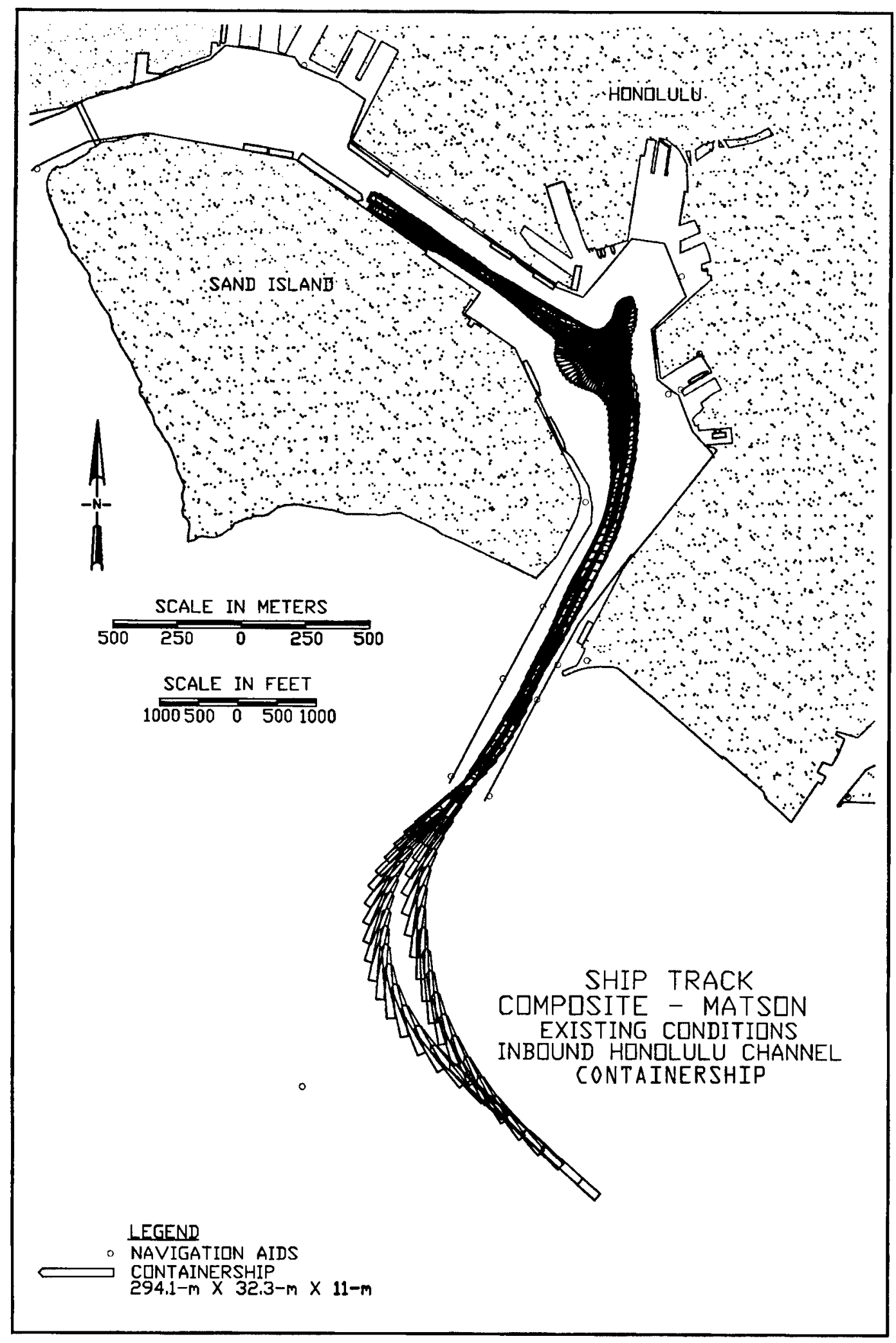

Plate 14 


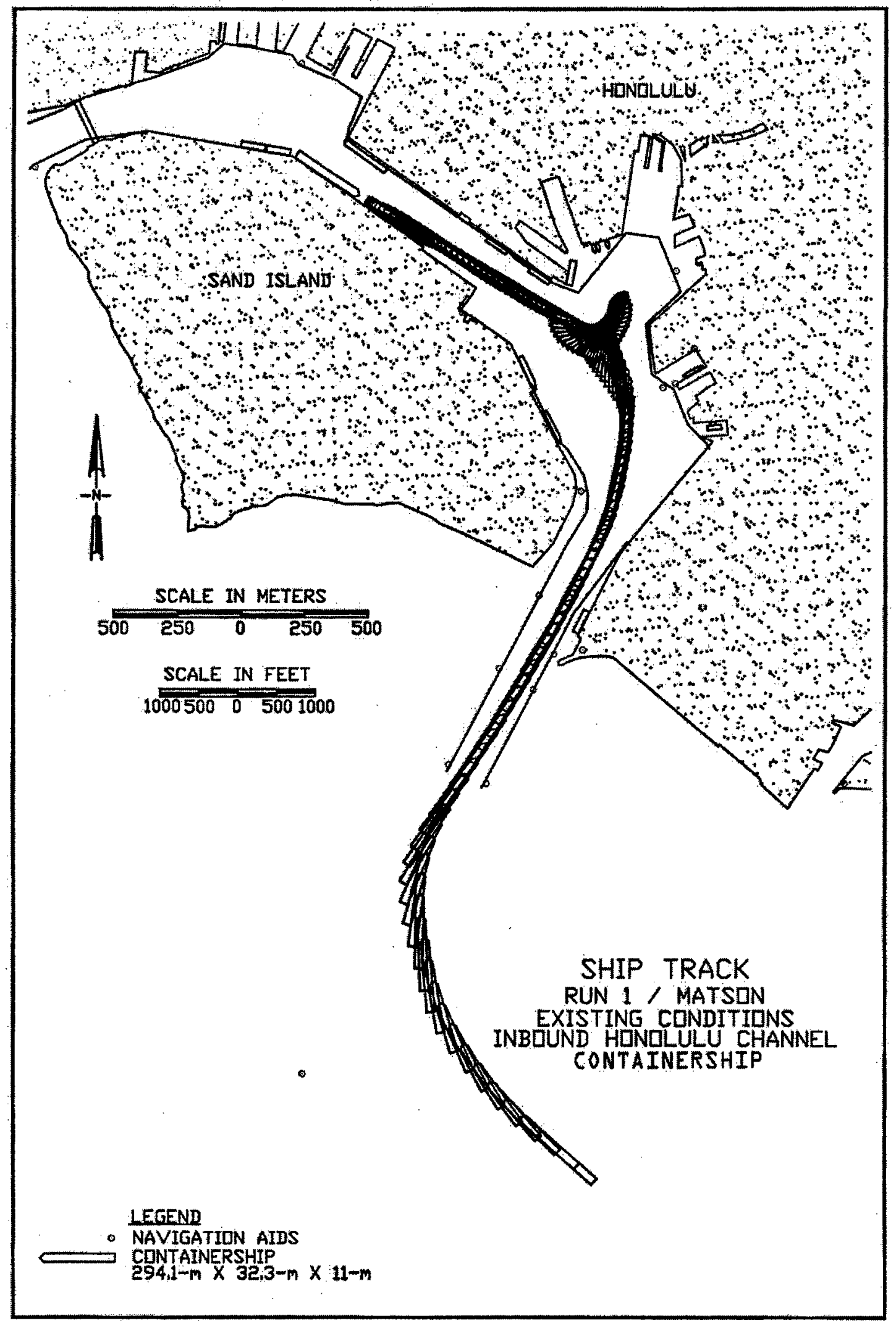

Plate 15 


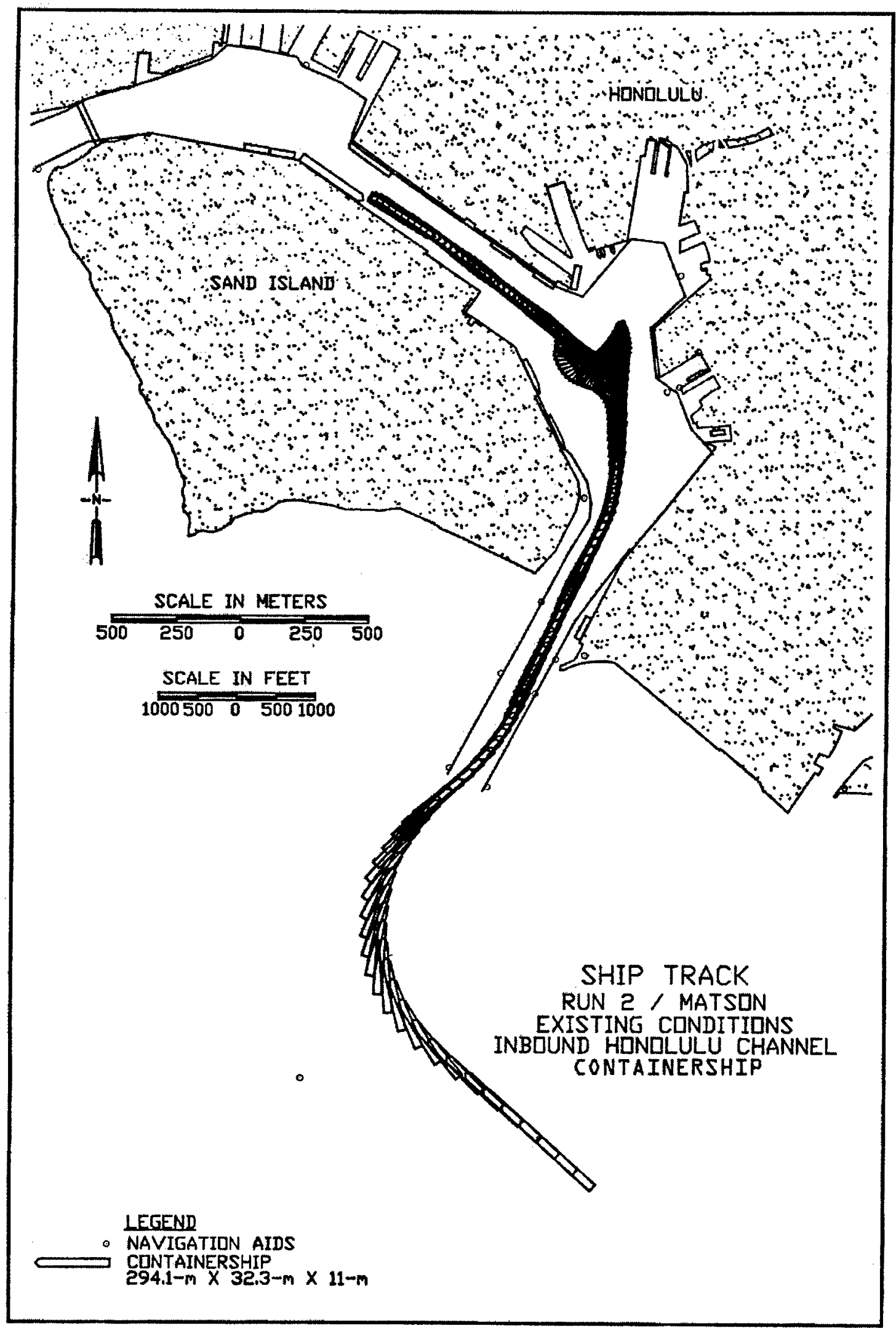

Plate 16 


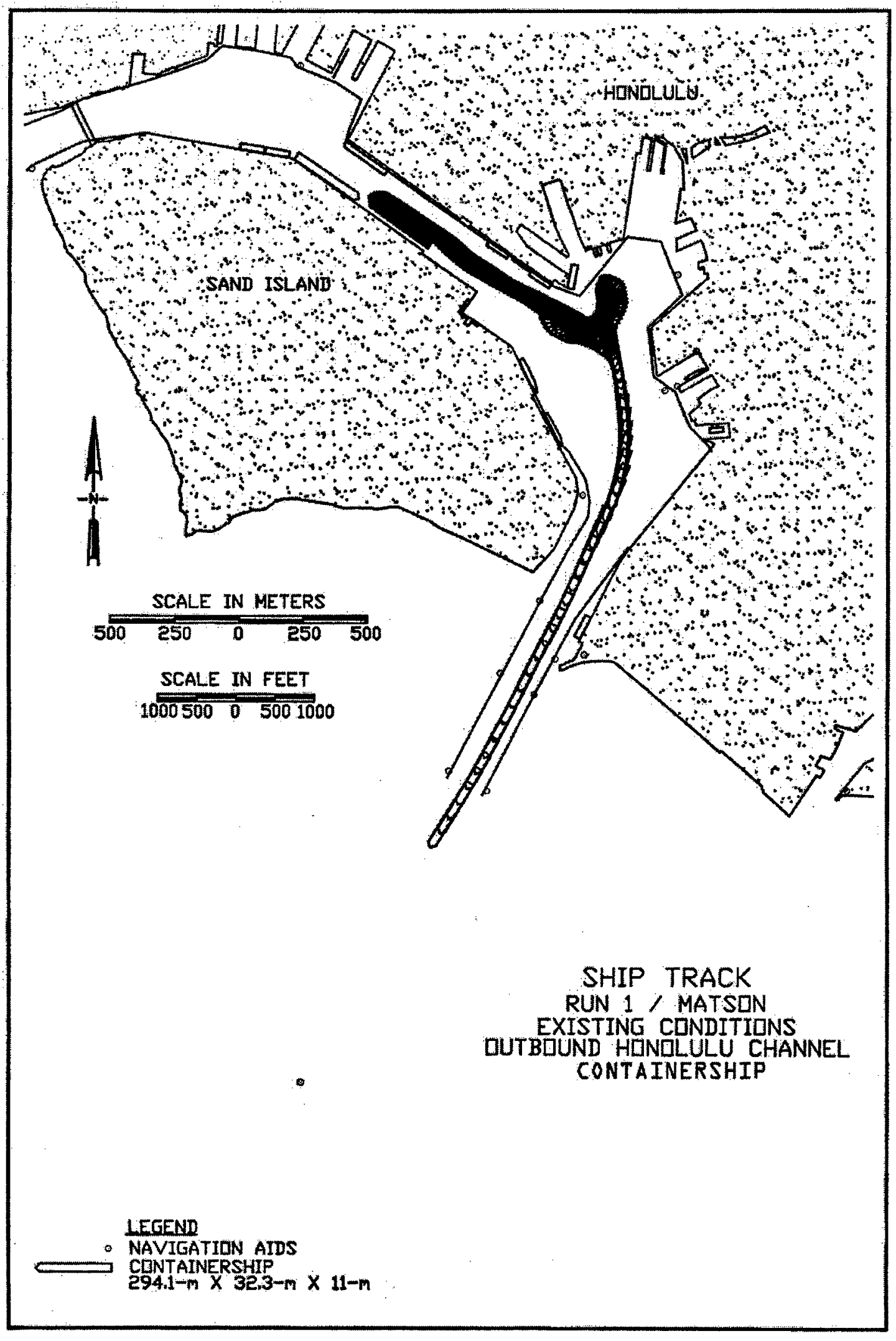

Plate 17 


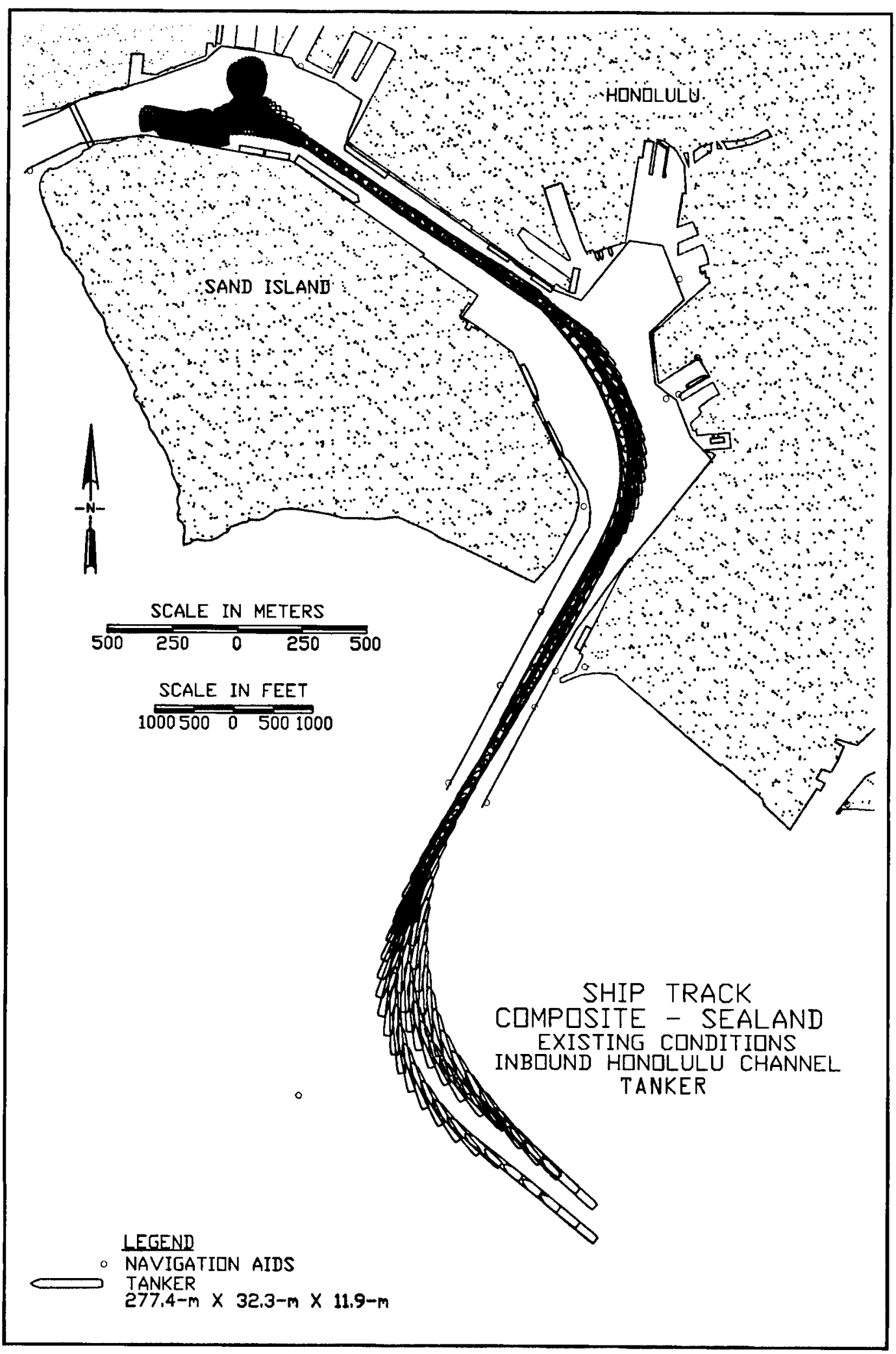

Plate 18 


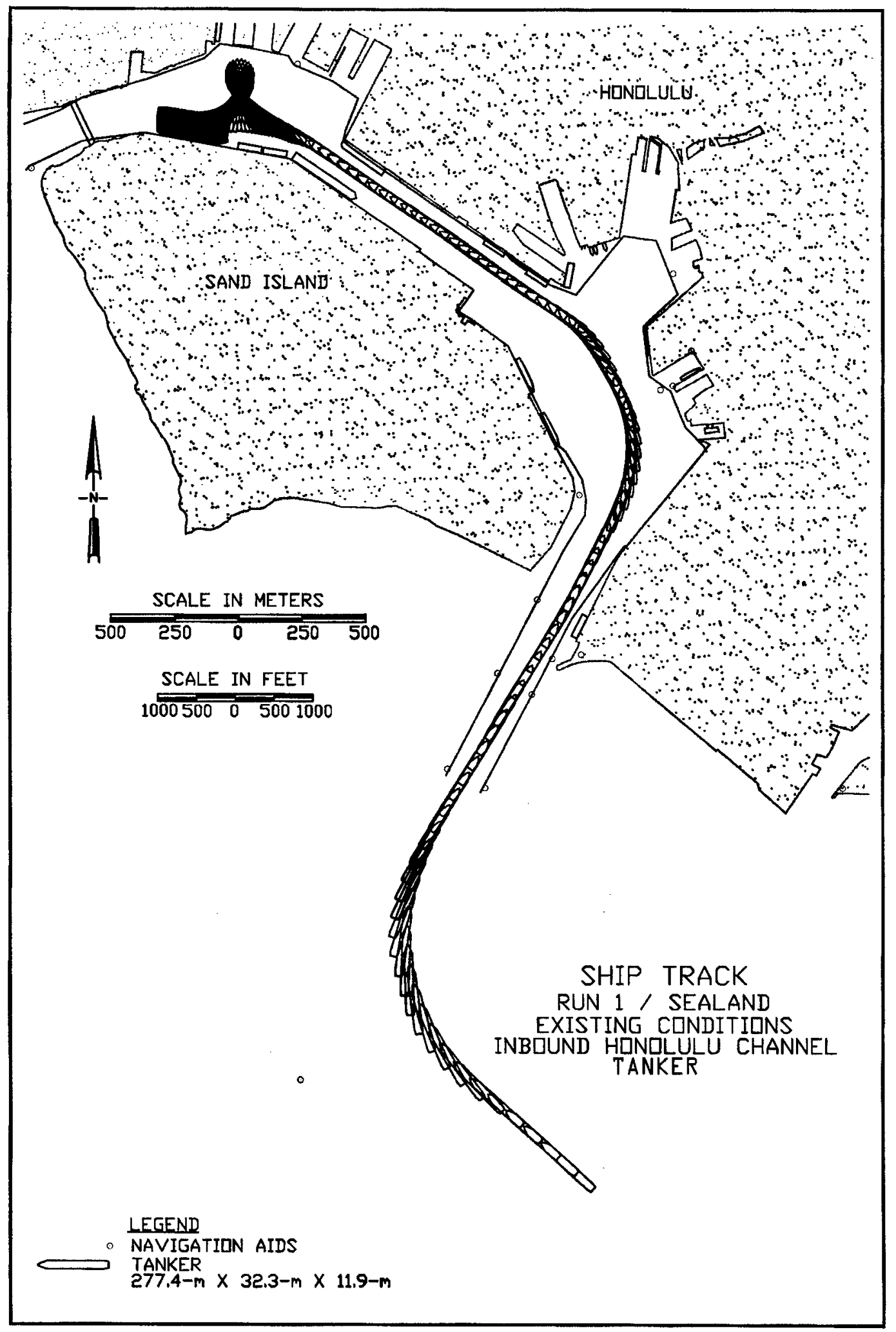

Plate 19 


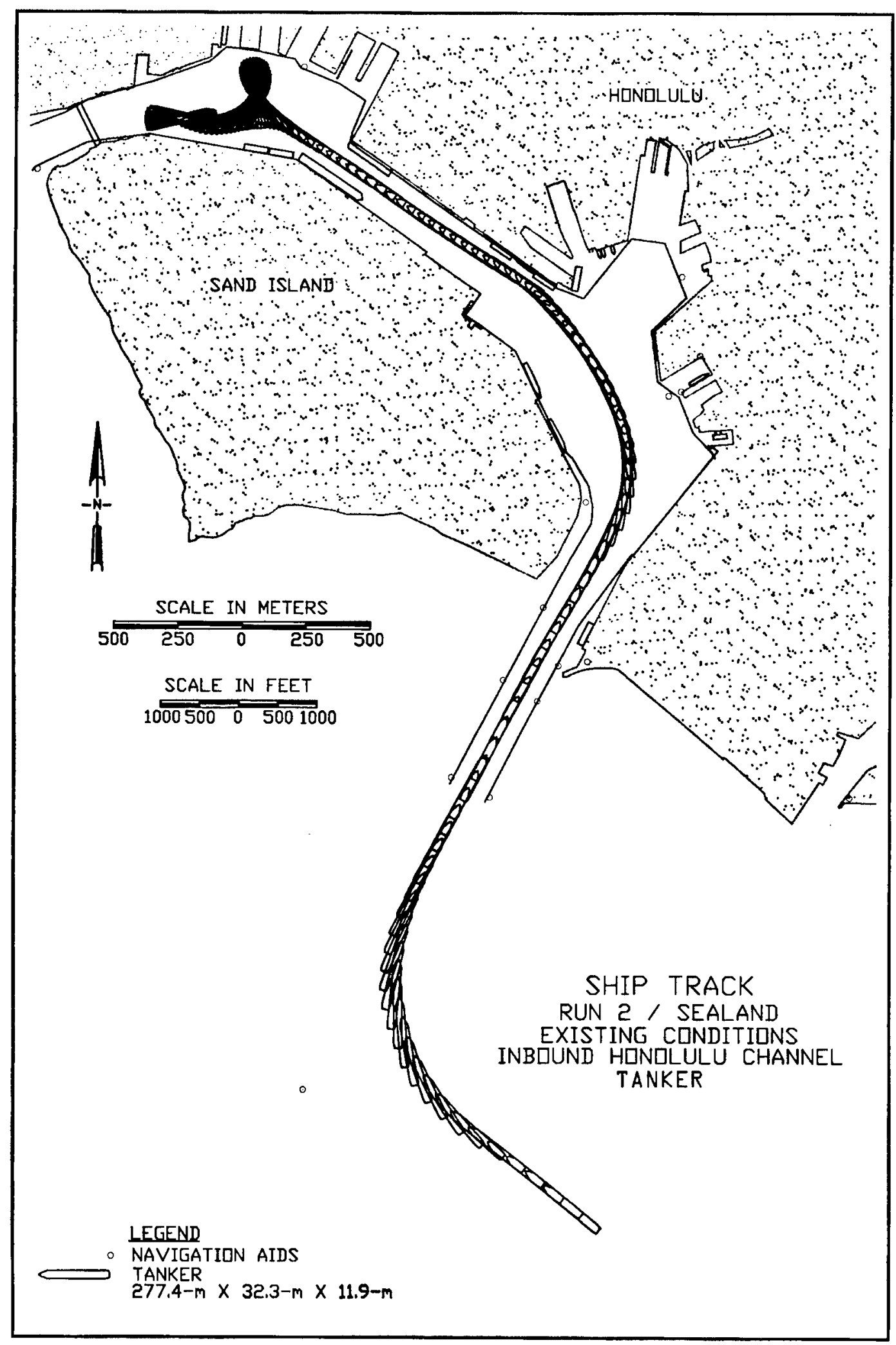

Plate 20 


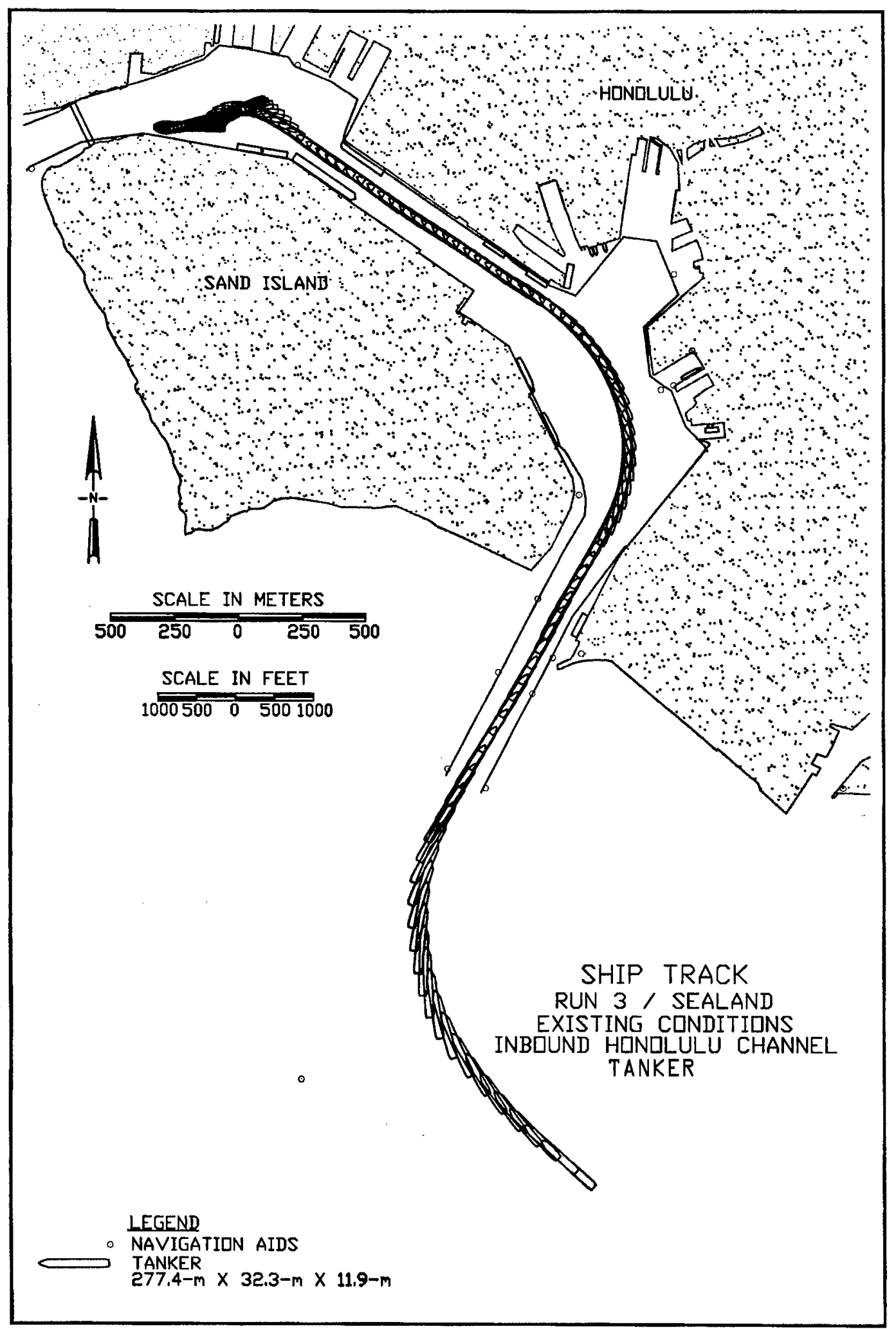

Plate 21 


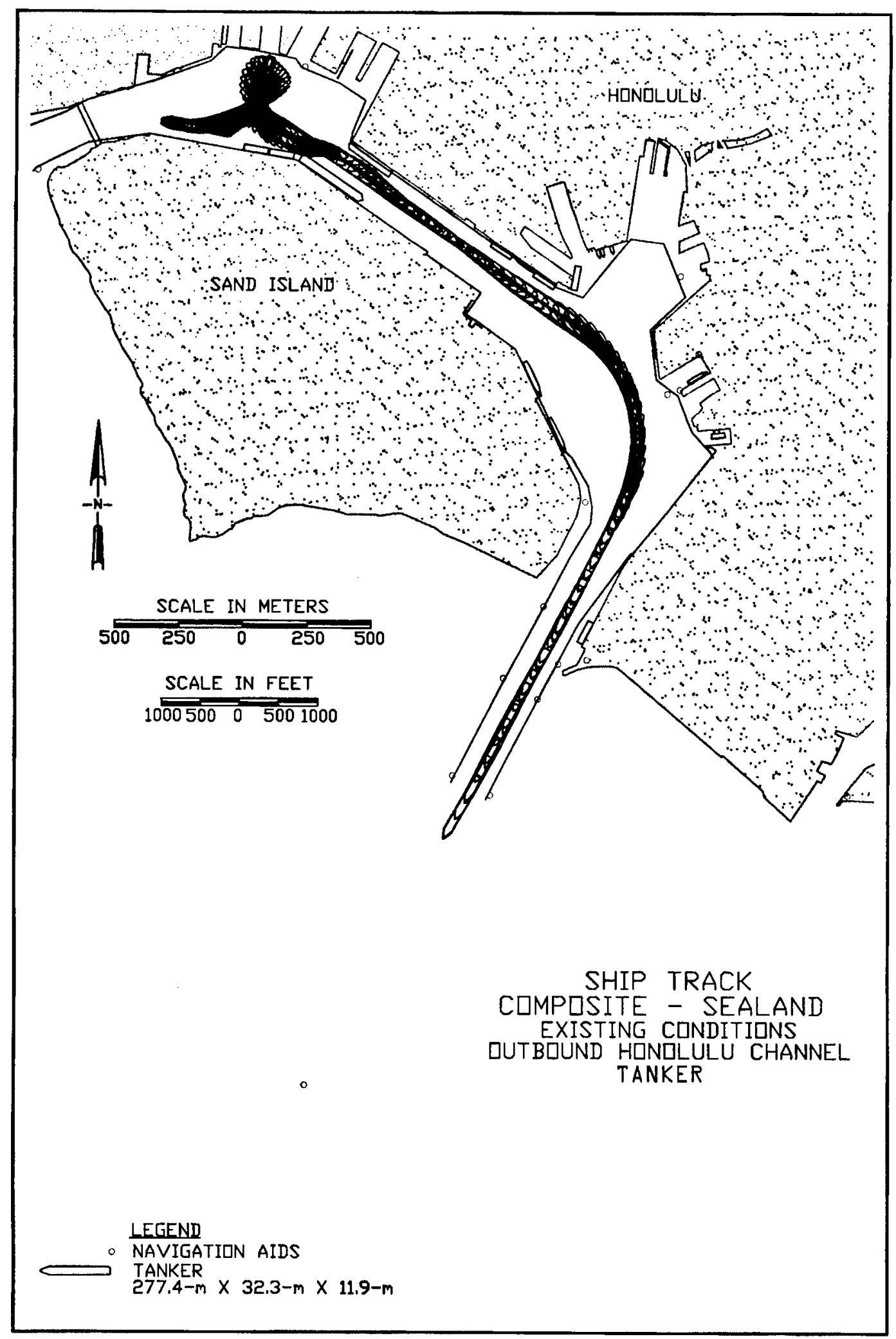

Plate 22 


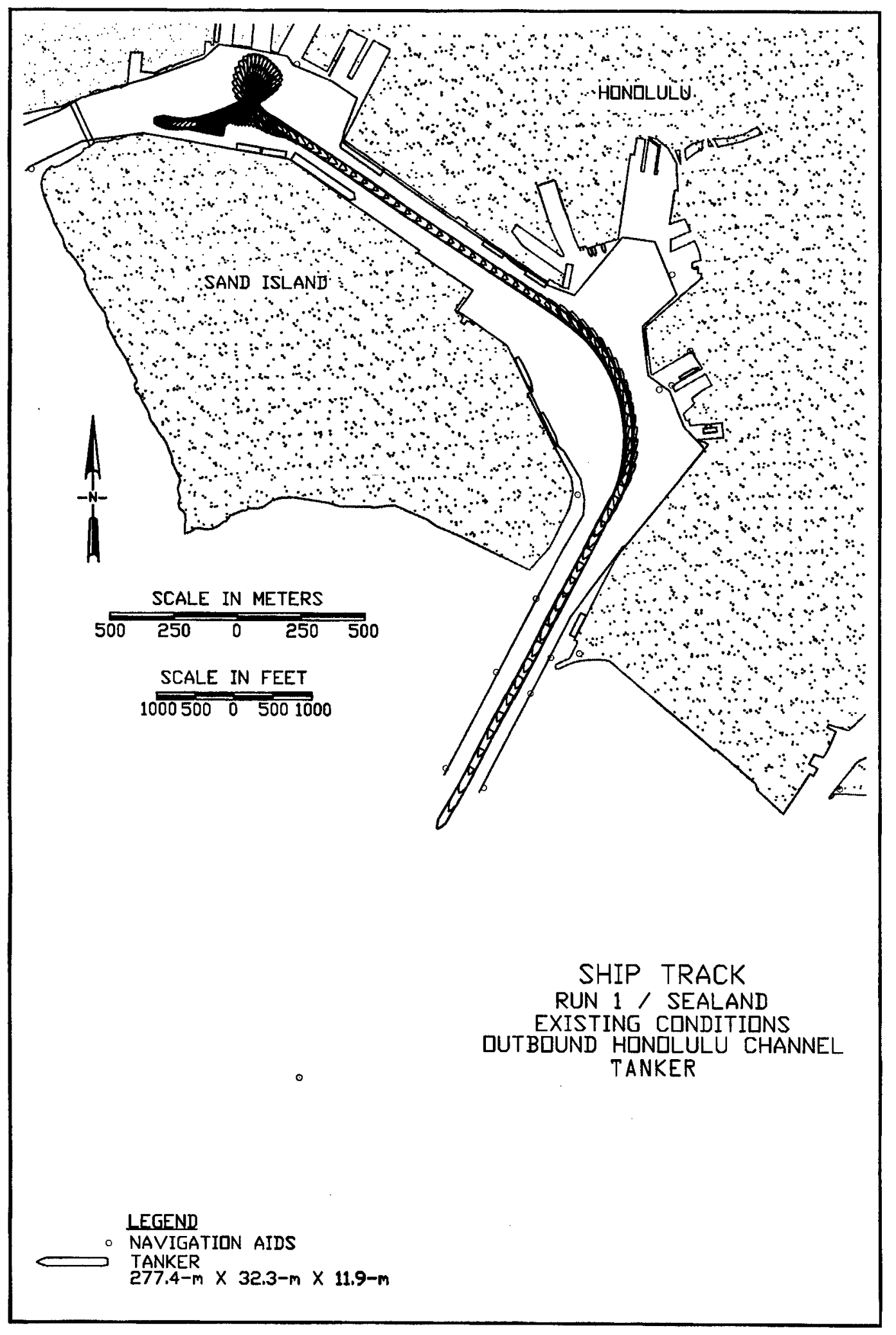

Plate 23 


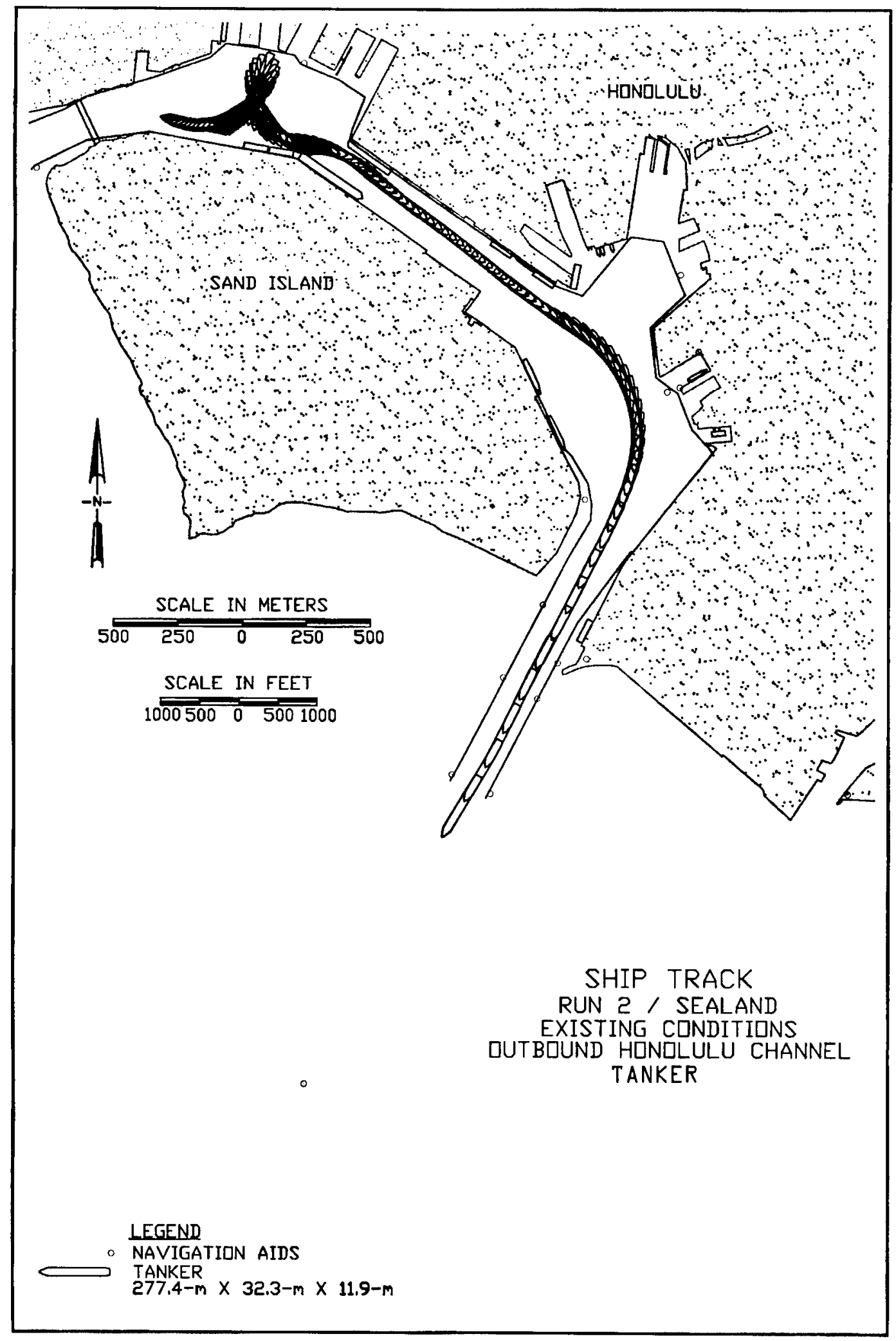

Plate 24 


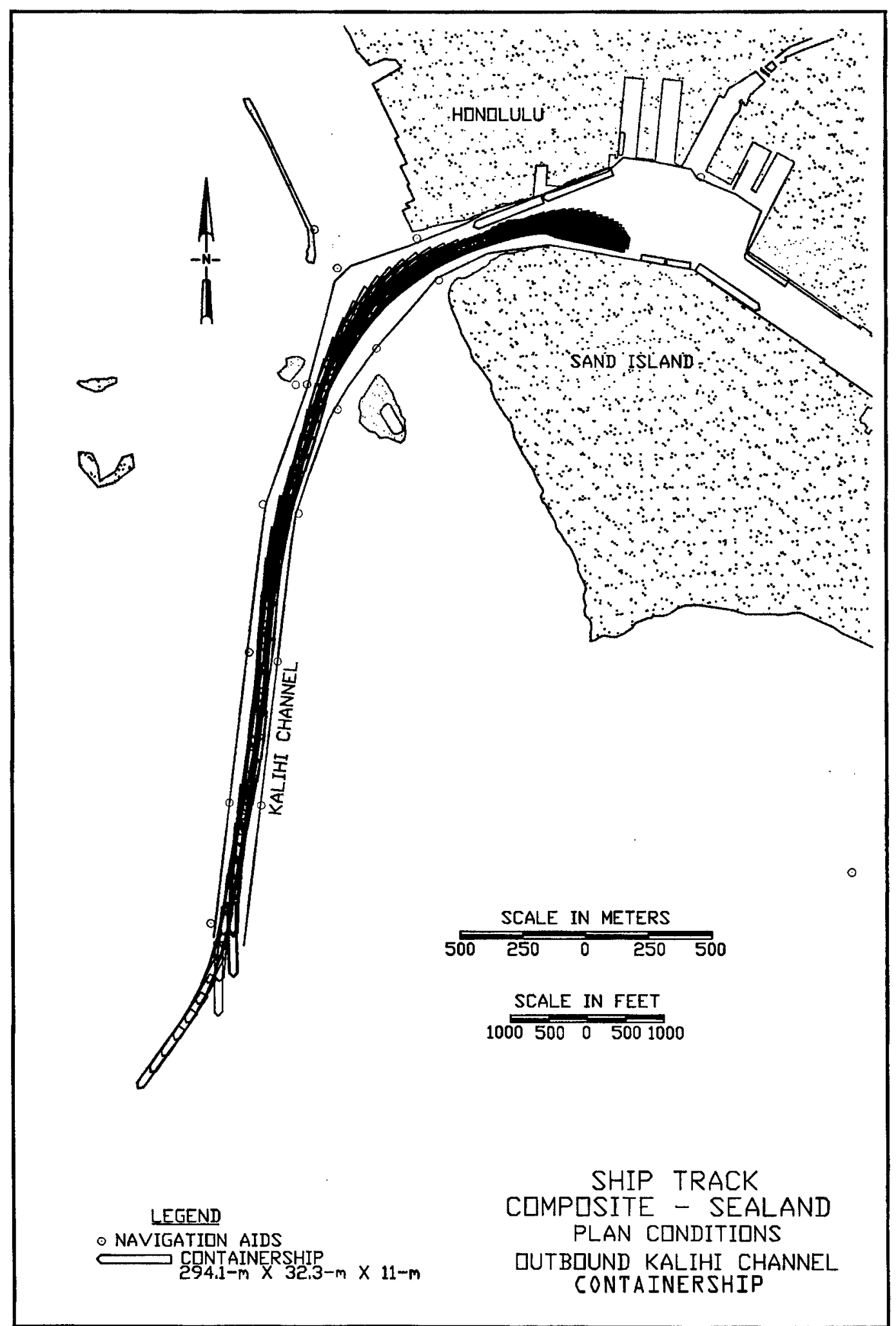

Plate 25 


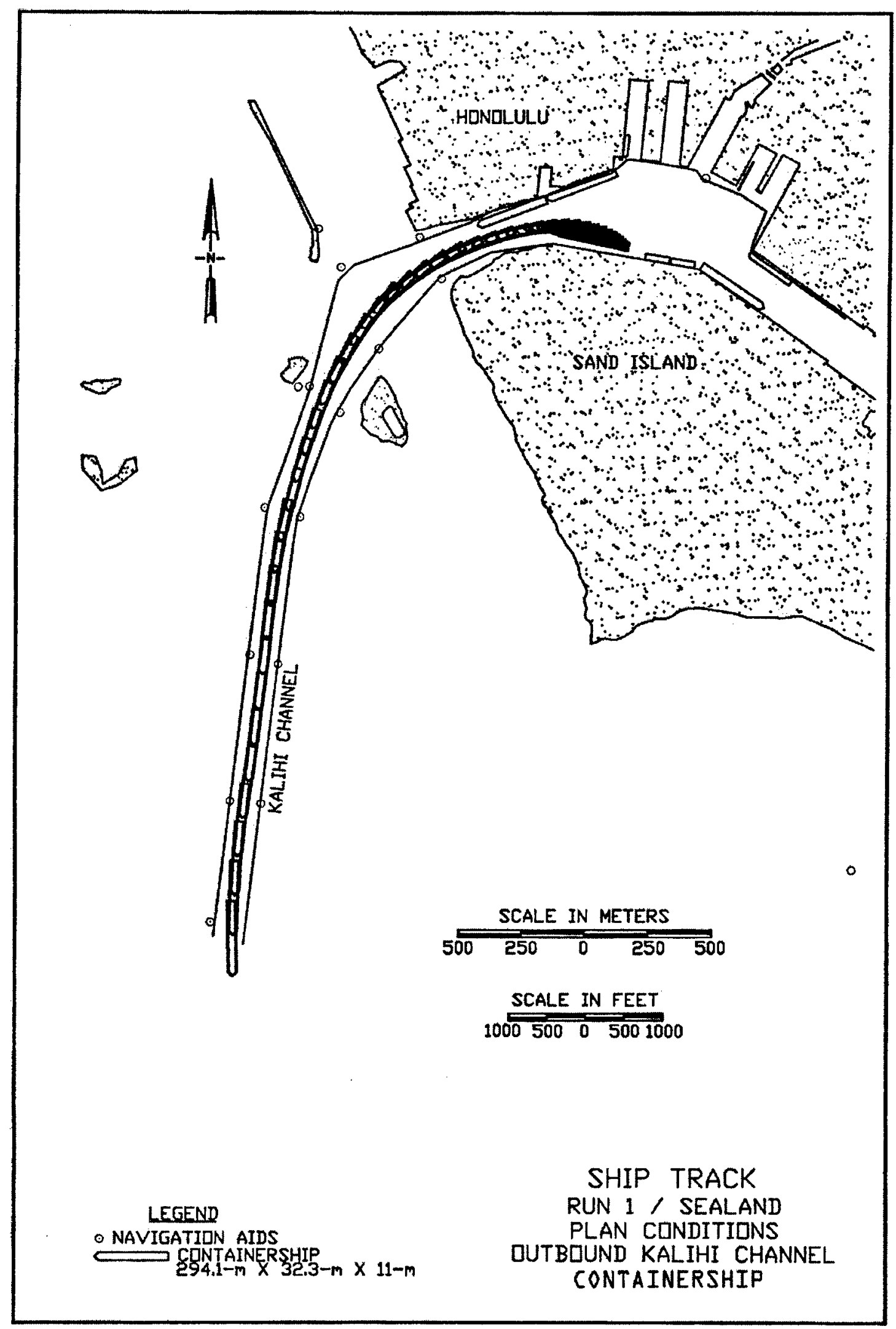

Plate 26 


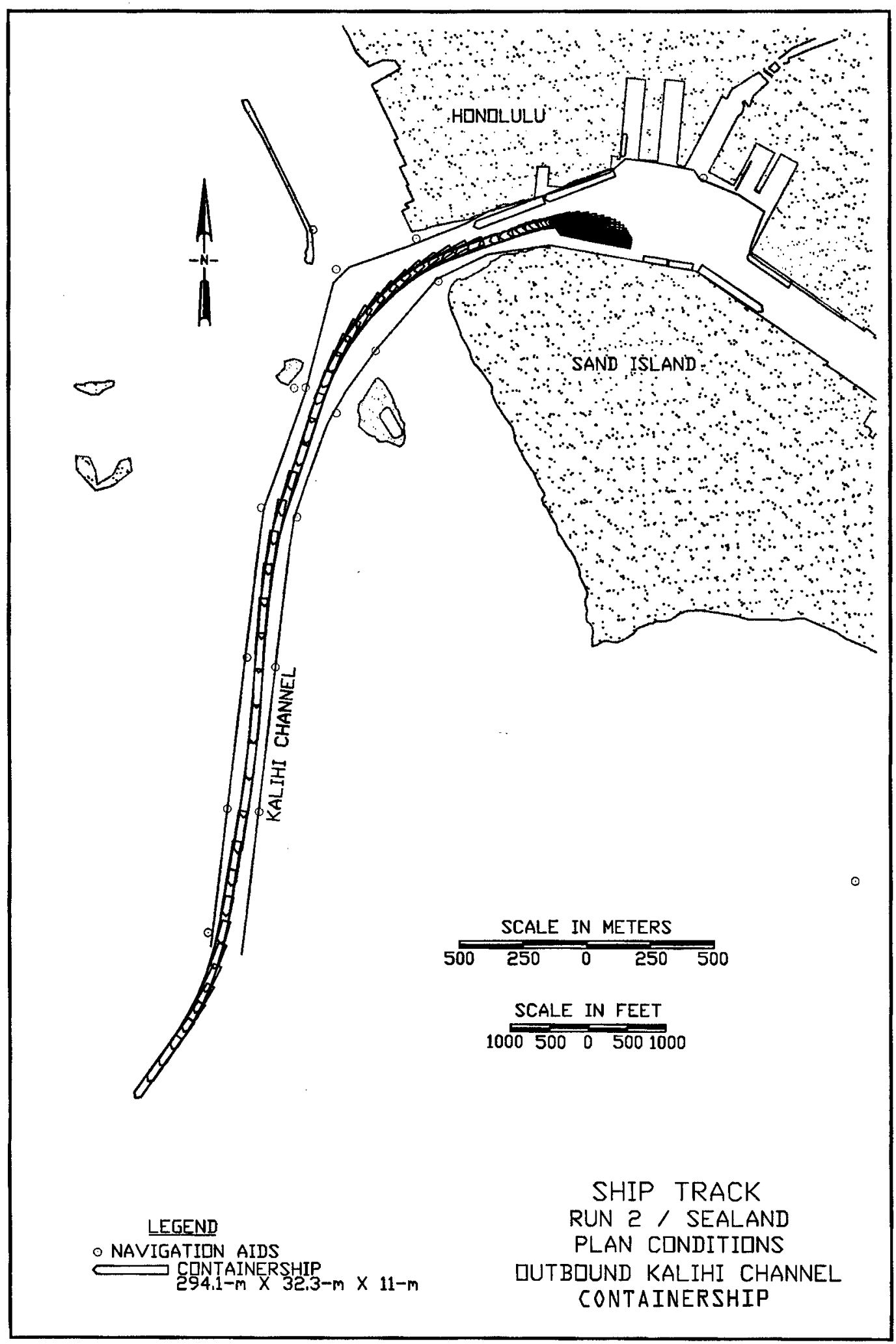

Plate 27 


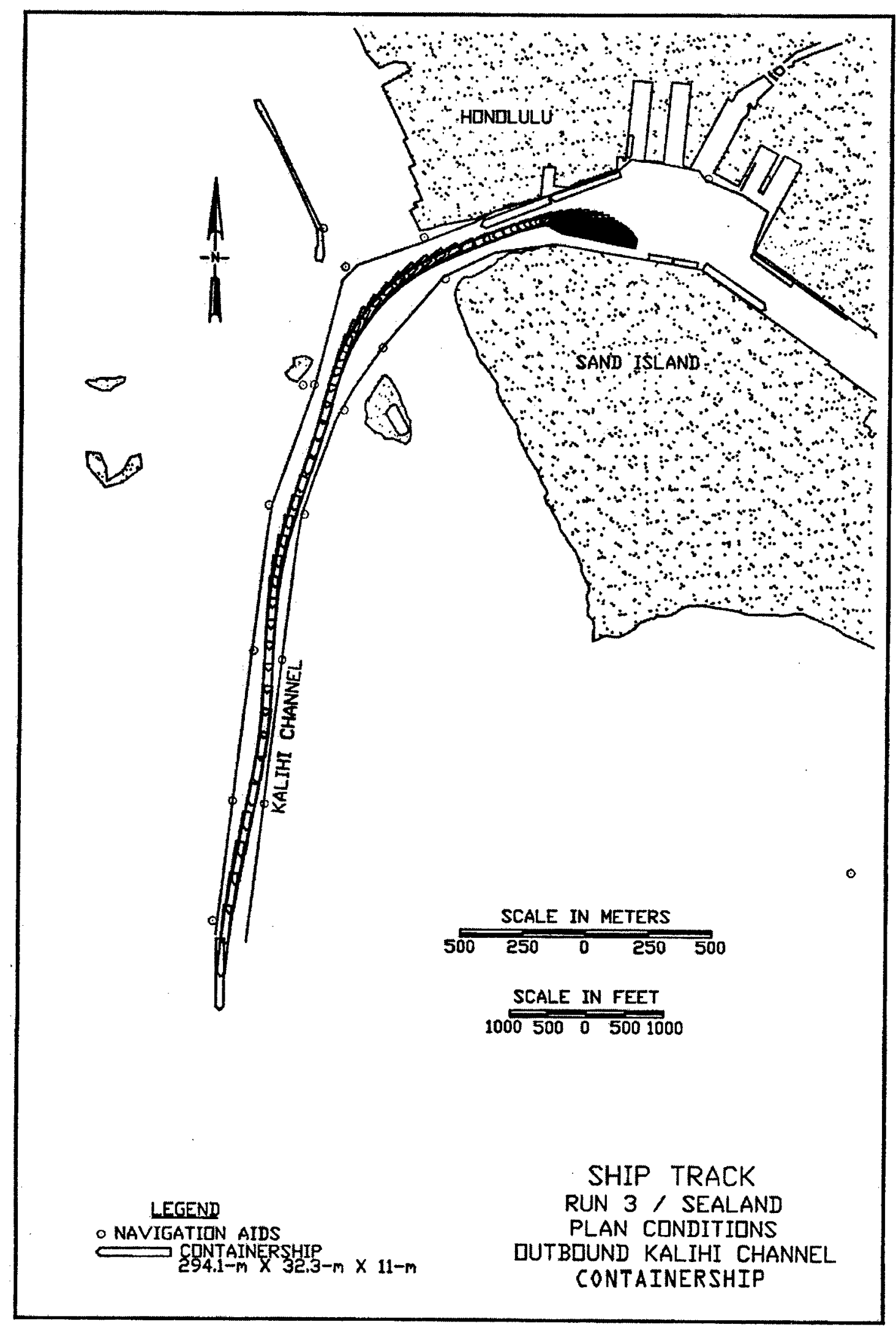

Plate 28 


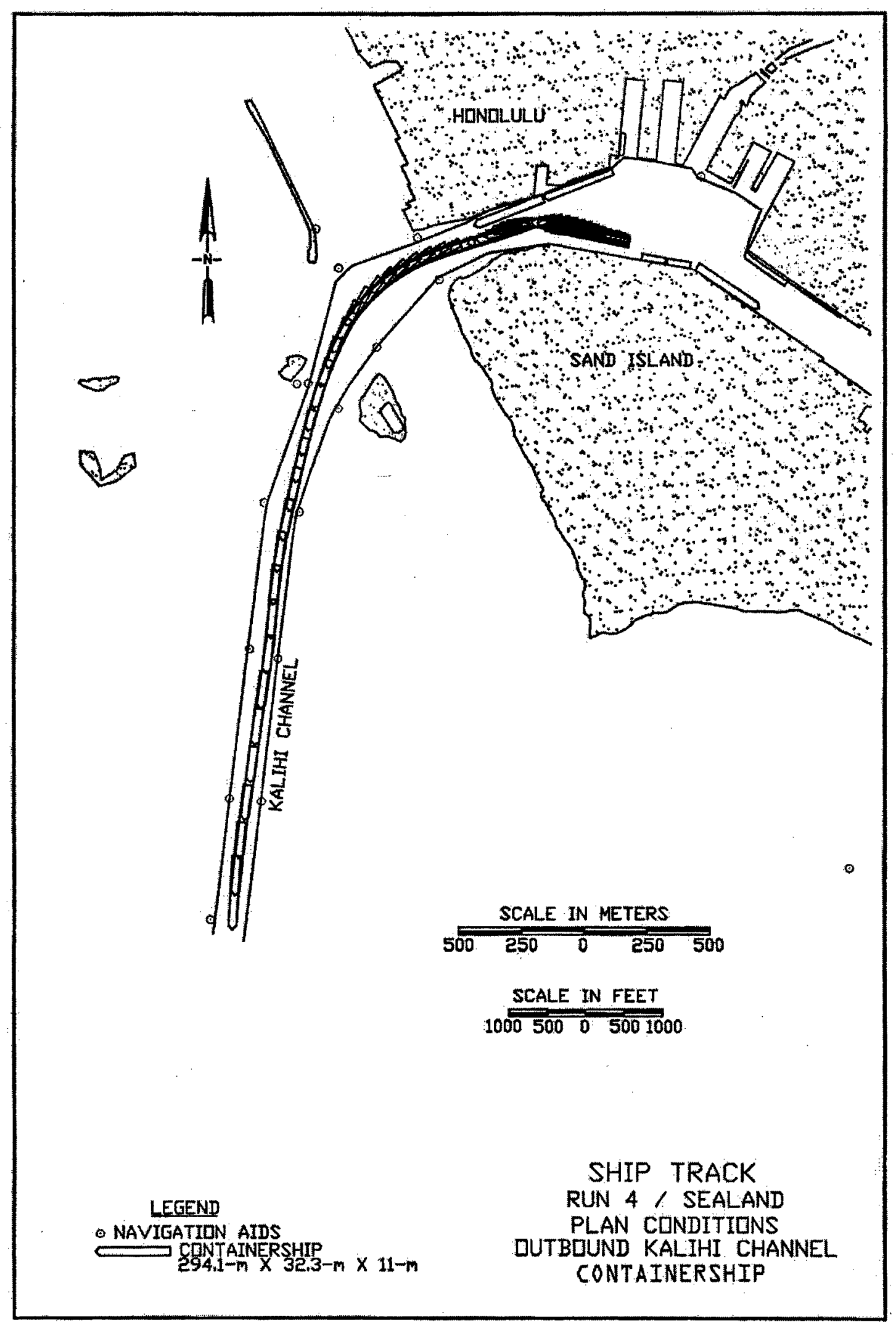

Plate 29 


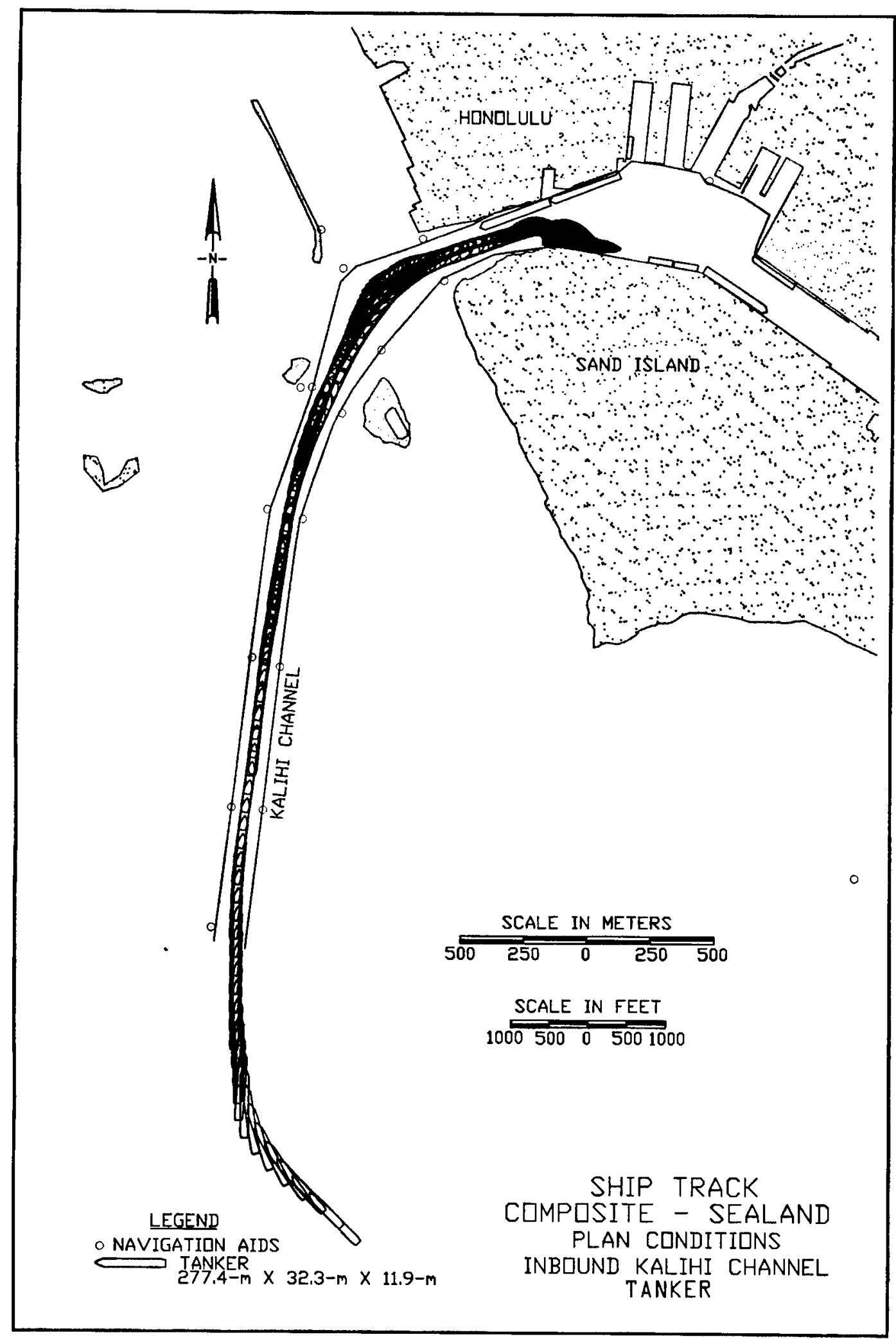

Plate 30 


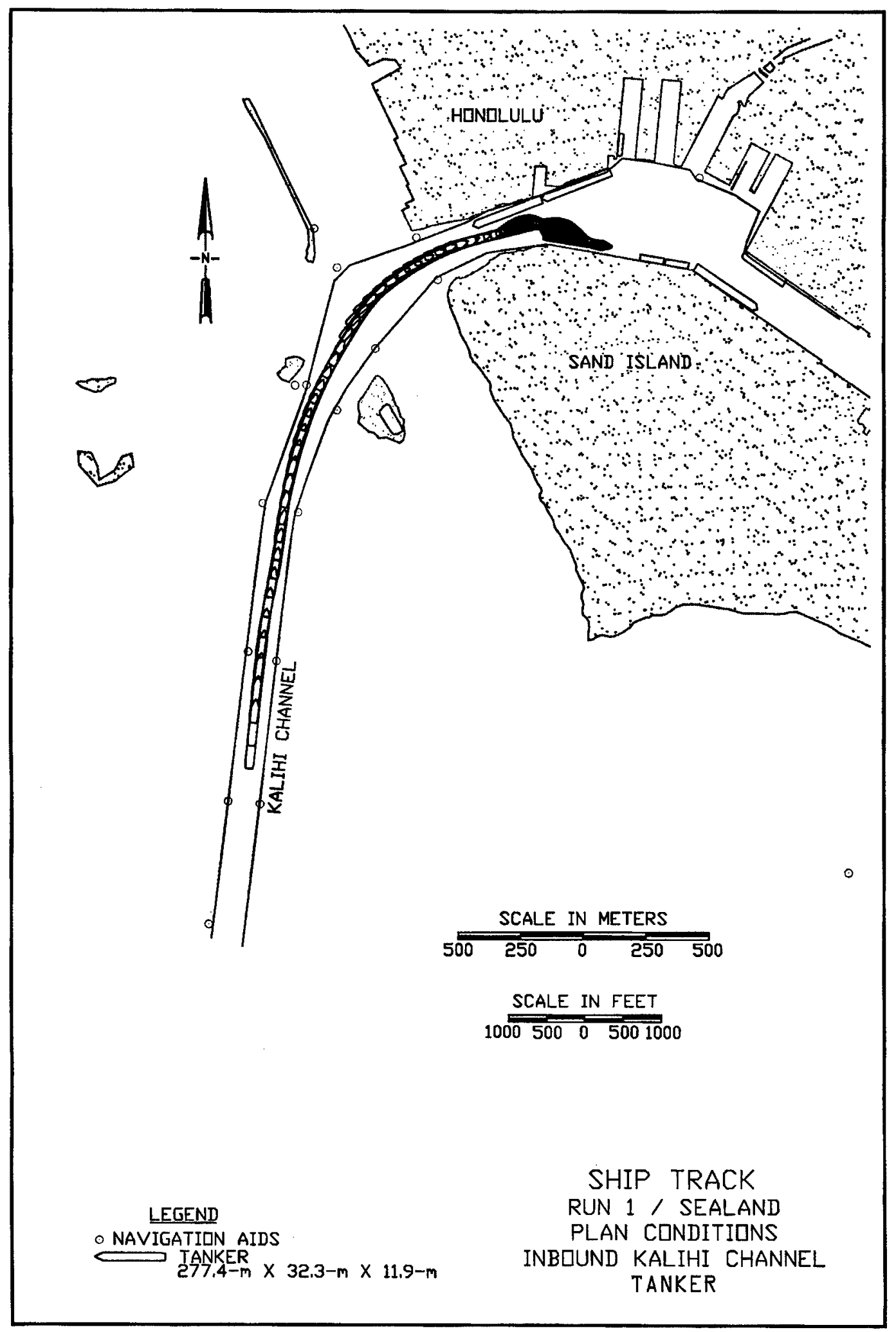

Plate 31 


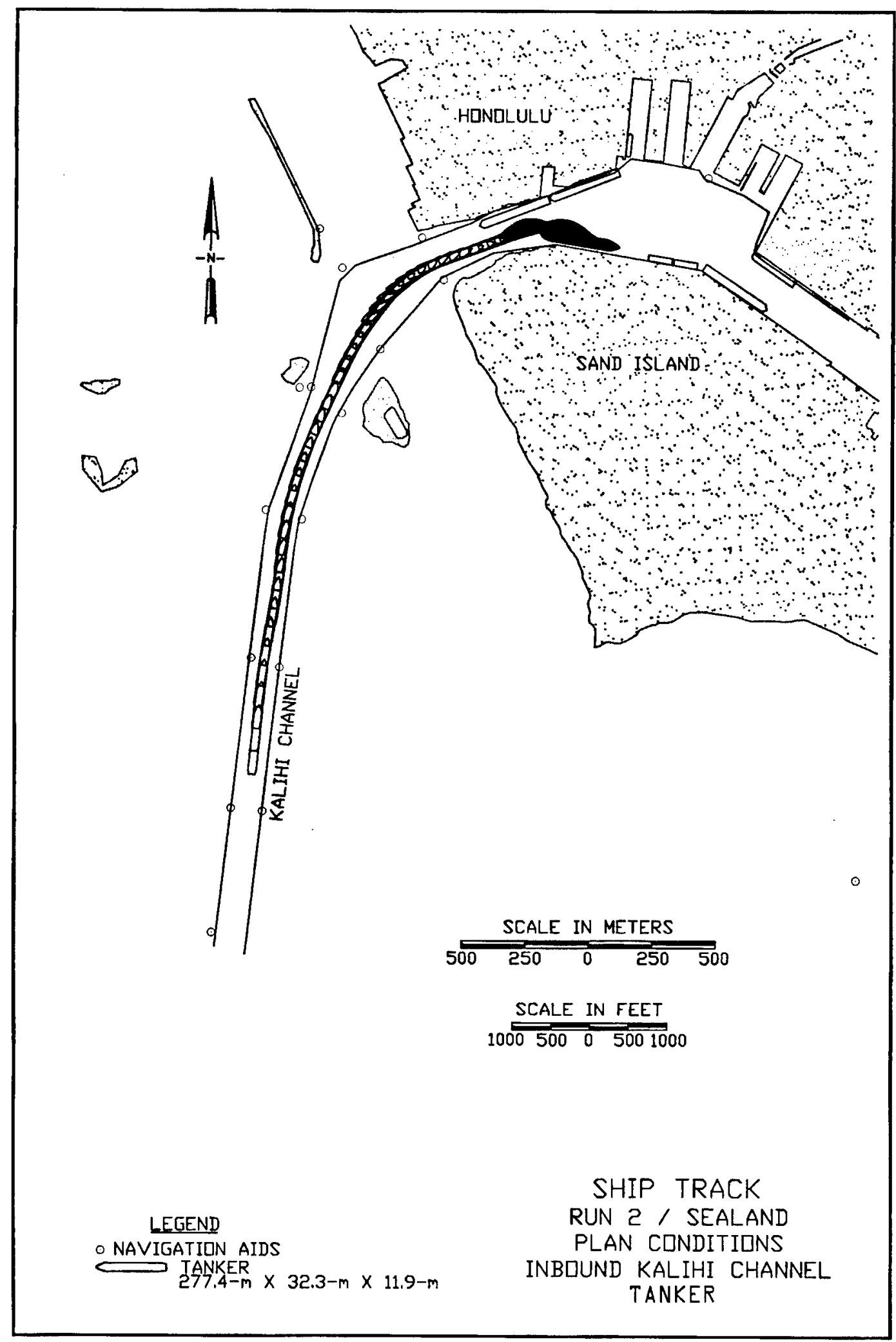

Plate 32 


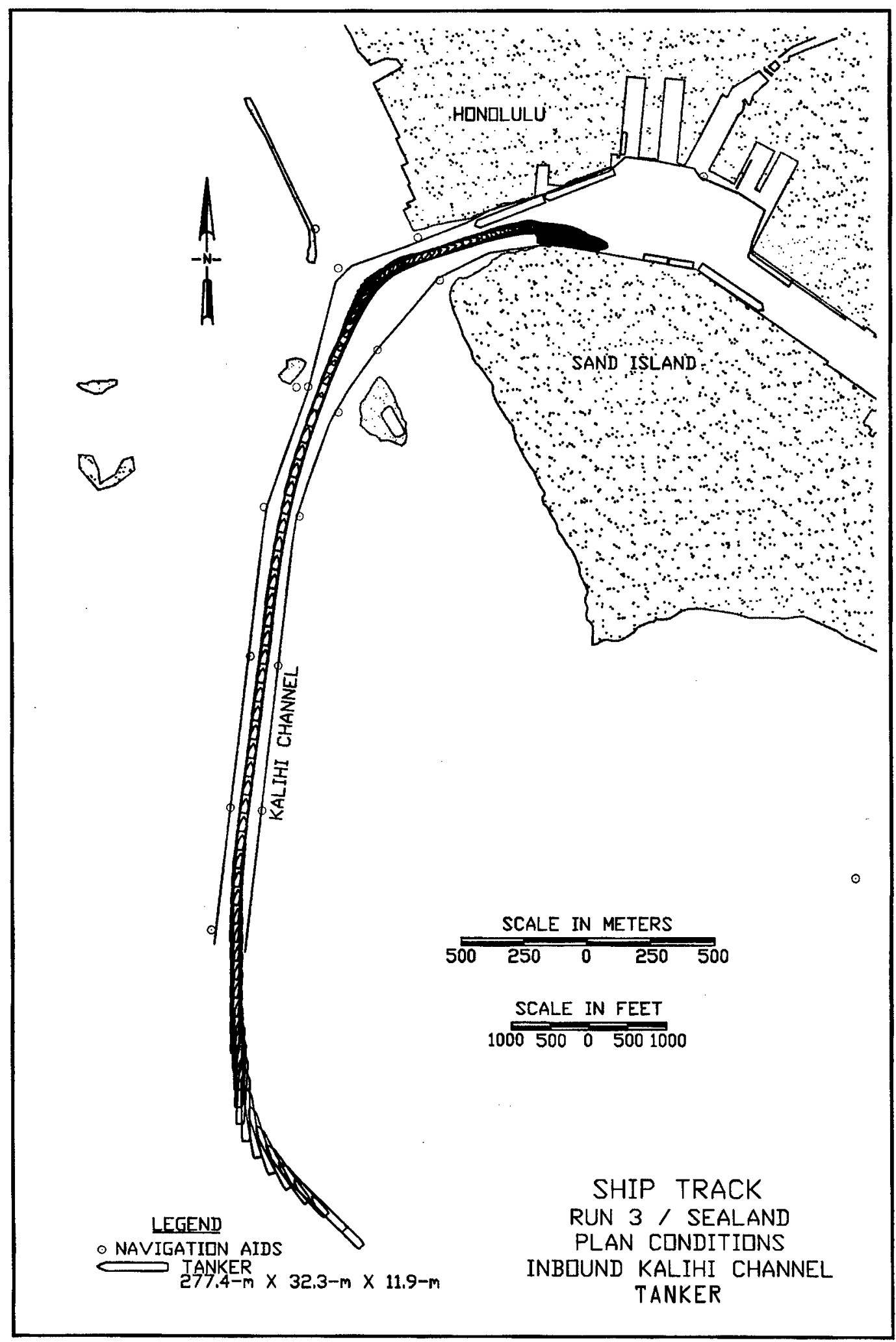

Plate 33 


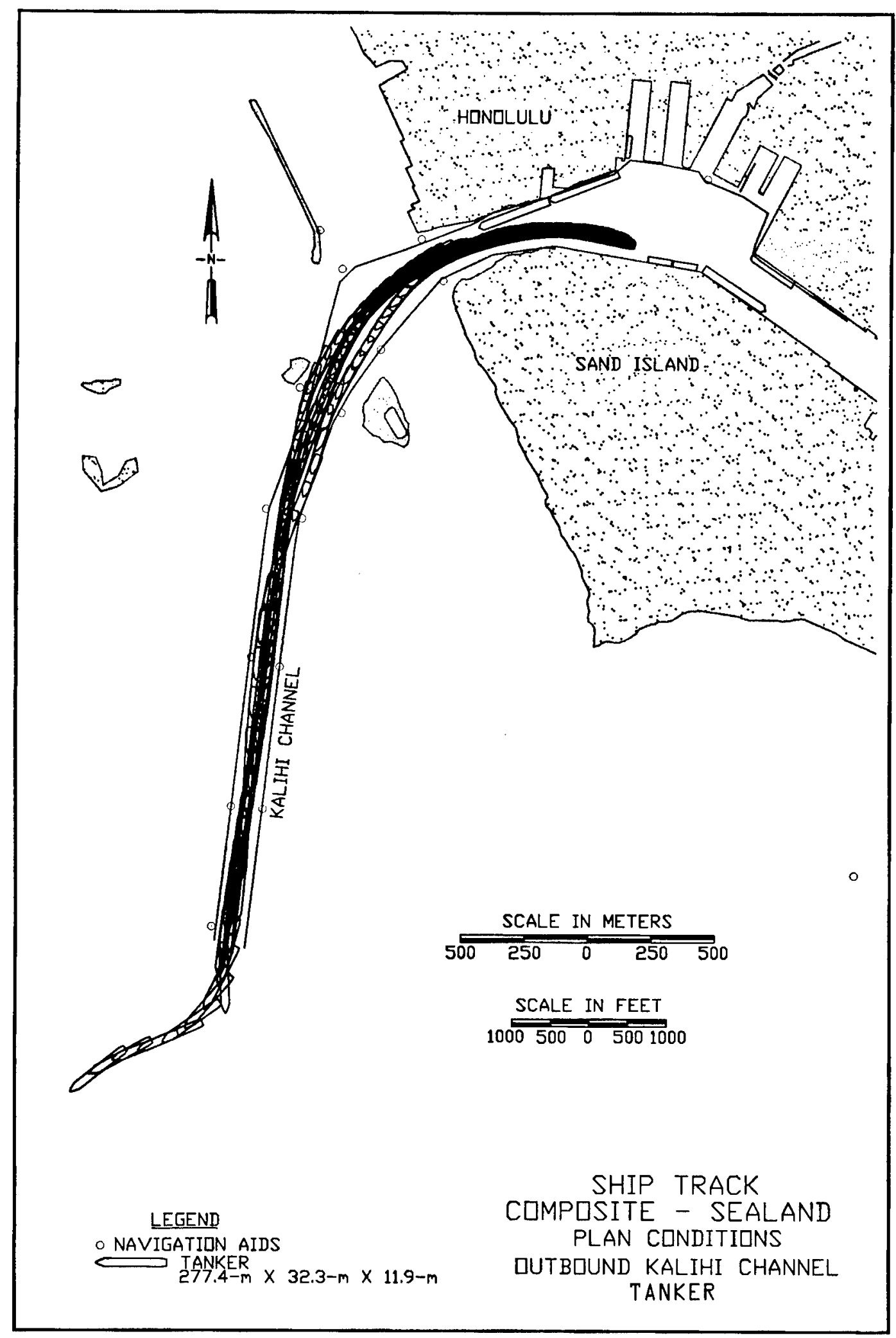

Plate 34 


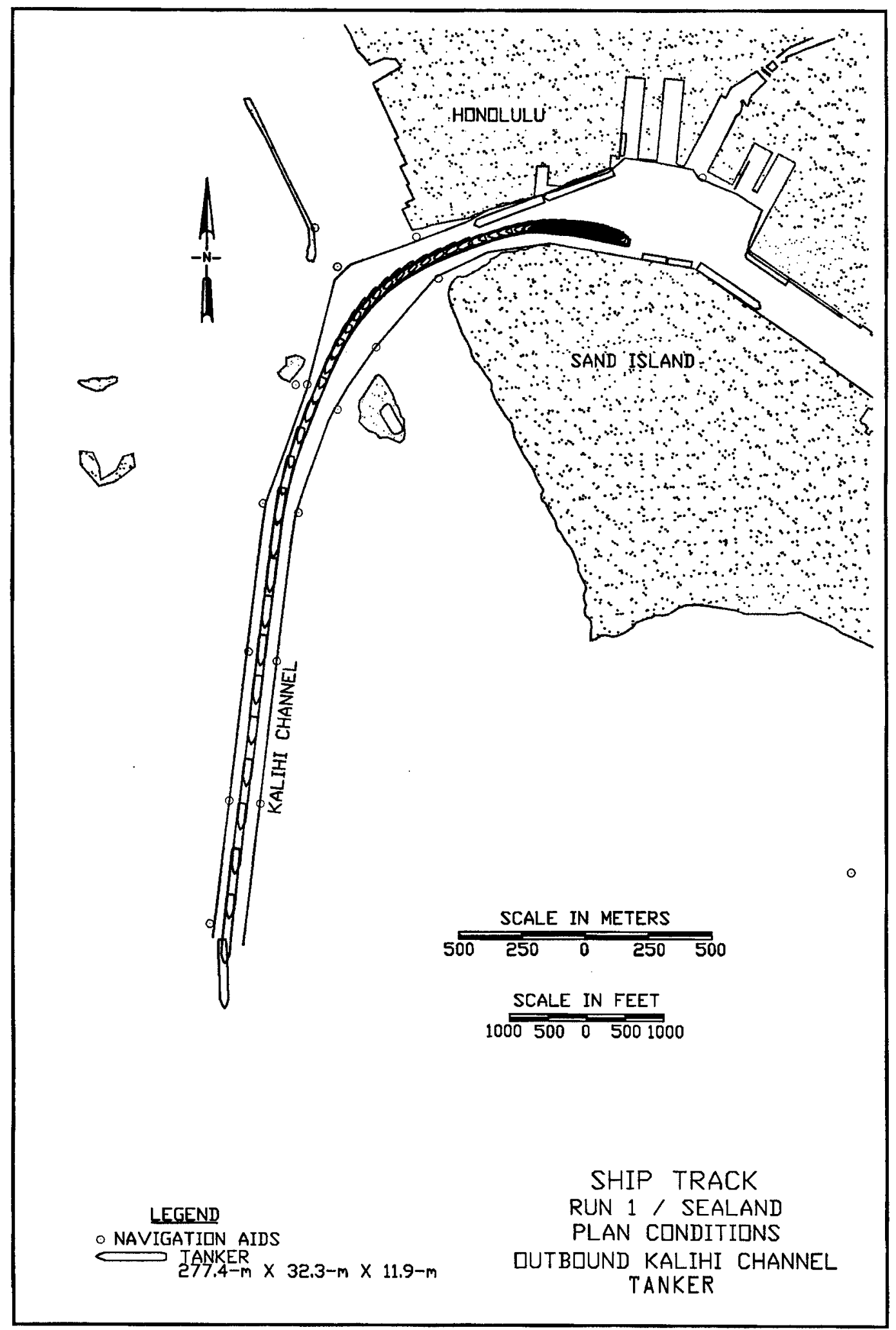

Plate 35 


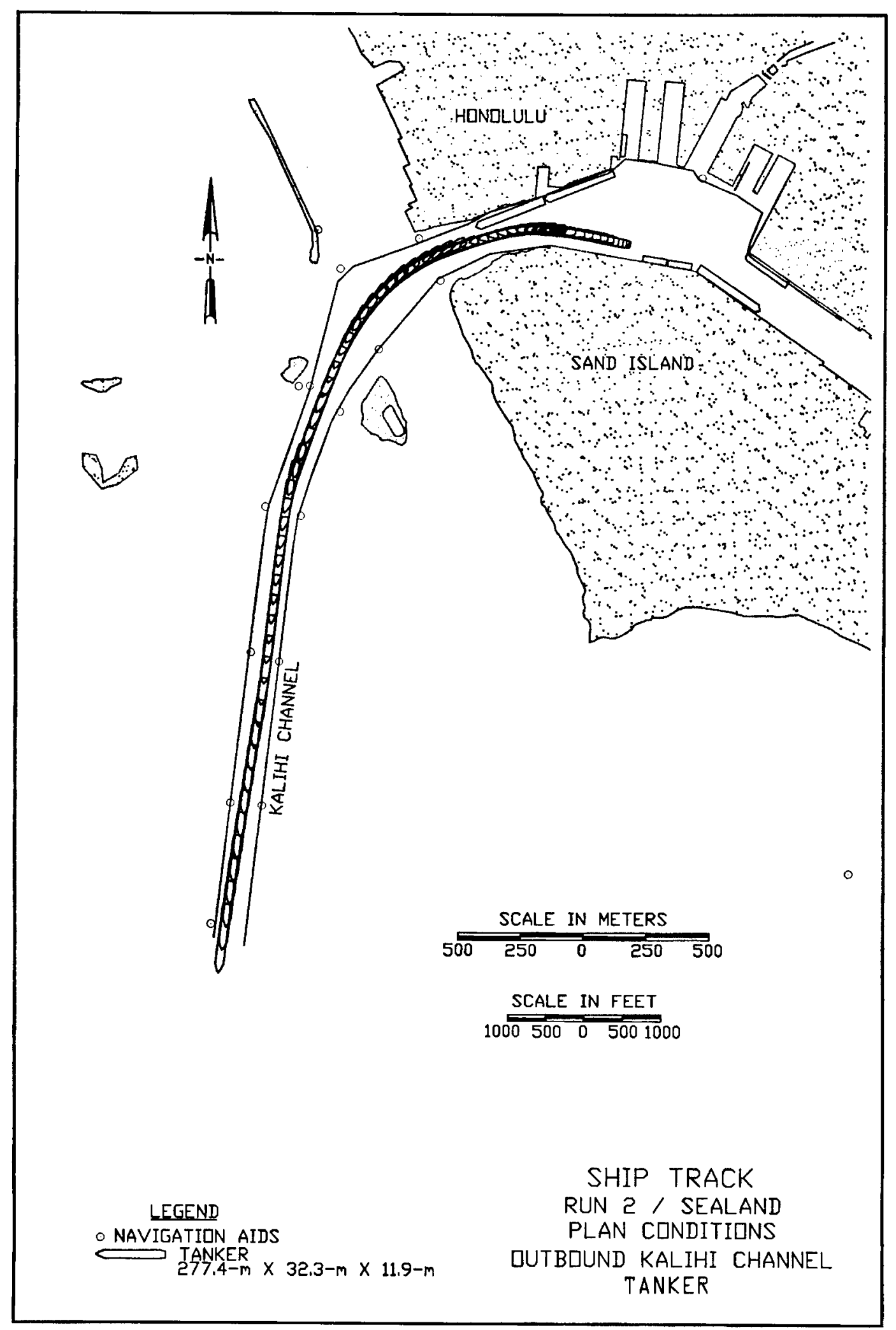

Plate 36 


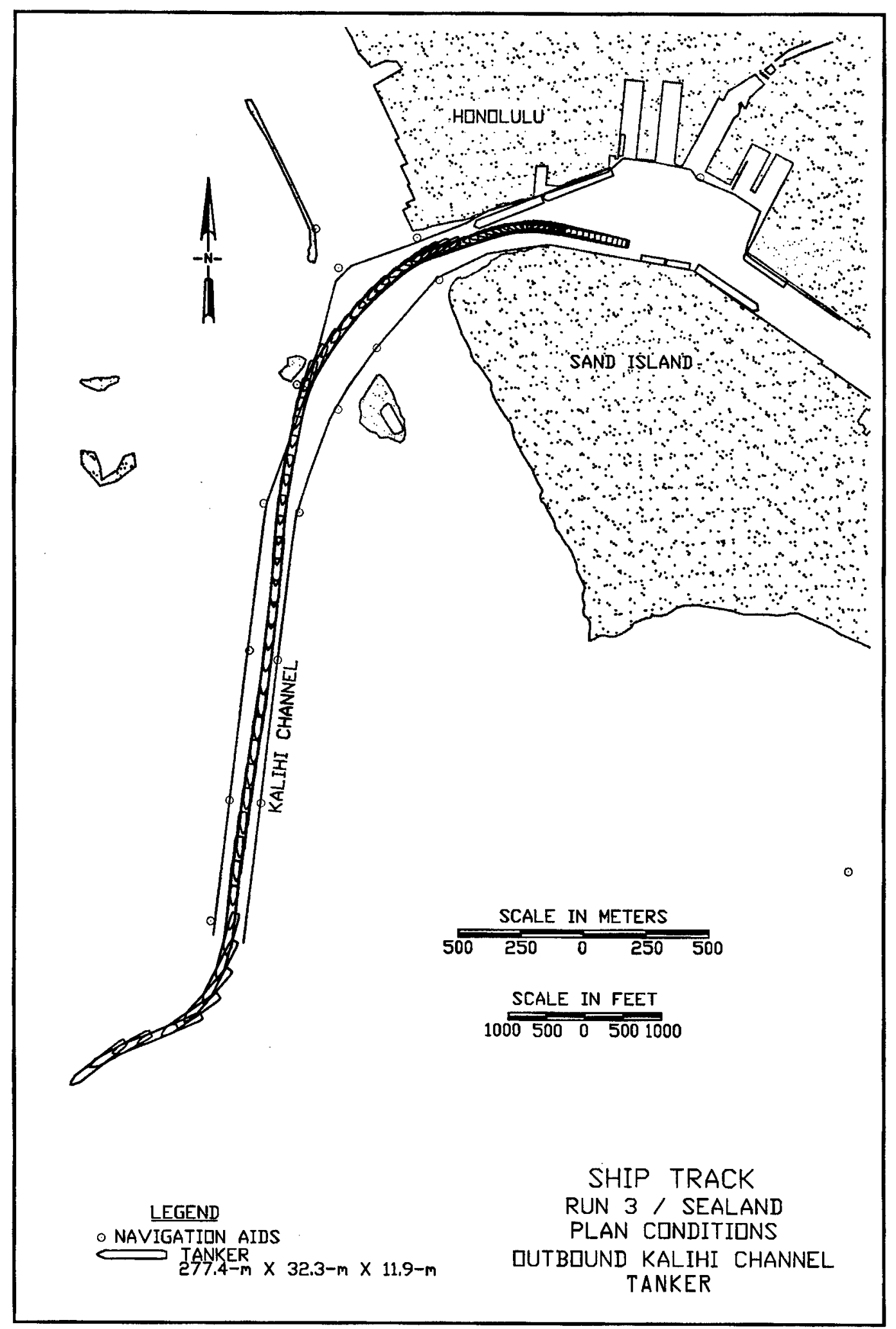

Plate 37 


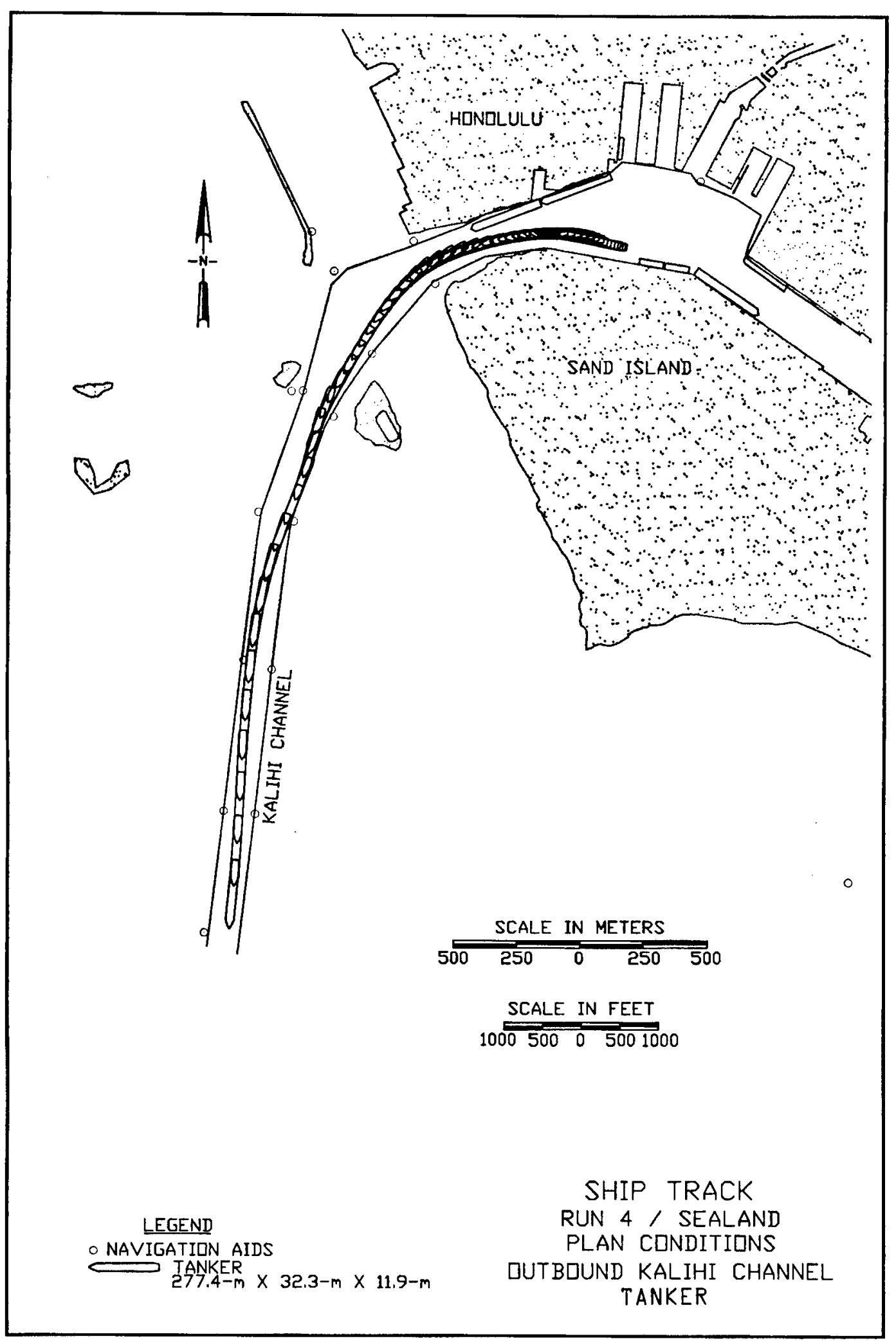

Plate 38 


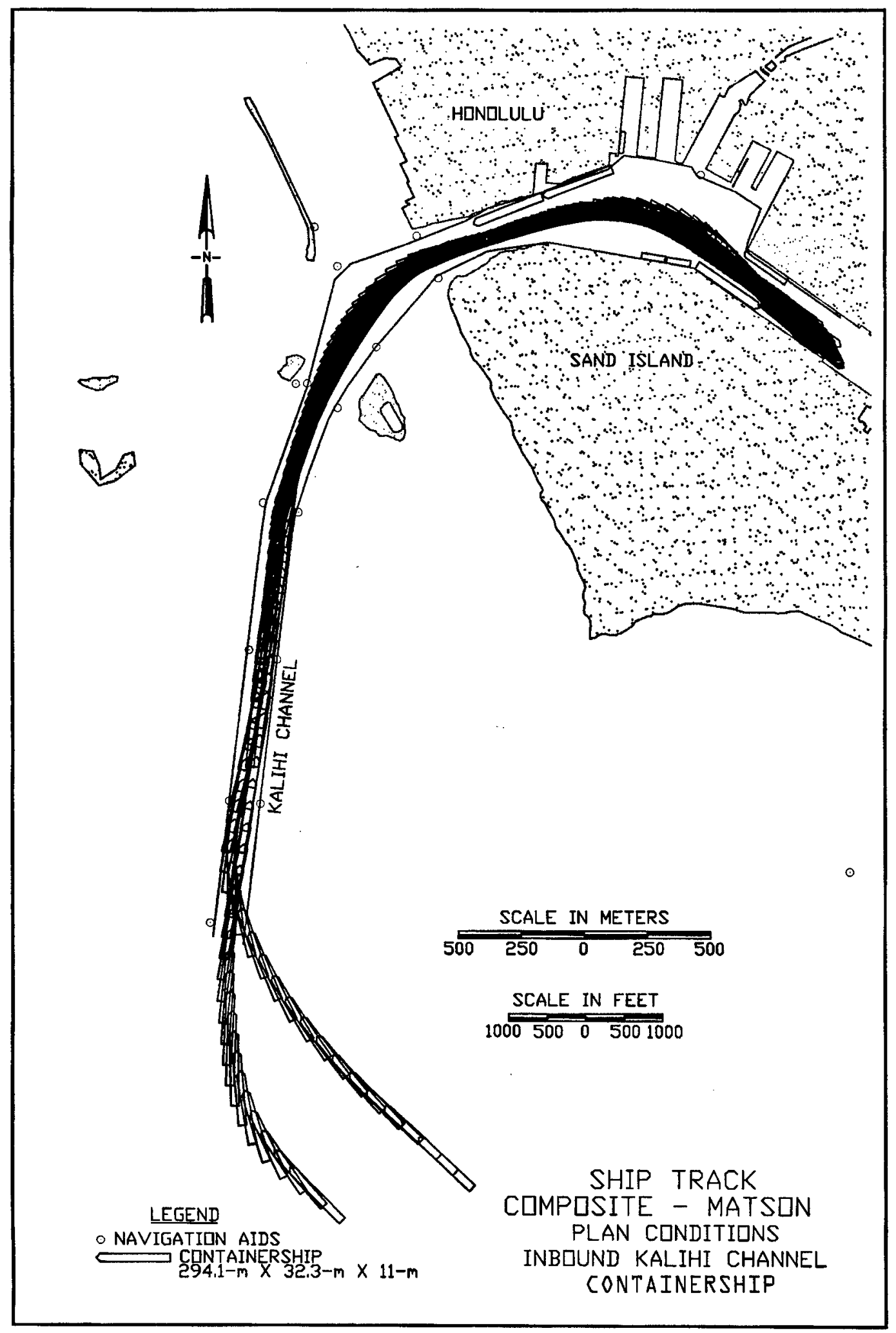

Plate 39 


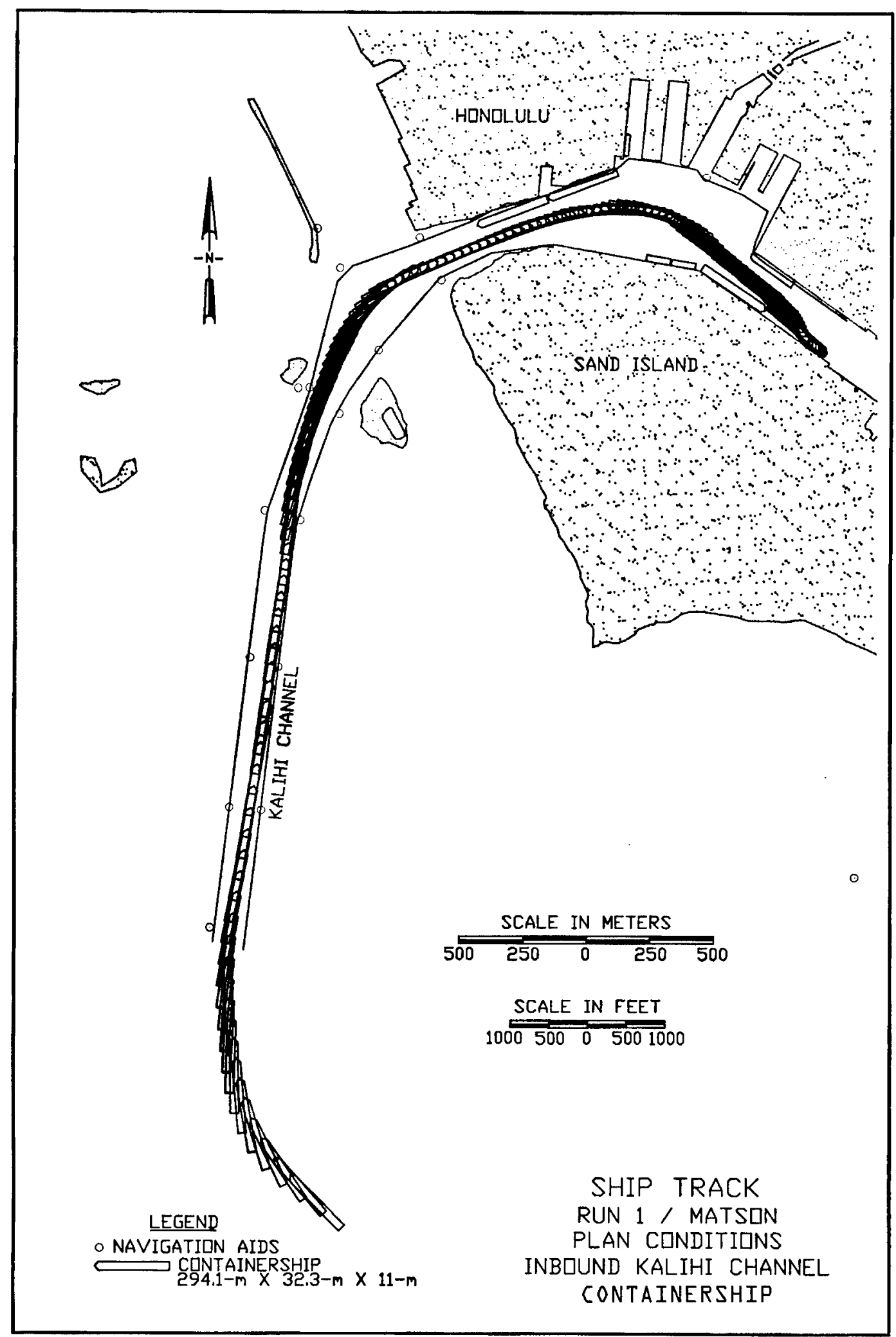

Plate 40 


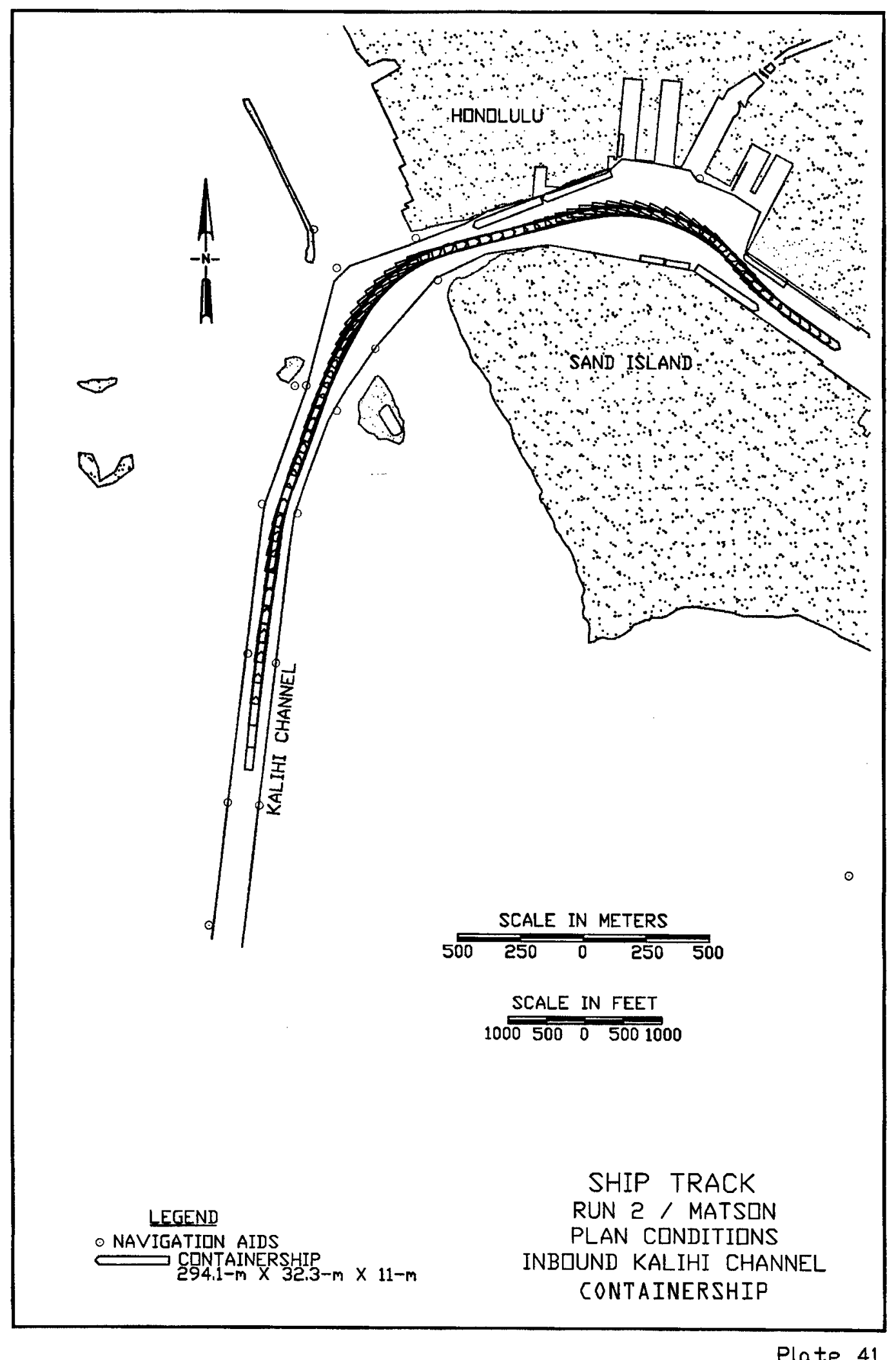




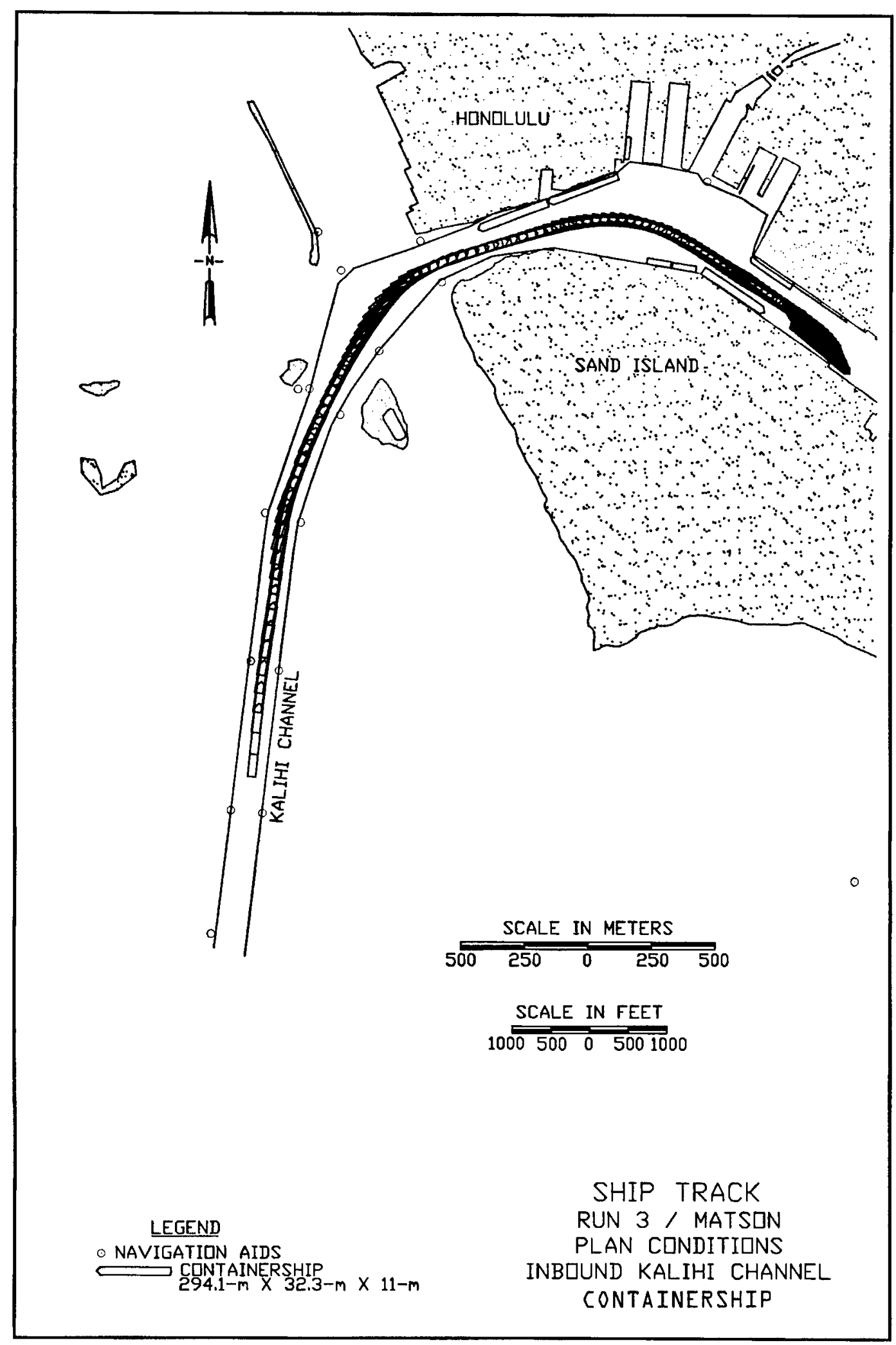

Plate 42 


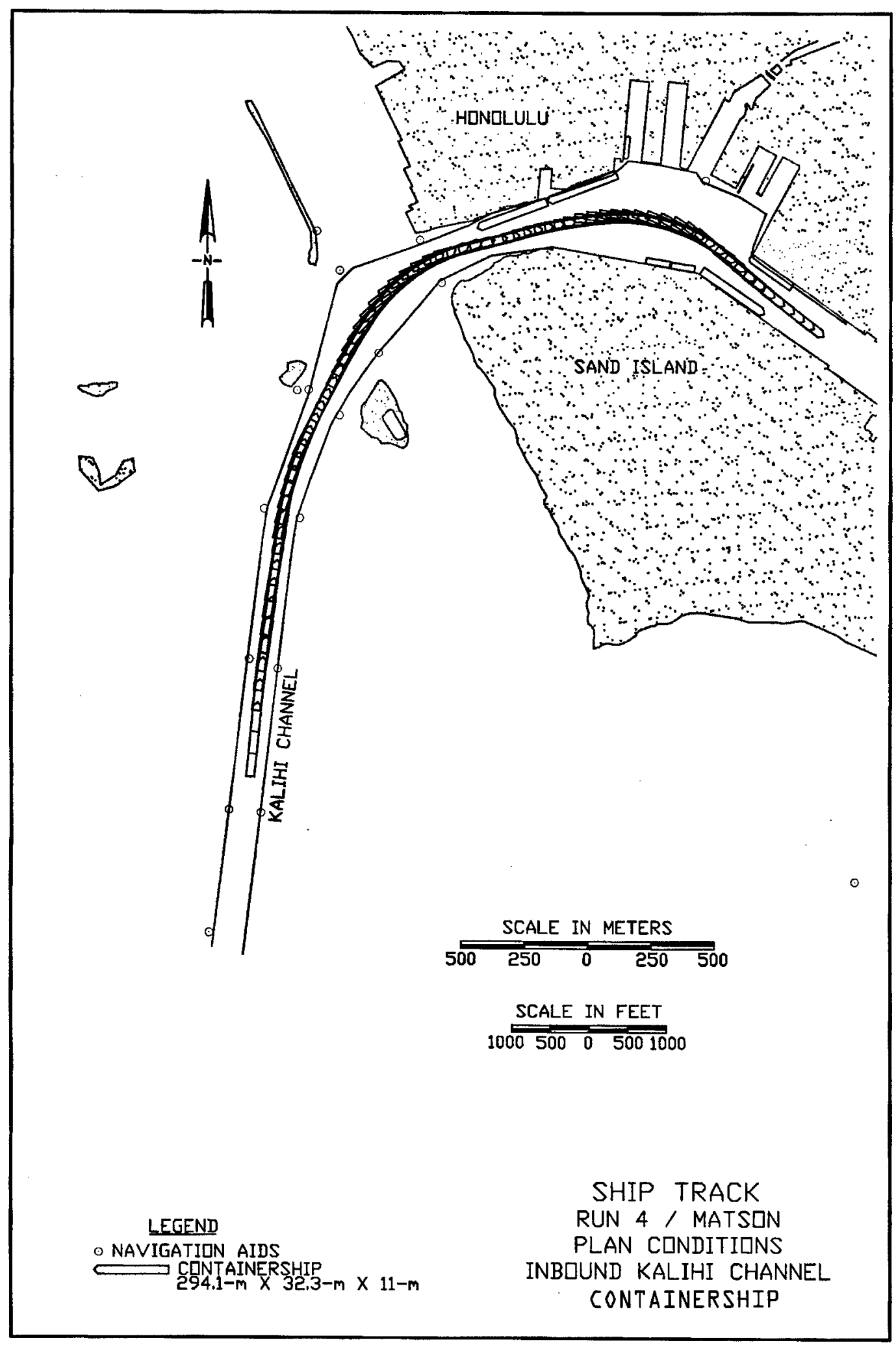

Plate 43 


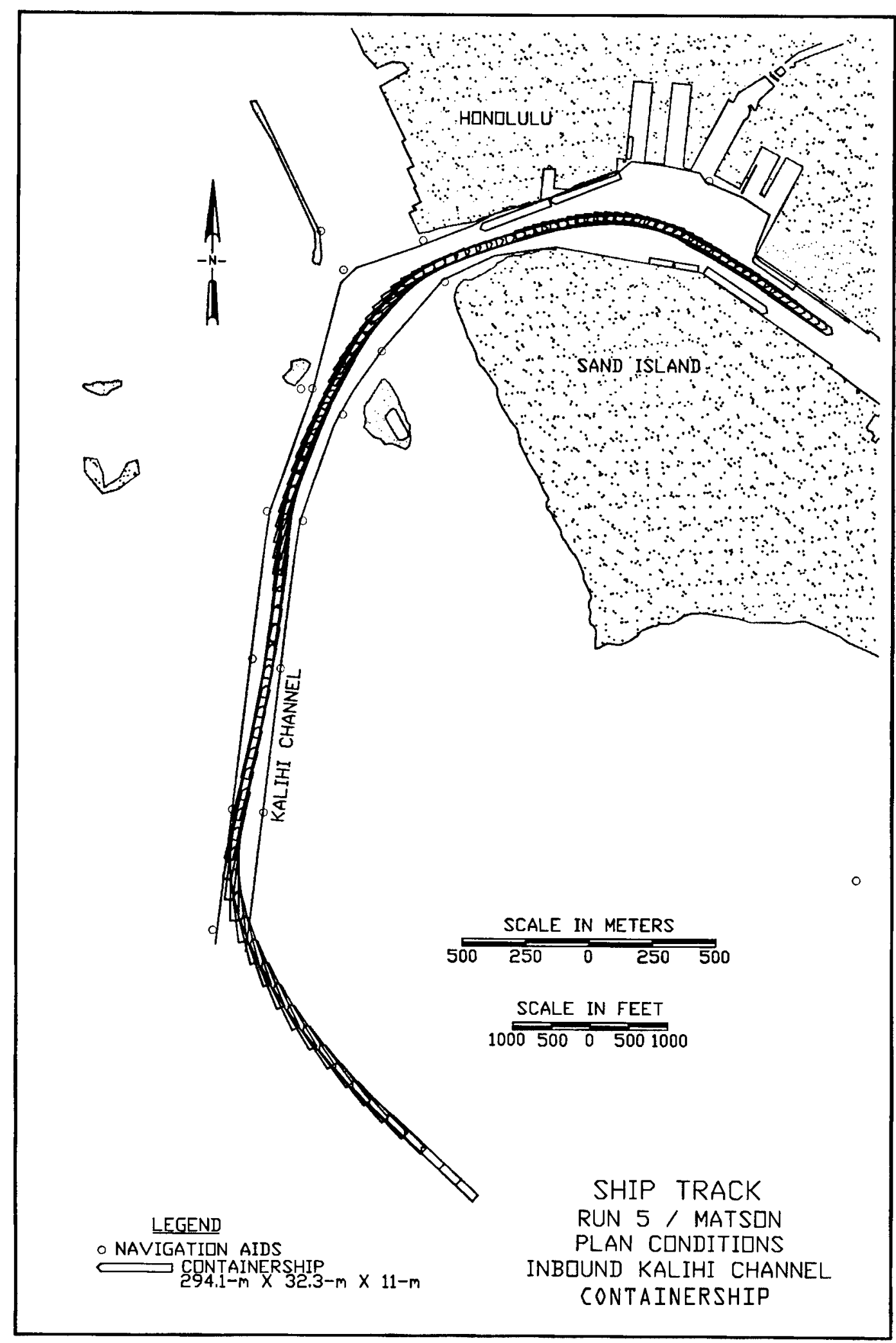

Plate 44 


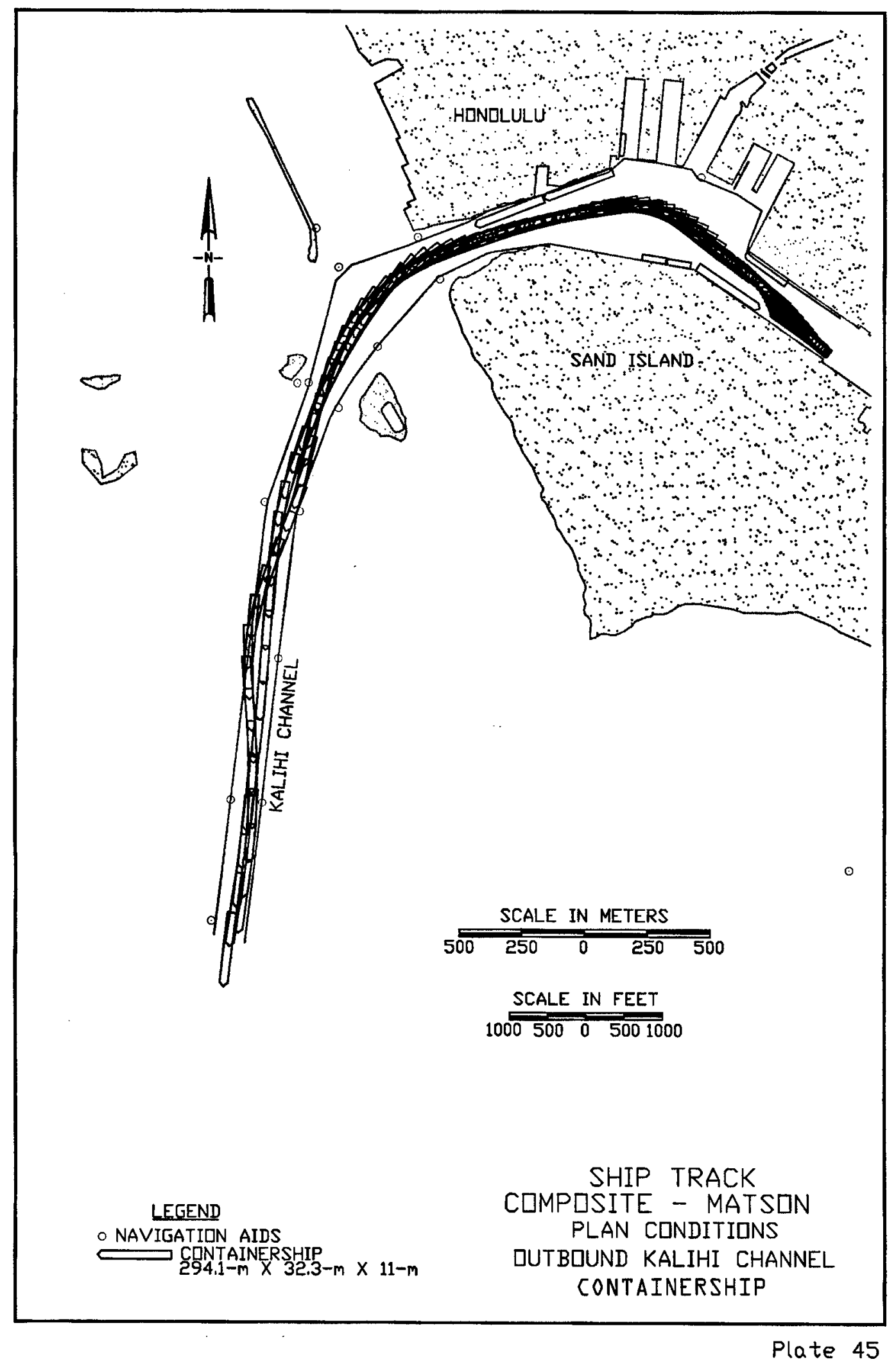




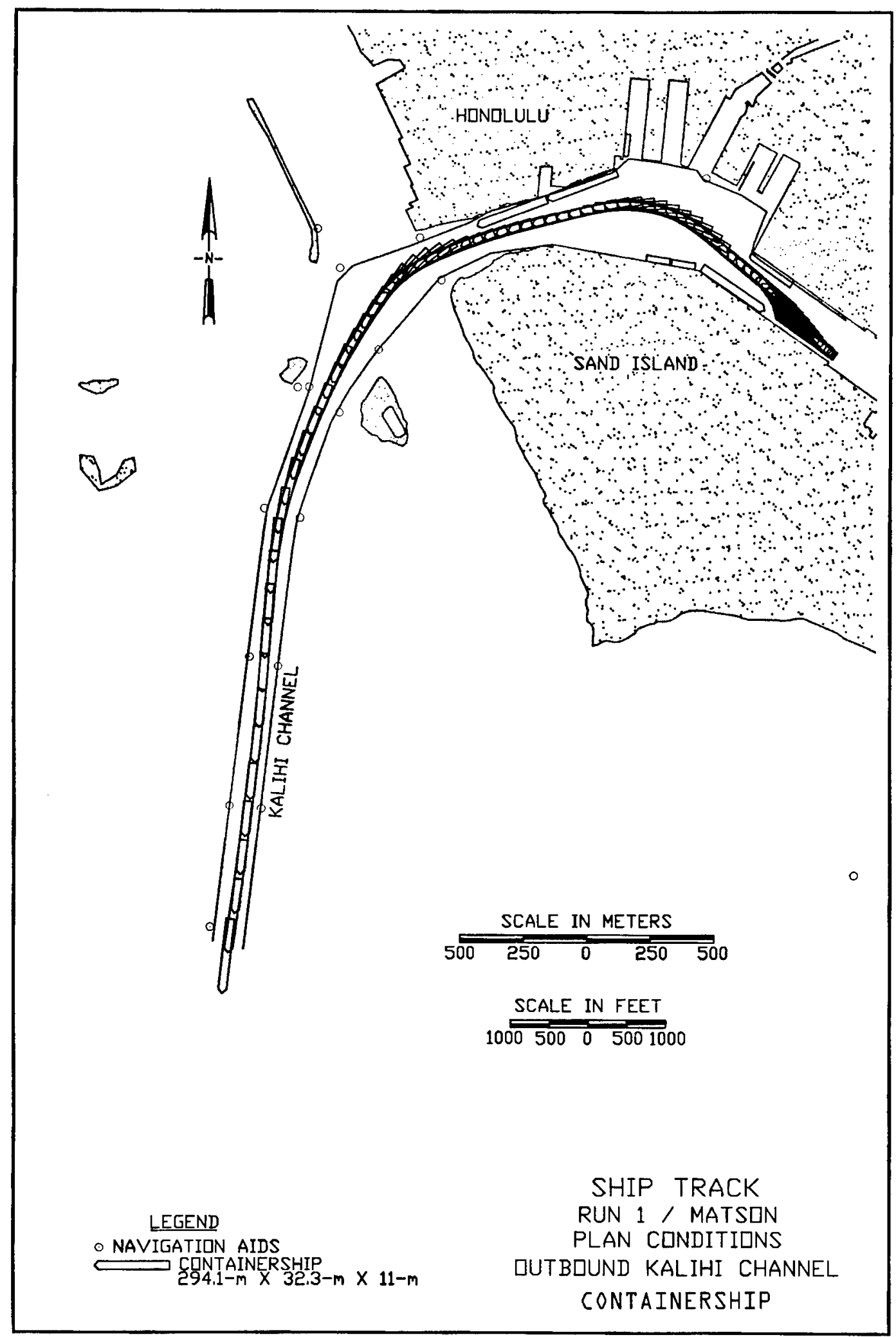

Plate 46 


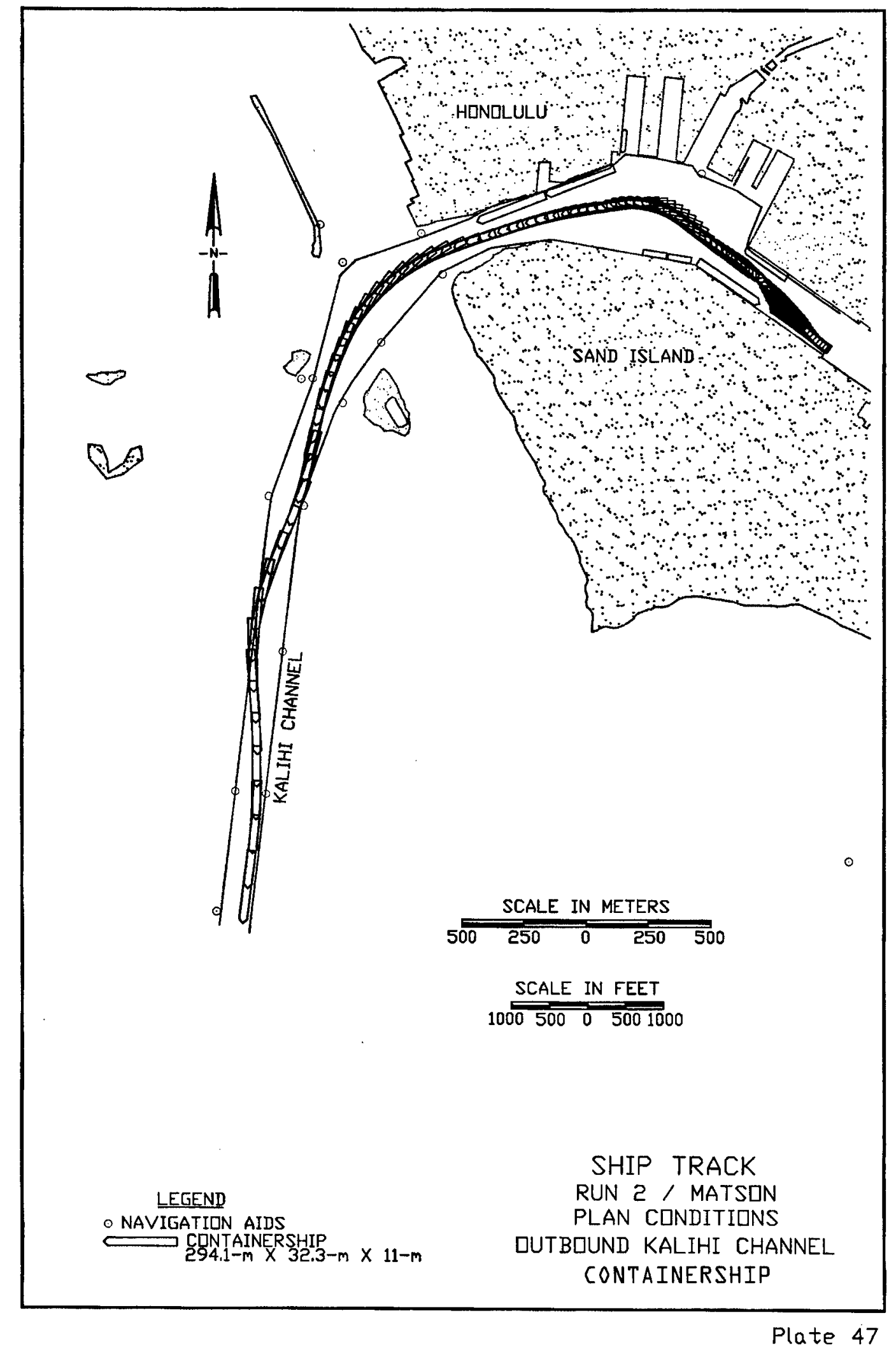




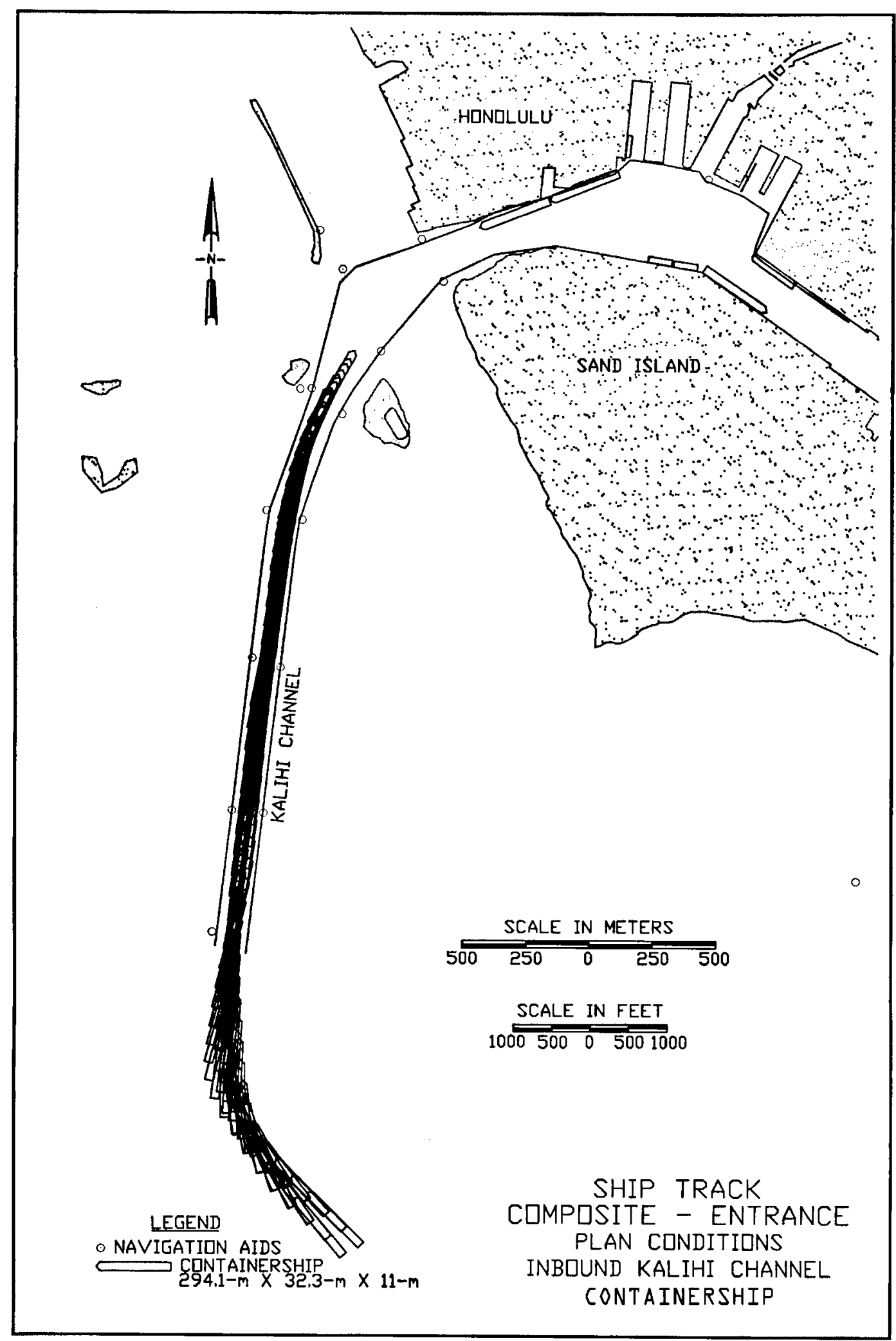

Plate 48 


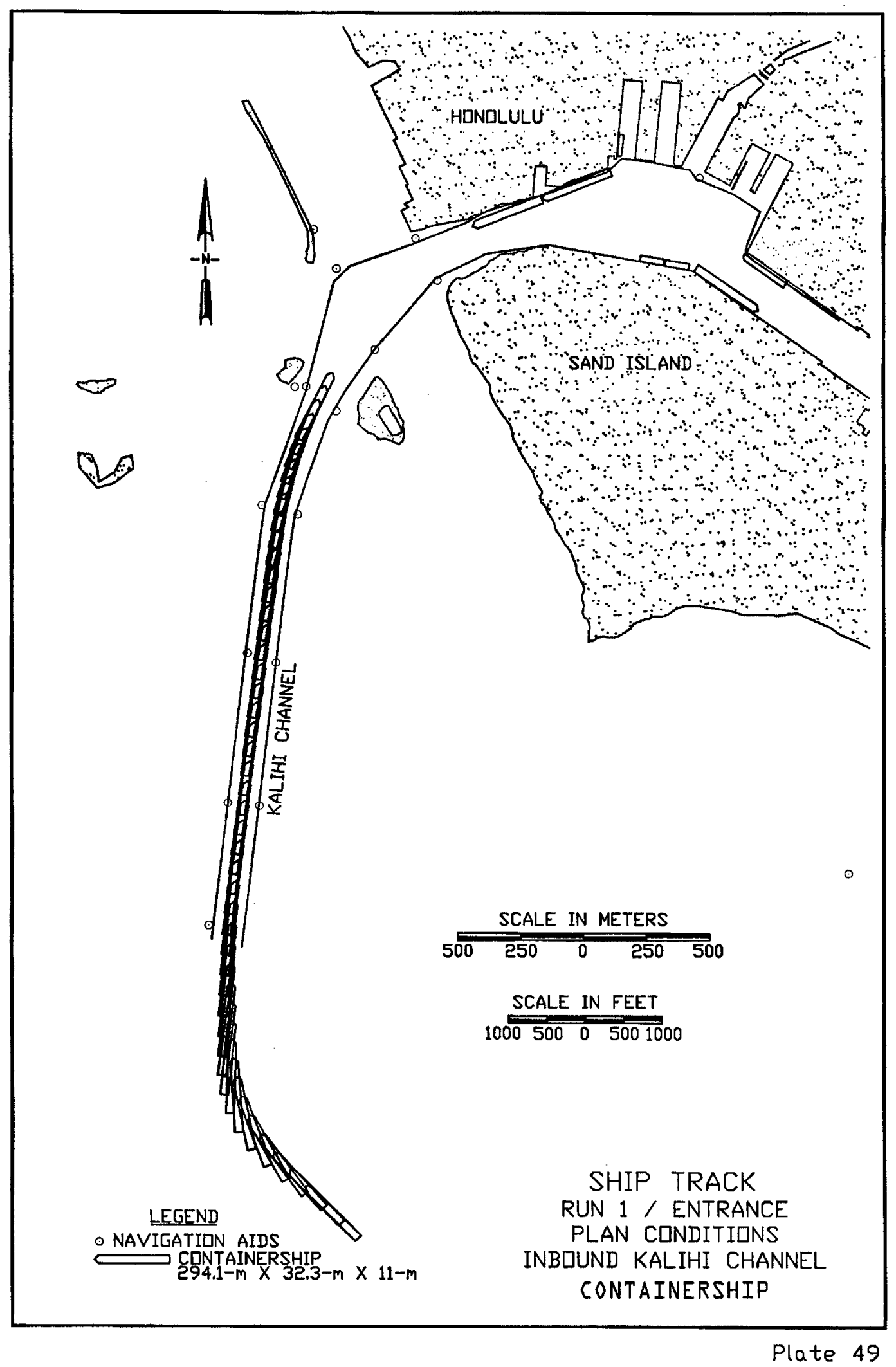




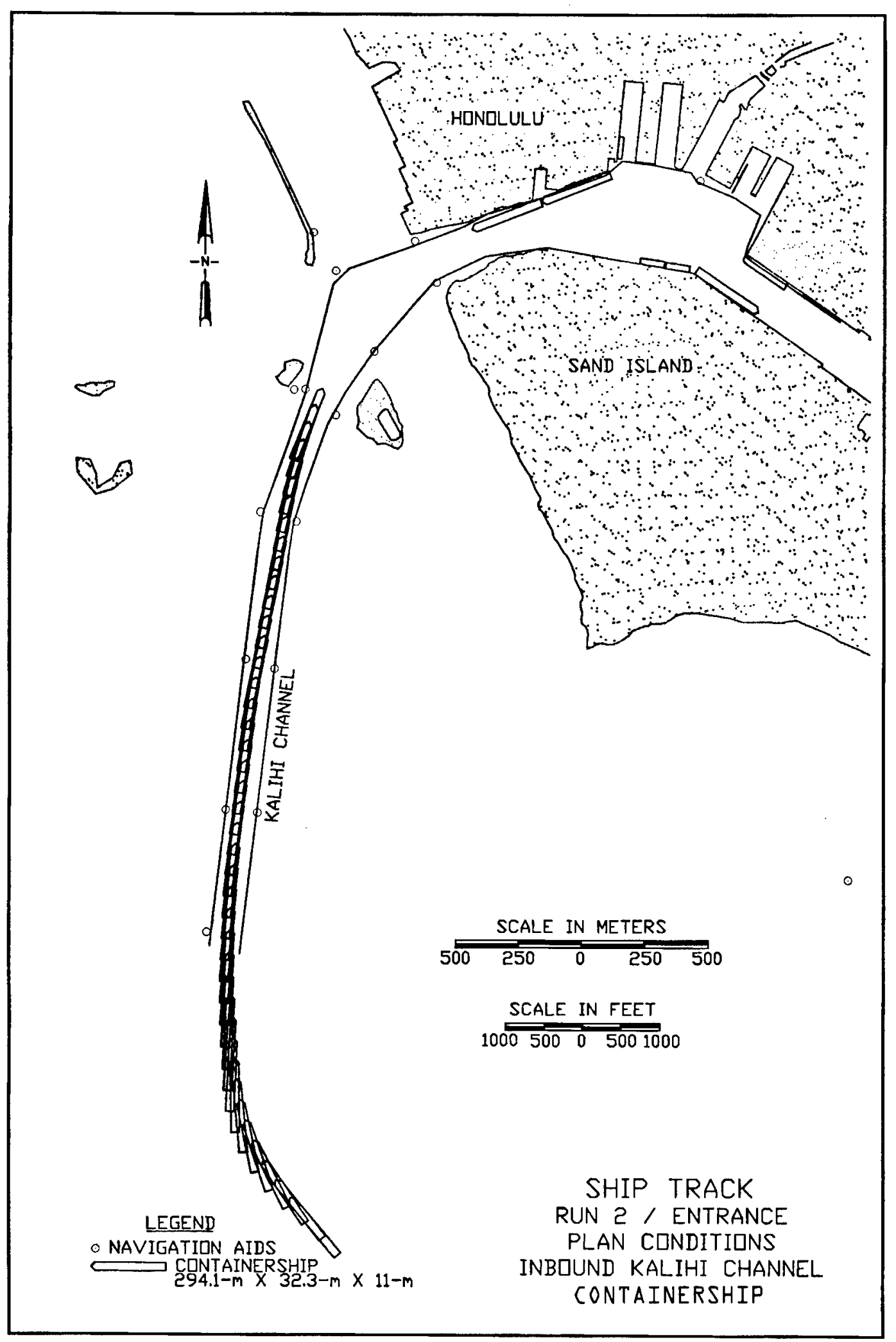

Plate 50 


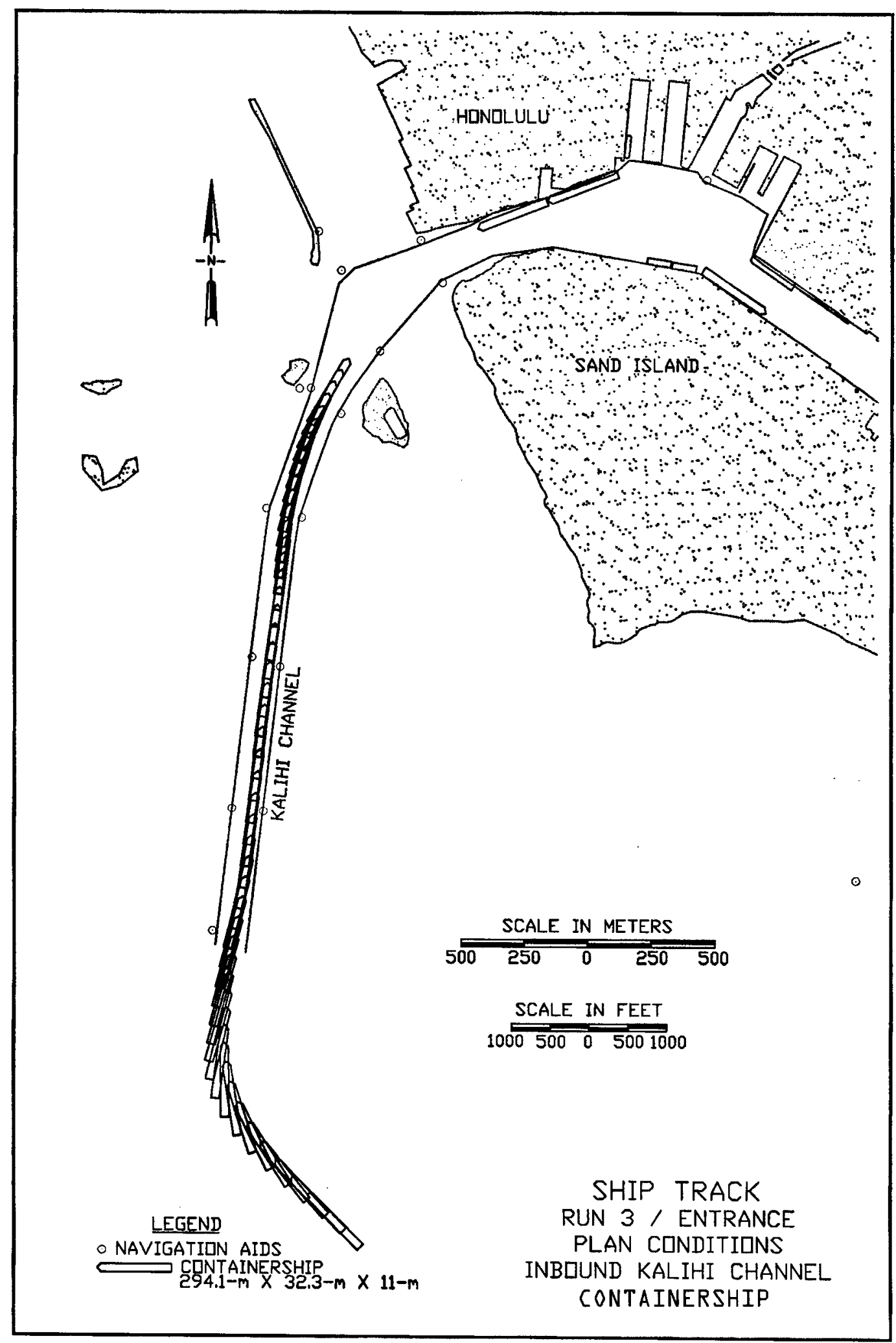

Plate 51 


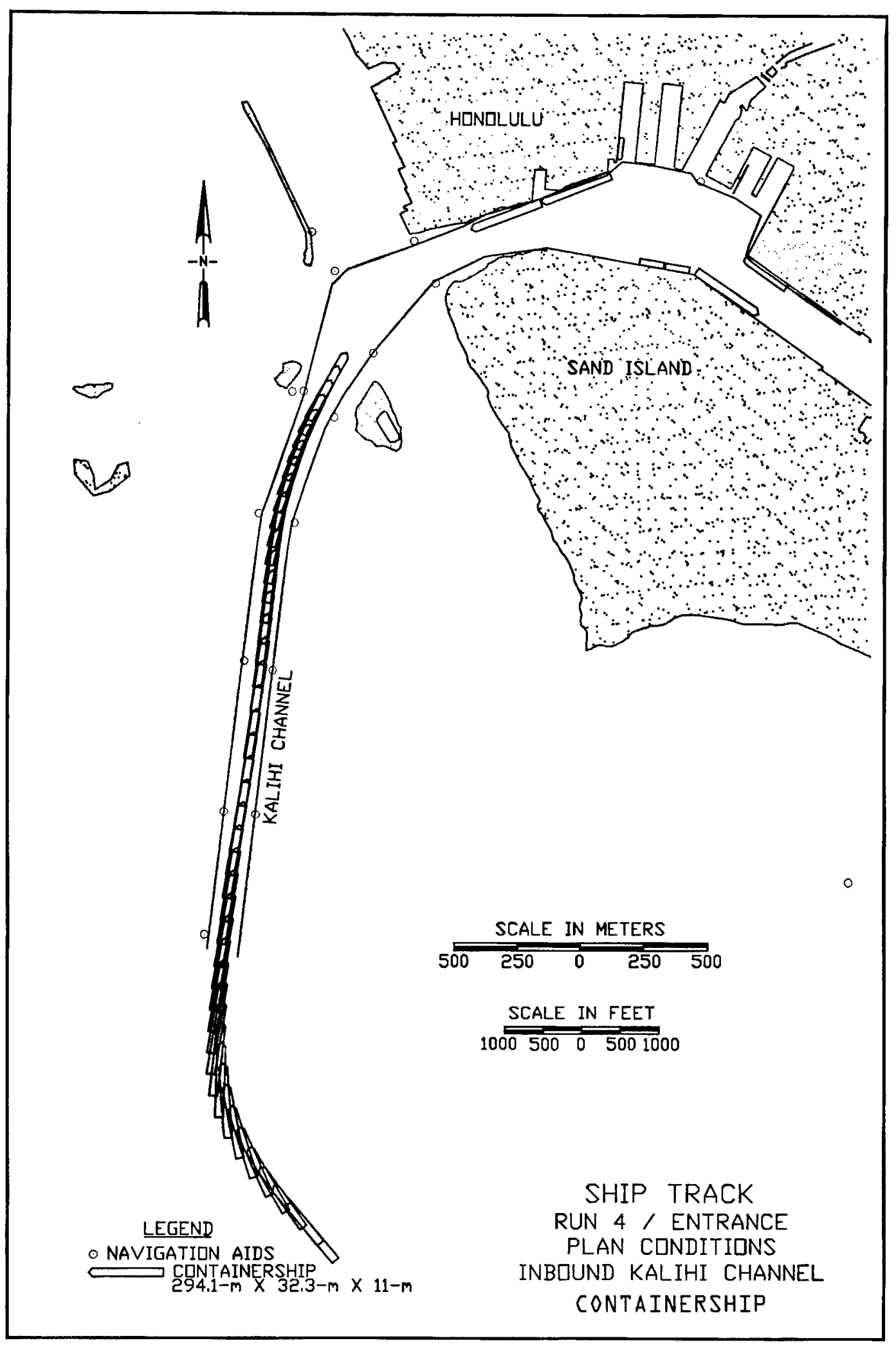

Plate 52 


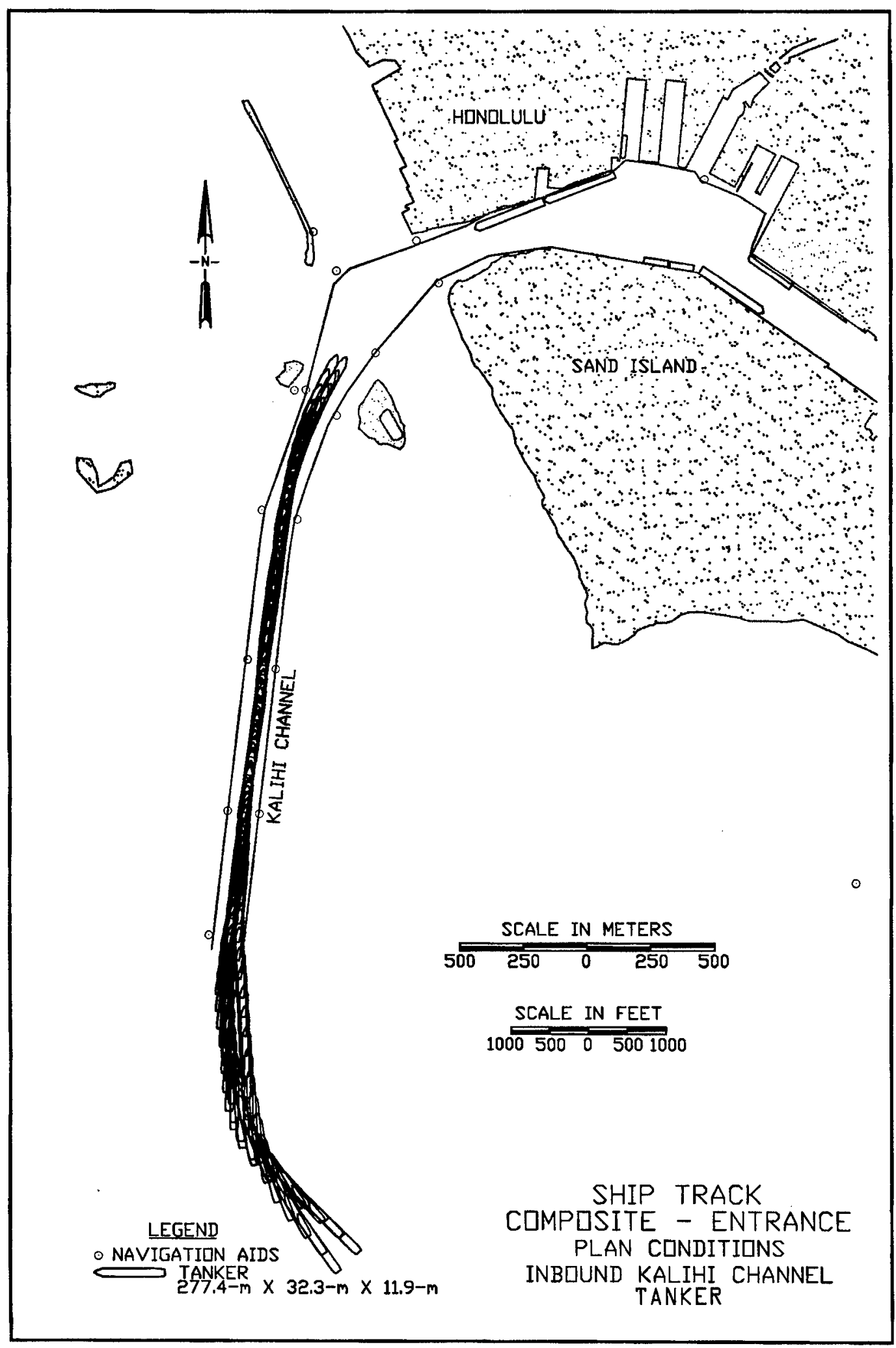

Plate 53 


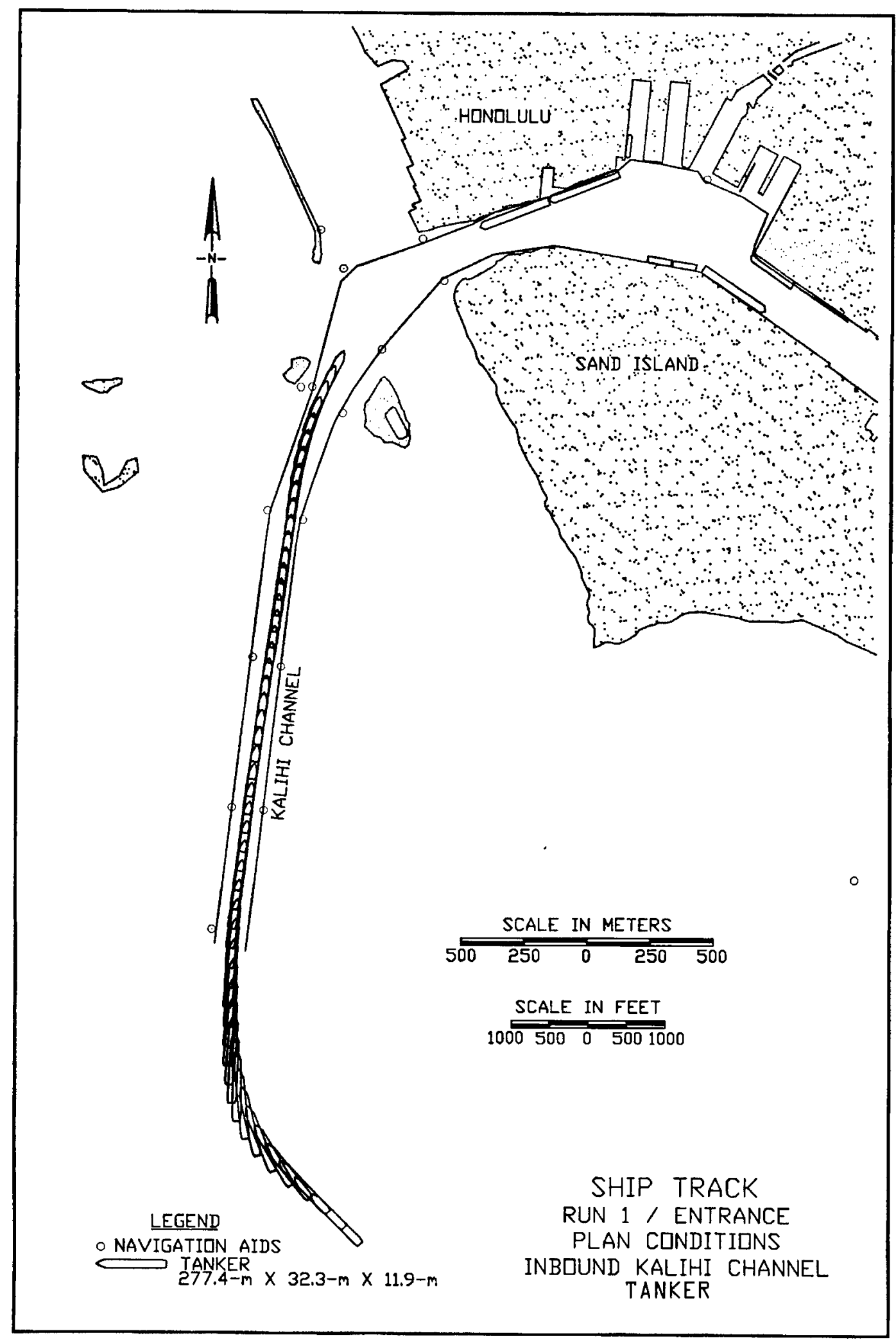

Plate 54 


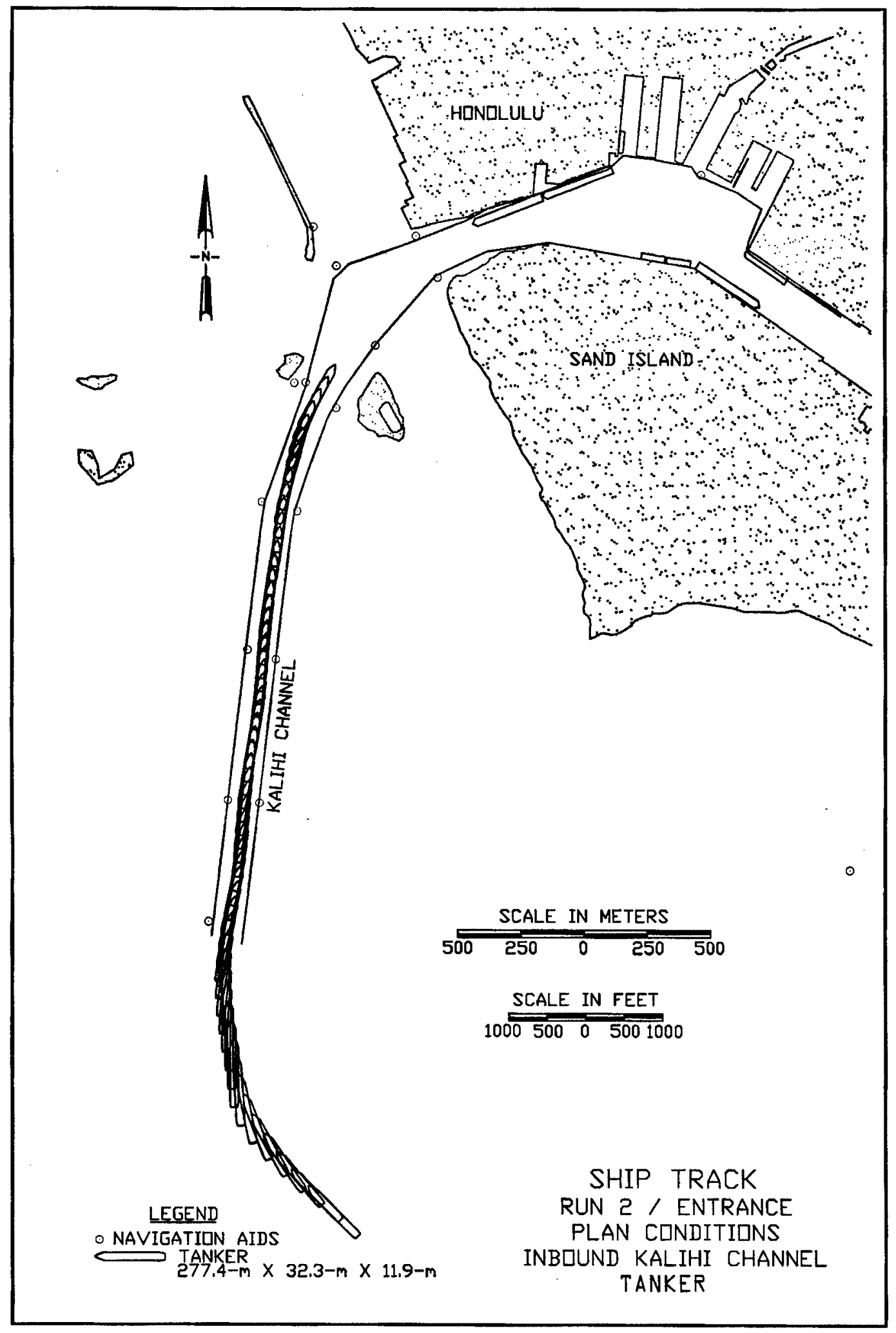

Plate 55 


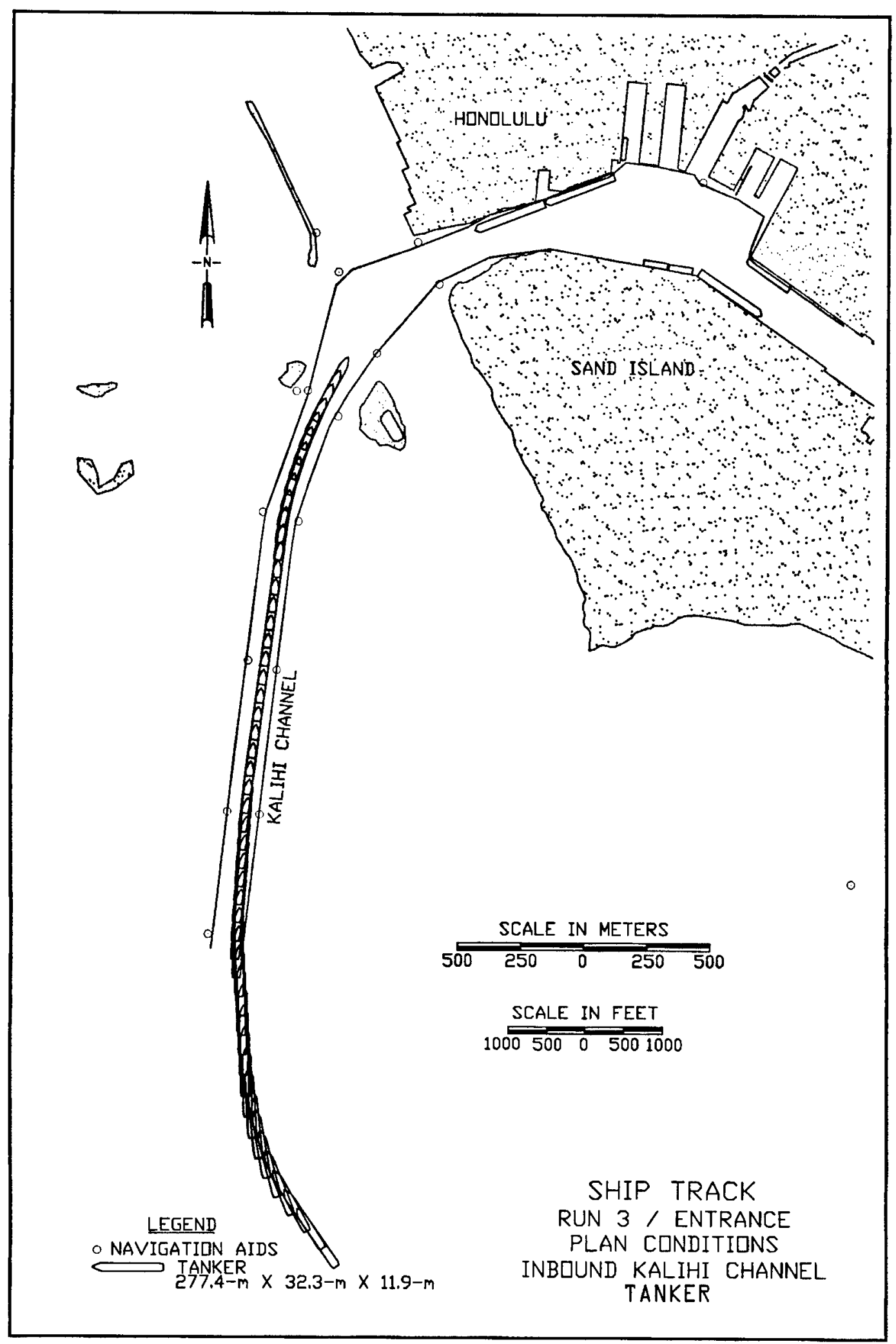

Plate 56 


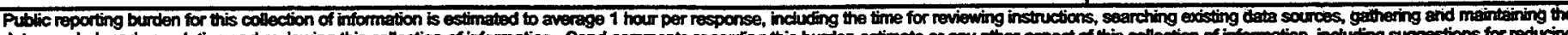

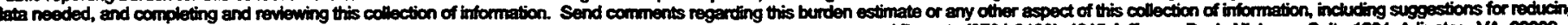

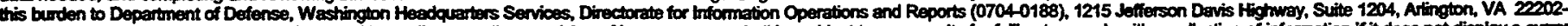

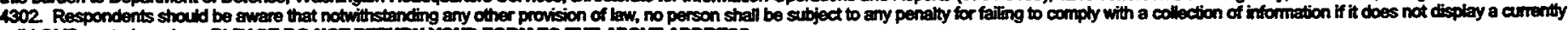
valid OMB Control number. PLEASE DO NOT RETURW YOUR FOR TO THE ABOVE AODRESS.

\begin{tabular}{l|ll|l|} 
1. REPORT DATE (DDMM-YYYY & 2. REPORT TYPE & $\ddots$ & 3. DATES COVERED (FIOM - TO)
\end{tabular}

September 2001

4. TITLE AND SUBTTILE

Final report

Ship Navigation Simulation Study, Kalihi Channel Reopening, Honolulu Harbor, Oahu, Hawaï

\section{AUTHOR(S)}

Gary C. Lynch, José A. Sanchez 5a. CONTRACT NUMBER

5b. GRANT NUWBER

5C. PROGRAM ELEMENT NUMBER

5d. PROJECT NUMBER

5e. TASK NUMBER

5.. WORK UNT NUMBER

\section{PERFORUING ORGANIZATION NANE(S) AND ADDRESS(ES)}

8. PERFORMING ORGANIZATION REPORT NUMBER

U.S. Army Engineer Research and Development Center

Coastal and Hydraulics Laboratory

ERDC/CHL TR-01-23

3909 Halls Ferry Road

Vicksburg, MS 39180-6199

\section{SPONSORING I MONITORING AGENCY NAME(S) AND ADDRESS(ES) •}

U.S. Army Engineer District, Honolulu

Building 230

Fort Shafter, HI $36858-5440$

11. SPONSOR/MONTOR'S REPORT NUMBER(S)

\section{DISTRIBUTION / AVALABILTY STATEMENT}

Approved for public release; distribution is unlimited.

\section{SUPPLEMENTARY NOTES}

\section{ABSTRACT}

Honolulu Harbor, located on the southern side of Oahu, Hawaii, has one entrance, the main channel entrance. Because of the closure of the lift on the Sand Island Bridge and the addition of a second, nonlift bridge, Kalihi Channel no longer opens into Honolulu Harbor. A tunnel has been proposed to replace the Sand Island Bridge, and, with the destruction of the old bridge, the possibility for ships and tows/barges to transit Kalihi Channel as well as the main Honolulu Channel would exist once again. Although the harbor operated with these two channels before the closure of the first bridge and the construction of the second bridge, changes in vessel dimensions since the closure and the proposed deepening of Kalihi Channel (to make it the same depth as the rest of the harbor) made a navigation study necessary to evaluate the efficiency and safety of the project.

\section{SUEJECT TERMS}

$\begin{array}{lll}\text { Bridge } & \text { Hawaii } & \text { Simulation } \\ \text { Deep-draft ships } & \text { Honolulu Harbor } & \\ \text { Harbor } & \text { Navigation } & \end{array}$

\begin{tabular}{|c|c|c|c|c|c|}
\hline \multicolumn{3}{|c|}{ 16. SECURIYY CLASSIFICATION OF: } & \multirow{2}{*}{$\begin{array}{l}\text { 17. LIMTITATION } \\
\text { OF ABSTRACT }\end{array}$} & \multirow{2}{*}{$\begin{array}{l}\text { 18. NUMBER } \\
\text { OF PAGES }\end{array}$} & 19a. NAME OF RESPONSIBLE PERSON \\
\hline $\begin{array}{l}\text { a. REPORT } \\
\text { UNCLASSIFIED }\end{array}$ & $\begin{array}{l}\text { b. ABSTRACT } \\
\text { UNCLASSIFIED }\end{array}$ & $\begin{array}{l}\text { c. THIS PAGE } \\
\text { UNCLASSIFIED }\end{array}$ & & & $\begin{array}{l}\text { 19b. TELEPHONE NUMBER (indude area } \\
\text { code) }\end{array}$ \\
\hline
\end{tabular}


